Maria Eugênia Moraes

Efeitos do $\beta$-glucano solúvel, administrado por diferentes vias, na imunomodulação de IgA e IgG séricos em aves desafiadas e não desafiadas por Escherichia coli 
Maria Eugênia Moraes

\section{Efeitos do $\beta$-glucano solúvel, administrado por diferentes vias, na imunomodulação de IgA e IgG séricos em aves desafiadas e não desafiadas por Escherichia coli}

Dissertação apresentada ao Programa de Pós-Graduação em Patologia Experimental e Comparada da Faculdade de Medicina Veterinária e Zootecnia da Universidade de São Paulo para a obtenção do título de Mestre em Ciências.

Departamento:

Patologia

Área de concentração:

Patologia Experimental e Comparada

Orientador:

Prof. Dr. Antonio José Piantino Ferreira 
Autorizo a reprodução parcial ou total desta obra, para fins acadêmicos, desde que citada a fonte.

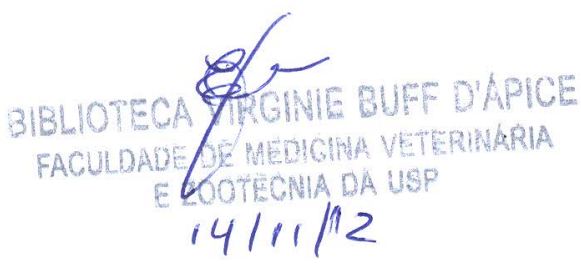

DADOS INTERNACIONAIS DE CATALOGAÇÃO-NA-PUBLICAÇÃO

(Biblioteca Virginie Buff D’Ápice da Faculdade de Medicina Veterinária e Zootecnia da Universidade de São Paulo)

T.2688 Moraes, Maria Eugênia

FMVZ Efeitos do ß-glucano solúvel, administrado por diferentes vias, na imunomodulação de IgA e IgG séricos em aves desafiadas e não desafiadas por Escherichia coli / Maria Eugênia Moraes .- 2012 $113 \mathrm{f}$ : : il.

Dissertação (Mestrado) - Universidade de São Paulo. Faculdade de Medicina Veterinária e Zootecnia. Departamento de Patologia, São Paulo, 2012.

Programa de Pós-Graduação: Patologia Experimental e Comparada.

Área de concentração: Patologia Experimental e Comparada.

Orientador: Prof. Dr. Antonio José Piantino Ferreira.

1. ß-Glucano solúvel. 2. Imunomoduladores. 3. Colibacilose. 4. Frangos de corte. I. Titulo. 
UNIVERSIDADE DE SÃO PAULO

\section{FACULDADE DE MEDICINA VETERINÁRIA E ZOOTECNIA}

\section{Comissão de Ética no uso de animais}

\section{CERTIFICADO}

Certificamos que o Projeto intitulado "Efeitos do $\beta$-glucano administrado por diferentes vias na imunomodulação de $\operatorname{IgA}$ e $\operatorname{IgG}$ sérica em aves desafiadas e não desafiadas com Escherichia coli", protocolado sob o $n^{\circ}$ 2613/2012, utilizando 200 (duzentos) frangos de corte, sob a responsabilidade do(a) Prof. Dr. Antonio José Piantino Ferreira, está de acordo com os princípios éticos de experimentação animal da "Comissão de Ética no uso de animais" da Faculdade de Medicina Veterinária e Zootecnia da Universidade de São Paulo e foi aprovado em reunião de $11 / 4 / 2012$.

We certify that the Research "Effects of $\beta$-glucan administred by different routes in the immunododulation of $\operatorname{IgA}$ and IgG seric in chickens challenged and not challenged with Escherichia coli", protocol number 2613/2012, utilizing 200 (two hundred) chickens, under the responsibility Prof. Dr. Antonio José Piantino Ferreira, agree with Ethical Principles in Animal Research adopted by "Ethic Committee in the use of animals" of the School of Veterinary Medicine and Animal Science of University of São Paulo and was approved in the meeting of day $4 / 11 / 2012$.

São Paulo, 19 de julho de 2012.

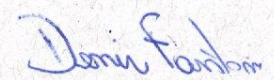

Denise Tabacchi Fantoni

Presidente 


\section{FOLHA DE AVALIAÇÃO}

Nome: Moraes, Maria Eugênia.

Título: Efeitos do $\beta$-glucano solúvel, administrado por diferentes vias, na imunomodulação de $\lg A$ e $\lg G$ séricos em aves desafiadas e não desafiadas por Escherichia coli.

Dissertação apresentada ao Programa de Pós-Graduação em Patologia Experimental e Comparada da Faculdade de Medicina Veterinária e Zootecnia da Universidade de São Paulo para a obtenção do título de Mestre em Ciências

Data:

Banca Examinadora

Prof. Dr.

Instituição: Julgamento

Prof. Dr.

Instituição: Julgamento

Prof. Dr.

Instituição: Julgamento 


\section{DEDICATÓRIA}

Dedico esta conquista primeiramente à minha família, meu porto seguro.

À minha mãe, por ser minha fiel e melhor amiga, me ouvir e ajudar sempre. Ao meu pai, meu maior incentivador, pelo seu amor e carinho. O apoio de vocês foi fundamental para que esse sonho se tornasse real.

À minha "irmãzinha" Ju, que sempre me ajudou de todas as formas possíveis. Sou imensamente grata por tudo que você já fez por mim e pela sua amizade. Ao meu cunhado Tiago, pela amizade, apoio, ajuda em minhas mudanças e ótimas conversas.

Ao meu querido irmão Zé, por sempre me incentivar, por toda sua ajuda, pela sua amizade e carinho. À Grazi, minha cunhada e amiga há tanto tempo, pelo carinho e apoio de sempre.

Aos pequenos Mateus e Laura, queridos sobrinhos, que são tão importantes na minha vida.

Aos meus familiares: avós, tios e primos que estiveram me incentivando e ajudando ainda que indiretamente para a concretização deste trabalho. Em especial à minha madrinha Rosana e ao meu padrinho Carlos, pois em todas as etapas da minha vida estiveram presentes demonstrando carinho e amor.

Aos amigos que fiz em São Paulo, que tornaram mais alegres meus dias aqui. Também aos amigos que mesmo de longe se fizeram presentes. Em especial a minha amiga Tácia, por seu apoio constante.

Muito obrigada, amo vocês! 


\section{AGRADECIMENTOS}

Agradeço ao Professor Antonio pela orientação, oportunidade e por todos os ensinamentos. Muitíssimo obrigada!

À Claudete, com quem tanto aprendi. Por toda sua ajuda que foi imprescindível para a concretização deste trabalho e por sua disposição em ensinar sempre. A minha gratidão.

Agradeço a Bruna e a Gabriele. Vocês foram minha família em São Paulo, muito obrigada pela amizade e pelo imenso apoio no dia a dia, que foi fundamental. À Gabriele agradeço também por toda ajuda e companheirismo em cada etapa deste mestrado.

Agradeço ao Luis e a Silvana, queridos amigos, pela excelente convivência e por estarem sempre dispostos a ajudar.

Agradeço ao Mauricio, por todo apoio. Por ter feito minhas estantes enormes de microtubos, pela ajuda com as anilhas das aves. Enfim, por sempre procurar ter idéias que facilitem nosso trabalho no laboratório. Mas agradeço principalmente pela sua amizade. Muito obrigada Maumau!

Ao Dennis, pela amizade, pelas piadas, pela disposição e boa vontade em ajudar sempre. Muito obrigada por tudo Dennaum!

Agradeço aos queridos amigos Elena, Luciana Allegretti, Luciana Scanavini, Prof. a Terezinha, Liliana, Márcia, Marta e Wanderley, foi muito bom conviver e aprender com vocês.

À Joelma, pela amizade e especialmente pela imensa ajuda com as análises estatísticas. A minha gratidão.

Ao Antônio Carlos agradeço pela ajuda com a solubilização do glucano. Muito obrigada! 
Agradeço aos estagiários e alunos de iniciação cientifica, por todo auxílio, amizade e agradável convivência, especialmente a Lilian, Lívia, Carla, Andréia, Carol, Matheus, Daniel, Milena e Gabriela.

Agradeço aos funcionários pelo excelente convívio. De maneira especial a Lívia, Rosinha, Hermes, Luiz, Nelsinho, Marcos, Garcia, Daniel, Rogério, Dulce, Edson, Guimarães, Becker, Tereza Cristina, Lúcio e Herculano. E também aos funcionários da biblioteca e da secretaria de pós-graduação, sempre tão dispostos a ajudar.

Ressalto meu agradecimento àqueles que me ajudaram durante 0 experimento com o manejo das aves, colheitas de sangue e necropsias: Daniel, Gabriele, Silvana, Luis, Juliana, Dennis, Joelma e Wanderley. A ajuda de vocês foi fundamental, muitíssimo obrigada!

Agradeço a Professora Lilian, pela orientação no Programa de Aperfeiçoamento do Ensino (PAE) e por cada ensinamento.

Agradeço a Master Nutrição Animal por ter fornecido a ração sem promotores de crescimento e coccidiostáticos. E ao meu pai, que me ajudou a encontrar uma empresa que aceitasse fazer a ração nessas condições.

Ao Laboratório de Farmacologia Aplicada e Toxicologia, que disponibilizou o leitor de ELISA. Especialmente a especialista de laboratório Nicolle, por todo auxilio e pela disposição em ajudar.

Ao Laboratório de Ornitopatologia, onde essa pesquisa foi realizada. Por proporcionar as condições necessárias não apenas para a realização da presente pesquisa, mas também para muitos outros aprendizados.

Agradeço a CAPES pelo suporte financeiro e a Faculdade de Medicina Veterinária e Zootecnia da Universidade de São Paulo, especialmente ao Departamento de Patologia Experimental e Comparada, pela oportunidade. 
Agradeço e glorifico a Deus, em quem deposito a minha fé e que em tudo tem me sustentado.

"Que a glória seja dada a Deus, que é poderoso para fazer infinitamente mais do que tudo quanto pedimos ou pensamos, conforme o seu poder que opera em nós."

(Efésios 3:20) 


\section{RESUMO}

MORAES, M. E. Efeitos do $\beta$-glucano solúvel, administrado por diferentes vias, na imunomodulação de $\lg A$ e $\lg G$ séricos em aves desafiadas e não desafiadas por Escherichia coli. [Effects of soluble $\beta$-glucan, administered by different routes, in immunomodulation of serum $\lg A$ and $\lg G$ in chickens challenged and not challenged by Escherichia coll]. 2012. 113 f. Dissertação (Mestrado em Ciências) Faculdade de Medicina Veterinária e Zootecnia, Universidade de São Paulo, São Paulo, 2012.

Os $\beta$-glucanos são polissacarídeos que possuem atividade imunomoduladora. A colibacilose é uma das principais doenças da avicultura, pois causa grandes perdas econômicas. Diante da necessidade de se estabelecer a ação do $\beta$-glucano solúvel nas aves, foram realizados dois experimentos. Um para se avaliar os efeitos do $\beta$ glucano solúvel, administrado por diferentes vias, na produção de anticorpos séricos $\lg A$ e $\lg G$, nos parâmetros zootécnicos e outro na infecção por Escherichia coli (EC). Os experimentos foram realizados ao mesmo tempo, em galpões diferentes, sendo alojados 160 frangos de corte da linhagem Ross (Aviagen ${ }^{\circledR}$ ), do primeiro ao $42^{\circ}$ dia de idade. $\beta$-glucano solúvel foi administrado no primeiro dia, na dose de $215 \mu \mathrm{g} / \mathrm{ave}$, nas seguintes vias de administração: subcutânea (SC), ocular (OC) e oral (VO). O controle negativo foi o mesmo para os dois experimentos. Os tratamentos do Experimento 1 (Vias de Administração) foram: T2(SC), T3(OC) e T4(VO). O experimento onde as aves foram desafiadas por Escherichia coli foi o Experimento 2 ( $\beta$-glucano e Escherichia coli). As mesmas vias de inoculação foram também estudadas nestes tratamentos, assim: T5 (controle positivo) foi desafiado e não recebeu o $\beta$-glucano solúvel, T6(SC+EC), T7(OC+EC) e T8(VO+EC). O desafio foi realizado com $E$. coli sorotipo $\mathrm{O119}$, por via saco aéreo torácico direito aos 14 dias de idade, sendo que cada ave recebeu $4 \times 10^{6}$ UFC. As aves foram pesadas semanalmente para a análise dos parâmetros zootécnicos e toda ração adicionada foi pesada. Aos 28, 35 e 42 dias foi colhido sangue de todas as aves para se determinar por ensaio imunoenzimático indireto (ELISA indireto) as concentrações séricas de $\lg G$ e IgA totais. Nas aves infectadas foi determinado o escore de lesão, analisando a intensidade das lesões em sacos aéreos, fígado e coração. No Experimento 1 (Vias de Inoculação) os resultados mostraram concentrações séricas 
de IgA nas aves do $\mathrm{T} 4(\mathrm{OC})$ menores que nas aves dos demais tratamentos. Em relação a IgG as aves do T4(VO) apresentaram concentrações maiores que aquelas dos demais tratamentos. No Experimento 2 ( $\beta$-glucano e Escherichia coli) as aves do $\mathrm{T7}(\mathrm{OC}+\mathrm{EC})$ tiveram as menores concentrações de $\lg \mathrm{A}$ e apresentaram a melhor viabilidade dentre as aves dos grupos desafiados. As aves do T6(SC+EC) apresentaram concentrações maiores de $\lg G$ aos 35 e 42 dias. Quanto ao escore de lesão houve redução no grau de lesão em todos os grupos que receberam o $\beta$ glucano solúvel, exceto no saco aéreo torácico direito. Sugere-se que o uso do $\beta$ glucano solúvel possa reduzir as lesões causadas por Escherichia coli. A administração por via ocular levou a melhor viabilidade nas aves desafiadas, apesar de ter menor produção de anticorpos IgA tanto nas aves infectadas como nas aves não desafiadas. Serão necessários mais estudos para se estabelecer melhor as ações imunomoduladoras do $\beta$-glucano nas aves.

Palavras-chave: $\beta$-Glucano Solúvel. Imunomoduladores. Colibacilose. Frangos de Corte. 


\section{ABSTRACT}

MORAES, M. E. Effects of soluble $\beta$-glucan, administered by different routes, in immunomodulation of serum IgA and IgG in chickens challenged and not challenged by Escherichia coli. [Efeitos do $\beta$-glucano solúvel administrado por diferentes vias na imunomodulação de $\lg A$ e $\lg \mathrm{G}$ séricos em aves desafiadas e não desafiadas por Escherichia coli]. 2012. 113 f. Dissertação (Mestrado em Ciências) 2012. 113 f. Dissertação (Mestrado em Ciências) - Faculdade de Medicina Veterinária e Zootecnia, Universidade de São Paulo, São Paulo, 2012.

The $\beta$-glucans are polysaccharides that possess immunomodulatory activity. The colibacillosis is a major disease of poultry; it contributes to great economic losses. Faced with the need to establish the action of soluble $\beta$-glucan in birds, two experiments were conducted. One to evaluate the effects of soluble $\beta$-glucan administered by different routes, in the production of serum IgA and IgG antibodies in zootechnical parameters and other infection in Escherichia coli (EC). The experiments were performed simultaneously in different warehouses, being housed 160 broilers Ross (Aviagen $\AA$ ) from first to 42nd days of age. $\beta$-glucano soluble was administered on the first day, the dose of $215 \mu \mathrm{g} / \mathrm{bird}$ on the following routes of administration: subcutaneous (SC), ocular (OC) and oral (PO). The negative control was the same for both experiments. The treatments of the experiment called Experiment 1 (Routes of Administration) were: T2 (SC), T3(OC) and T4(VO). The experiment where birds were challenged by Escherichia coli was termed Experiment 2 ( $\beta$-glucan e Escherichia coli). The same routes of inoculation were also studied in these treatments, thus: T5 (positive control), was challenged and did not receive soluble $\beta$-glucan, T6 $(\mathrm{SC}+\mathrm{EC}), \mathrm{T} 7(\mathrm{OC}+\mathrm{EC})$ and $\mathrm{T} 8(\mathrm{VO}+\mathrm{EC})$. The challenge was performed with $E$. coli serotype 0119 , through the right thoracic air sac at 14 days of age, each bird was given $4 \times 10^{6} \mathrm{CFU}$. The birds were weighed weekly for analysis of zootechnical parameters ration added and the whole was weighed. At 28, 35 and 42 days blood was collected from all birds to determine by Enzyme linked immunosorbent assay (ELISA) serum concentrations of total $\lg G$ and $\lg A$. In birds infected was determined the injury score by analyzing the intensity of the lesions in air sacs, liver and heart. In the Experiment 1 (Routes of Inoculation) the results showed serum $\lg A$ in birds of $\mathrm{T} 4(\mathrm{OC})$ smaller than the other treatments in birds. 
Regarding IgG the birds of $\mathrm{T} 4(\mathrm{VO})$ had levels greater than those of other treatments. In Experiment 2 ( $\beta$-glucan and Escherichia coll) birds of $\mathrm{T7}(\mathrm{OC}+\mathrm{EC}$ ) had the lowest concentrations of $\operatorname{lgA}$ and showed the best viability among groups of birds challenged. Birds of $\mathrm{T} 6(\mathrm{SC}+\mathrm{EC})$ showed higher concentrations of $\operatorname{IgG}$ at 35 and 42 days. As for the injury score decreased the degree of injury in all groups receiving $\beta$ glucan soluble except in right thoracic air sac. It is suggested that the use of $\beta$-glucan soluble can reduce injuries caused by Escherichia coli. The administration by ocular route led to better viability challenged birds, despite having lower production of $\lg \mathrm{A}$ in both the infected birds as the birds not challenged. Further studies are needed to better establish the immunomodulatory actions of $\beta$-glucan in birds.

Keywords: Soluble $\beta$-Glucan. Immunomodulators. Colibacillosis. Broilers. 


\section{LISTA DE FIGURAS}

Figura 1 - Estrutura molecular do 1,3/1,6- $\beta$-D-glucano................................ 27

Figura 2 - Concentrações séricas de IgA nas diferentes idades e nos diferentes tratamentos.

Figura 3 - Efeitos principais nas concentrações séricas de $\operatorname{lgA}$ em relação a idade e ao tratamento.

Figura 4 - Concentrações séricas de IgG nas diferentes idades e nos diferentes tratamentos.

Figura 5 - Efeitos principais nas concentrações séricas de lgG em relação a idade e ao tratamento

Figura 6 - Comparação entre as concentrações de $\lg A$ e $\lg G$ detectadas pelo ELISA.

Figura 7 - Peso médio (PM) semanal nos diferentes tratamentos................ 60

Figura 8 - Ganho de peso (GP) semanal nos diferentes tratamentos.......... 60

Figura 9 - Consumo médio semanal nos diferentes tratamentos.................. 61

Figura 10 - Conversão alimentar semanal nos diferentes tratamentos........... 62

Figura 11 - Média do ganho de peso acumulado entre as repetições............. 63

Figura 12 - Conversão alimentar relativa a todo o período experimental........ 63

Figura 13 - Viabilidade durante todo o período experimental.......................... 64

Figura 14 - Índice de eficiência produtiva (IEP)......................................... 64

Figura 15 - Contagem bacteriana realizada após a inoculação das aves....... 65

Figura 16 - Concentrações séricas de IgA determinadas nas diferentes idades e nos diferentes tratamentos.......................................... 67

Figura 17 - Efeitos principais nas concentrações séricas de $\lg A$ em relação a idade e ao tratamento............................................................. 68

Figura 18 - Concentrações séricas de IgG determinadas nas diferentes idades e nos diferentes tratamentos......................................... $\quad 70$

Figura 19 - Efeitos principais nas concentrações séricas de IgG em relação a idade e ao tratamento

Figura 20 - Comparação entre as concentrações de IgA e IgG detectadas pelo ELISA. 
Figura 21 - Peso médio (PM) semanal nos diferentes tratamentos................ 78

Figura 22 - Ganho de peso (GP) semanal nos diferentes tratamentos.......... 79

Figura 23 - Consumo médio semanal nos diferentes tratamentos.................. 79

Figura 24 - Conversão alimentar semanal nos diferentes tratamentos........... 80

Figura 25 - Ganho de peso relativo a todo o período experimental................ 81

Figura 26 - Conversão alimentar relativa a todo o período experimental........ 81

Figura 27 - Viabilidade relativa a todo o período experimental....................... 82

Figura 28 - Índice de Eficiência Produtiva (IEP)....................................... 82

Figura 29 - Escore de lesão em sacos aéreos, coração e fígado das aves que morreram após o desafio e das que foram sacrifícadas aos

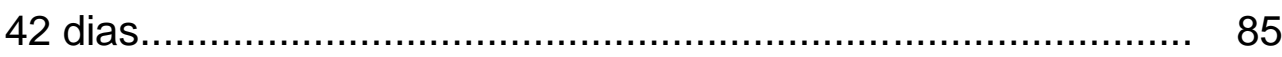




\section{LISTA DE TABELAS}

Tabela 1 - Diluição do soro padrão utilizado no ELISA de quantificação de

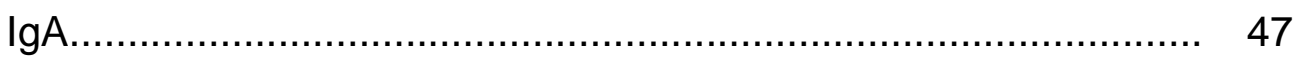

Tabela 2 - Diluição do soro padrão utilizado no ELISA de quantificação de $\lg G$

Tabela 3 - Concentrações de IgA sérica detectadas por ELISA de acordo com a via de inoculação e a idade das aves

Tabela 4 - Concentrações de IgA sérica detectadas por ELISA (em In) considerando apenas as vias de administração

Tabela 5 - Concentrações de IgA sérica detectadas por ELISA (em In) considerando apenas as diferentes idades.

Tabela 6 - Concentrações de IgG sérica detectadas por ELISA de acordo com a via de inoculação e a idade das aves.

Tabela 7 - Concentrações séricas de IgG detectadas por ELISA (em In) considerando apenas as vias de administração

Tabela 8 - Concentrações séricas de IgG detectadas por ELISA (em In) considerando apenas as diferentes idades................................. 54

Tabela 9 - Valor de P obtido na análise de variância simples ANOVA.......... 55

Tabela 10 - Análise descritiva dos parâmetros zootécnicos da primeira semana (média entre as repetições \pm desvio padrão).................. 56

Tabela 11 - Análise descritiva dos parâmetros zootécnicos da segunda semana (média entre as repetições \pm desvio padrão)

Tabela 12 - Análise descritiva dos parâmetros zootécnicos da terceira semana (média entre as repetições \pm desvio padrão).

Tabela 13 - Análise descritiva dos parâmetros zootécnicos da quarta semana (média entre as repetições \pm desvio padrão)

Tabela 14 - Análise descritiva dos parâmetros zootécnicos da quinta semana (média entre as repetições \pm desvio padrão).

Tabela 15 - Análise descritiva dos parâmetros zootécnicos da sexta semana (média entre as repetições \pm desvio padrão).

Tabela 16 - Análise descritiva dos parâmetros zootécnicos relativos a todo o 
período experimental (média entre as repetições \pm desvio padrão)

Tabela 17 - Concentrações séricas de IgA detectadas por ELISA nos diferentes tratamentos e idades

Tabela 18 - Concentrações séricas de IgA detectadas por ELISA (em In) considerando apenas as vias de administração

Tabela 19 - Concentrações séricas de IgA detectadas por ELISA (em In) considerando apenas as diferentes idades.

Tabela 20 - Concentrações séricas de IgG detectada por ELISA nos diferentes tratamentos e idade das aves.

Tabela 21 - Concentrações séricas de IgG detectadas por ELISA (em In) considerando apenas as vias de administração

Tabela 22 - Concentrações séricas de IgG detectadas por ELISA (em In) considerando apenas as diferentes idades

Tabela 23 - Valor de P obtido na análise de variância simples ANOVA.

Tabela 24 - Análise descritiva dos parâmetros zootécnicos na primeira semana (médias \pm desvio padrão)

Tabela 25 - Análise descritiva dos parâmetros zootécnicos na segunda semana (médias \pm desvio padrão).

Tabela 26 - Análise descritiva dos parâmetros zootécnicos na terceira semana (médias \pm desvio padrão)

Tabela 27 - Análise descritiva dos parâmetros zootécnicos na quarta semana (médias \pm desvio padrão)

Tabela 28 - Análise descritiva dos parâmetros zootécnicos na quinta semana (médias \pm desvio padrão)

Tabela 29 - Análise descritiva dos parâmetros zootécnicos na sexta semana (médias \pm desvio padrão)

Tabela 30 - Análise descritiva dos parâmetros zootécnicos relativos a todo o período experimental (médias das repetições \pm desvio padrão)..

Tabela 31 - Porcentagem de aves que morreram após o desafio com lesões em sacos aéreos classificadas em um escore de 0 a 4 .

Tabela 32 - Porcentagem de aves que morreram após o desafio com lesões em coração e fígado classificadas em um escore de 0 a 4 ........... 
Tabela 33 - Porcentagem de aves sacrificadas aos 42 dias com lesões em

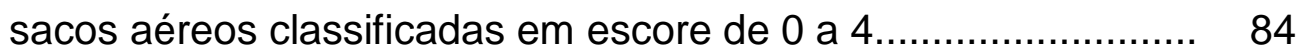

Tabela 34 - Porcentagem de aves sacrificadas aos 42 dias com lesões em

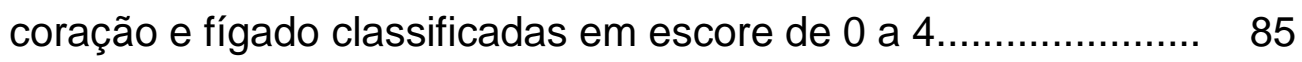

Tabela 35 - Grau de escore de lesão das aves que morreram após o desafio e das que foram sacrificadas aos 42 dias 


\section{LISTA DE QUADROS}

Quadro 1 - Fontes de $\beta$-glucano.............................................................. 28

Quadro 2 - Escores de lesão estabelecidos para o pericárdio, serosa 45 hepática e sacos aéreos 


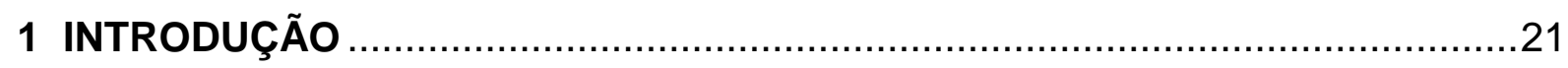

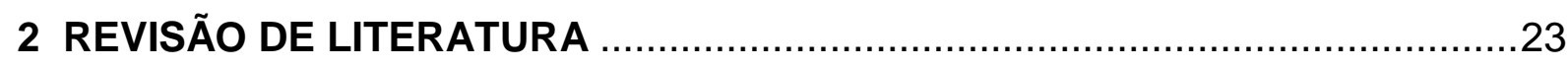

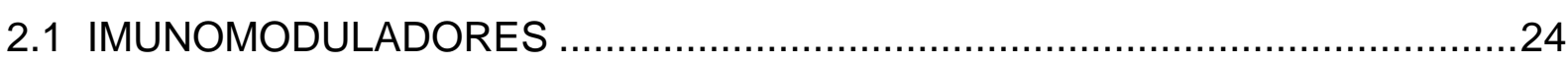

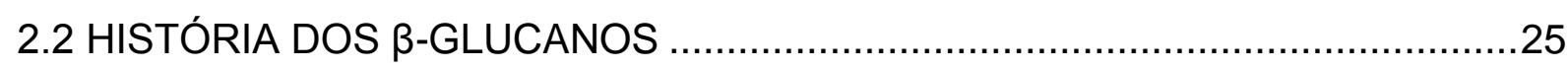

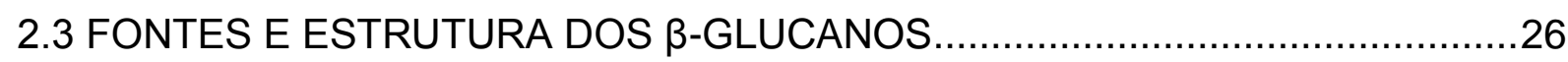

2.4 SISTEMA IMUNOLÓGICO E MECANISMOS DE AÇÃO DOS $\beta$-GLUCANOS ..29

2.5 EFEITOS BIOLÓGICOS DOS $\beta$-GLUCANOS ................................................ 34

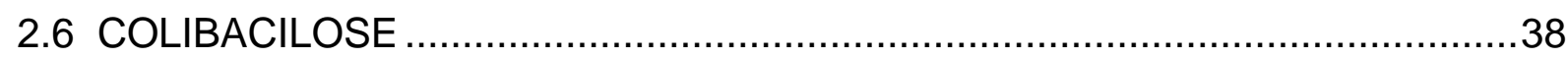

3 OBJETIVOS

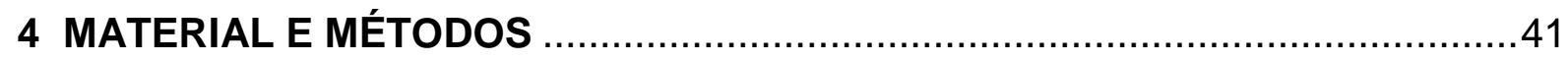

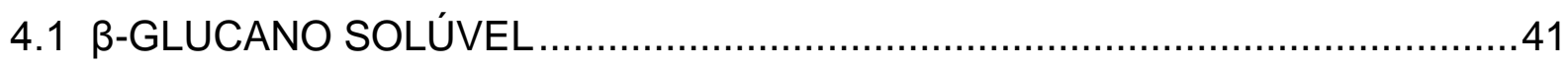

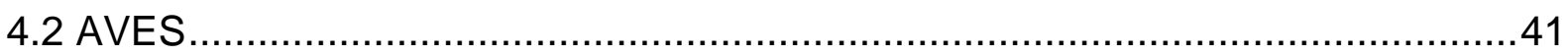

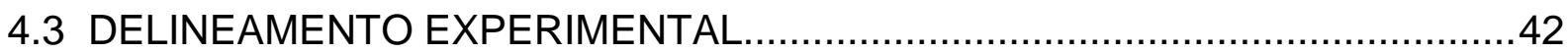

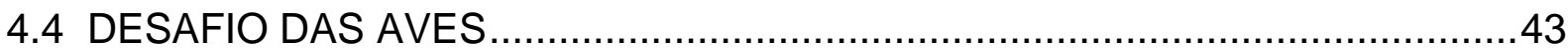

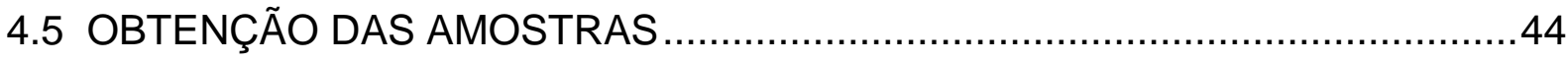

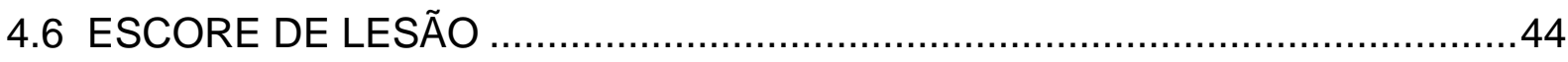

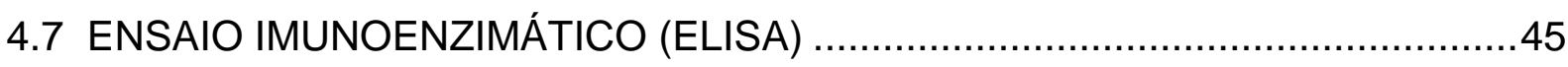

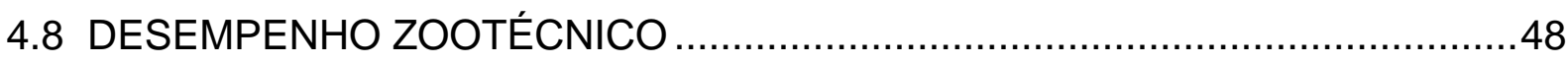

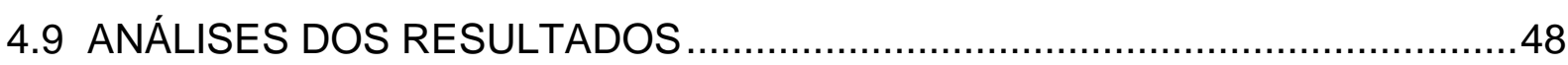

5 RESULTADOS

5.1 TESTE DE ESTERILIDADE E DO $\beta$-GLUCANO SOLÚVEL …......................49

5.2 RESULTADOS DO EXPERIMENTO 1: VIAS DE INOCULAÇÃO .....................49

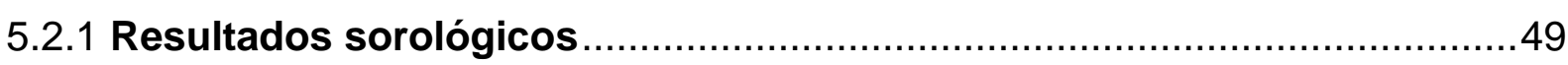

5.2.2 Resultados dos parâmetros zootécnicos.............................................56

5.3 RESULTADOS DO EXPERIMENTO 2: $\beta$-GLUCANO e ESCHERICHIA COLI ..65

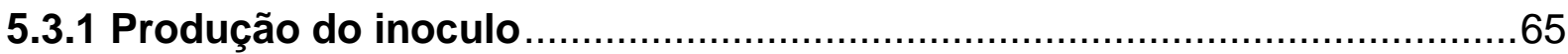

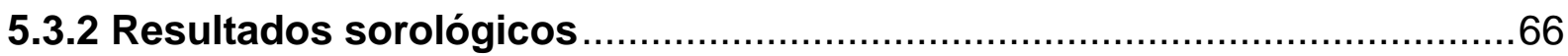

5.3.3 Resultados dos parâmetros zootecnicos..............................................

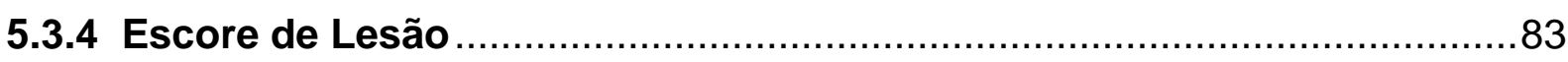

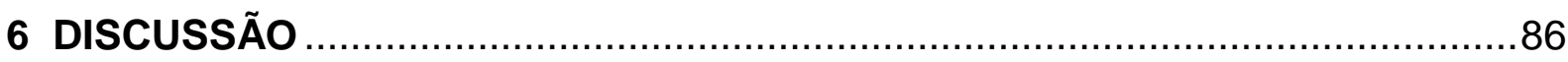

7 CONCLUSÃO 


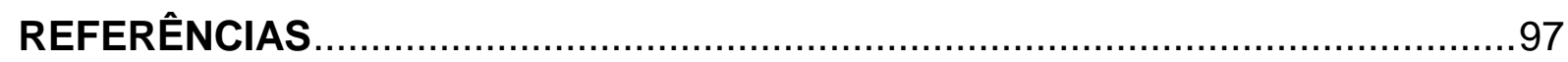

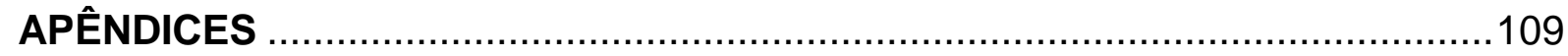




\section{INTRODUÇÃO}

O Brasil é um país de produção intensiva de aves comerciais, sendo que no ano de 2011 foram produzidas cerca de 13 milhões de toneladas de carne de frango (UBABEF, 2012).

Com a proibição progressiva do uso de antibióticos como promotores de crescimento na ração, foram estudados produtos como os probióticos, prebióticos (PETTERSON; BURKHOLDER, 2003), óleos essenciais (RIZZO, 2008), mananoligossacarídeos (SPRING et al., 2000), enzimas (TORRES et al., 2003) ácidos orgânicos (FARIA et al., 2009) e imunomoduladores como alternativas para substituí-los. O $\beta$-glucano é um imunomodulador que foi estudado como potente alternativa para substituir os antimicrobianos como promotores de crescimento (COX; DALLOUL, 2010).

Os $\beta$-glucanos são polissacarídeos constituintes estruturais da parede celular de levedura, particularmente de Saccharomyces cerevisiae, da parede celular de alguns cereais em grãos, de algumas bactérias, de alguns cogumelos e fungos filamentosos (MAGNANI; CASTRO-GÓMEZ, 2008). Na literatura consta a descrição de diversos efeitos do $\beta$-glucano, dentre estes a atividade imunomoduladora (COX et al., 2010a; LE et al., 2011; RAJAPAKSE et al., 2010).

$A$ atividade imunomoduladora do $\beta$-glucano é bem conhecida nos mamíferos, mas nas aves a descrição dos seus efeitos é recente (COX; DALLOUL, 2010). Tratando-se dos efeitos do $\beta$-glucano na sua forma solúvel sobre as aves a literatura é escassa. Pedroso (2009) observou que o $\beta$-glucano solúvel sulfatado associado a vacinas aviárias estimulava o sistema imunológico de frangos aumentando a produção de $\lg G$.

Colibacilose se refere às infecções causadas por Escherichia coli (E. coli) nos animais e no homem. E. coli é um bastonete curto Gram-negativo e pertencente a família Enterobacteriaceae (FERREIRA; REVOLLEDO; FERREIRA, 2009).

A colibacilose é uma das principais doenças da avicultura industrial, ocorrendo na maioria das vezes como uma infecção secundária a outros agentes. $E$. coli causa grandes prejuízos econômicos no mundo inteiro (FERREIRA; KNOBL, 2009). 
A prevenção e o controle da $E$. coli se baseia em medidas inespecíficas de manejo, uma vez que a ocorrência da doença apresenta aspectos multifatoriais como manejo, nutrição das aves, ventilação, estresse ambiental, densidade populacional, imunossupressão, dentre outros fatores (FERREIRA; KNOBL, 2009). Dessa forma, o uso de substancias imunomoduladoras pode contribuir para melhorar o estado imunológico da ave e assim aumentar a resposta do hospedeiro contra a E. coli.

Neste trabalho avaliou-se o uso do $\beta$-glucano sulfatado solúvel, por diferentes vias de administração, em frangos de corte. Avaliou-se também se o uso deste imunomudulador interferia na infecção por E. coli. Os parâmetros analisados foram as concentrações séricas de anticorpos da classe $\lg G$ e $\operatorname{lgA}$, os índices zootécnicos, e também o escore de lesão nos sacos aéreos, fígado e coração nas aves inoculadas por E. coli. 


\section{REVISÃO DE LITERATURA}

A preocupação em relação ao uso de antimicrobianos na produção animal tem sido um assunto de interesse cientifico nos últimos 40 anos. Em geral, a comunidade cientifica concorda que a utilização de antimicrobianos pode desencadear o surgimento de bactérias resistentes (FDA, 2012).

Tratando-se de antibióticos usados como aditivos em animais de produção que são semelhantes aos usados na terapia humana a preocupação é ainda maior (DARPOSSOLO et al., 2010). Nos últimos anos aumentou a consciência dos consumidores em relação aos riscos relativos aos resíduos nas carnes e a resistência bacteriana aos antibióticos. O que contribui para o aumento na pressão para banir o uso de antibióticos como promotores de crescimento (COX; DALLOUL, 2010). Dessa forma, países exportadores como o Brasil devem adequar à produção avícola procurando alternativas para substituir os antibióticos como aditivos (DARPOSSOLO et al., 2010).

Em consequência desses riscos, a União Europeia, em 2006, proibiu o uso de alguns antibióticos como aditivos na avicultura. Contudo, observou-se um declínio na saúde das aves e um aumento no uso terapêutico de antibióticos (CASTANON, 2007).

Diante deste cenário tem-se buscado alternativas capazes de manter a saúde animal sem impedir o bom desempenho (COX; DALLOUL, 2010). Os substitutos para os antibióticos como promotores de crescimento devem favorecer a eficiência alimentar e ser economicamente viáveis (DIBNER; RICHARDS, 2005).

O uso de imunomoduladores para melhorar os mecanismos da resposta imunológica do hospedeiro durante uma infecção pode ser suficiente e evitar o uso de antibióticos (TZINABOS, 2000). Produtos derivados de leveduras estão sendo estudados, principalmente os efeitos como imunomoduladores (COX; DALLOUL, 2010). 


\subsection{IMUNOMODULADORES}

Como consequência do interesse científico em elucidar os mecanismos imunológicos que atuam em uma infecção, houve um aumento nas informações, o que permitiu uma melhor compreensão da resposta imunológica do hospedeiro contra os agentes infecciosos. Diversos estudos tiveram como objetivo a descoberta de componentes capazes de modular a resposta imunológica, positivamente ou negativamente, para que ocorra um aumento na resistência às infecções. Dessa forma, é importante identificar as moléculas que atuam na resposta imunológica do hospedeiro para que esta resposta possa ser modificada, através da potencialização ou supressão, de maneira que se tenha a resposta desejada (TZIANABOS, 2000).

Compostos capazes de alterar a fisiologia são chamados de Modificadores da Resposta Biológica, estes podem ser divididos em dois diferentes grupos de acordo com o seu efeito, ou seja, as citocinas e os imunomoduladores. As citocinas regulam a resposta imunológica e são responsáveis pela comunicação entre as células do sistema imune. Os imunomoduladores podem tanto potencializar a resposta imunológica, como podem suprimir esta resposta agindo como um imunossupressor. Quando atua positivamente pode ser denominado imunopotencializador (NOVAK; VETVICKA, 2008).

Alguns fatores como a via de administração, o momento em que foi administrado e também a dose utilizada podem determinar o tipo de resposta gerada por um imunomodulador, ou seja, se irá potencializar ou suprimir a resposta imunológica do hospedeiro (TZIANABOS, 2000).

$\mathrm{Na}$ avicultura é importante considerar as possíveis diferenças na ação dos imunomoduladores com respeito às diferentes linhagens. Uma vez que o efeito benéfico pode ser observado em determinada linhagem e não se obter o mesmo resultado em uma linhagem diferente (REDMOND et al., 2010).

Diversos polissacarídeos isolados de micro-organismos e plantas podem ser utilizados como imunomoduladores, dentre estes os $\beta$-glucanos (SOLTANIAN et al., 2009).

Existem muitos estudos mostrando os efeitos dos $\beta$-glucanos como imunomoduladores. Um número expressivo de pesquisas foi realizado em camundongos (KOKOSHIS et al., 1978; WILLIAMS et al., 1988b; WILLIAMS et al., 
1989; SUZUKI et al., 1990; PATCHEN et al., 1998; YUN et. al., 2003; CRISPIM; MEDEIROS; SALES, 2004; VETVICKA; VANCIKOVA, 2010; USLU; BAGRIACIK, 2011). Entretanto, há descrições em diversas espécies como camarões (CHANG et al., 2011), peixes (ŞAHAN; DUMAN, 2010), minhocas (BESCHIN et al., 2008), ratos (WASHBURN et al.,1996), coelhos (KENNEDY et al., 1995), suínos (DRITZ et al., 1995; LI et al., 2006), ovelhas (WALLER; COLDITZ, 1999), aves (ZHANG; GUO; WANG, 2008) e humanos (CHAN; CHAN; SZE, 2009).

\subsection{HISTÓRIA DOS $\beta$-GLUCANOS}

As propriedades curativas dos cogumelos foram reconhecidas há milhares de anos. O primeiro relato registrado em relação as suas propriedades medicinais ocorreu em aproximadamente 3000 anos A.C. Embora muitos componentes possam estar envolvidos nessas propriedades, os $\beta$-glucanos foram os que receberam uma maior atenção (BROWN; GORDON, 2003).

Entre os anos de 1960 e 1970 ocorreram os primeiros estudos das propriedades dos $\beta$-glucanos. A história dos $\beta$-glucanos iniciou-se em diferentes continentes, com objetivos diferentes. Nos Estados Unidos e Europa estes eram estudar a ação do Zymozan, enquanto no Japão a sua ação anticancerígena (NOVAK; VETVICKA, 2009).

As pesquisas americanas e da Europa foram fundamentadas na avaliação dos efeitos imunomoduladores do Zymosan, que foi preparado e pesquisado inicialmente na década de 40 por Pillemer et al. (1941). Trata-se uma mistura de polissacarídeos, proteínas e lipídeos isolados da parede celular de Saccharomyces cerevisiae (NOVAK; VETVICKA, 2009) que age como potente imunoestimulante, principalmente para macrófagos. Além de induzir a liberação de uma serie de citocinas por neutrófilos (NOVAK; VETVICKA, 2008).

Estudos posteriores atribuíram os efeitos dos imunomoduladores do Zymosam ao $\beta$-glucano (RIGGI; DI LUZIO, 1961), contudo outros componentes do Zymosam também podem estar envolvidos na ativação destas células (NOVAK; VETVICKA, 2008; NOVAK; VETVICKA, 2009). 
No Japão as pesquisas foram direcionadas para a ação anticancerígena do $\beta$-glucano. Foram utilizados os $\beta$-glucanos oriundos de cogumelos, como por exemplo, o lentinan, que foi isolado primeiramente na Universidade Teikyo em Kawasaki, obtido do cogumelo Lentinula edodes (CHIHARA et al., 1969). O interesse nestes estudos se explica pela cultura do país em utilizar cogumelos medicinais como medicamento (NOVAK; VETVICKA, 2009).

Embora ao longo das últimas décadas os efeitos biológicos do $\beta$-glucano tenham sido muito estudados, as pesquisas com aves são relativamente recentes (COX; DALLOUL, 2010).

\subsection{FONTES E ESTRUTURA DOS $\beta$-GLUCANOS}

Os $\beta$-glucanos são encontrados em diversas fontes naturais como: plantas, fungos, algumas bactérias e algas (BROWN; GORDON, 2003, SOLTANIAN et al., 2009), sendo geralmente extraídos de fungos e leveduras (NOVAK; VETVICKA, 2008; VETVICKA; VANCIKOVA, 2010). Além desses, são estudados também os $\beta$ glucanos extraídos de algas marinhas, como o laminaran (Laminaria $s p$.) e de bactérias como o curdlan (Alcaligenes faecalis) (NOVAK; VETVICKA, 2008).

Os $\beta$-glucanos podem variar em relação aos parâmetros físico-químicos, ao peso molecular, a estrutura da cadeia principal, a frequência e comprimento das ramificações, a carga de seus polímeros, a estrutura em meio aquoso, a ordem superior de conformação (bobina aleatória, hélice única ou hélice tripla), o grau de polimerização e a solubilidade. Dentre estes parâmetros a estrutura de ordem superior e a solubilidade são de grande importância no reconhecimento e nos efeitos biológicos dos $\beta$-glucanos (BARSANTI et al., 2011).

A grande variabilidade na estrutura dos $\beta$-glucanos ocorre devido às diferentes fontes existentes (SOLTANIAN et al. 2009; COX; DALLOUL, 2010). O quadro 1, baseado na revisão de literaura feita por Barsanti et. al. (2011), mostra as fontes de $\beta$-glucanos, suas estruturas, ilustrando quão grande é a diversidade. Assim, pode-se considerar o quanto é dificil comparar os estudos encontrados na literatura e se estabelecer um consenso em relação aos efeitos dos $\beta$-glucanos. 
Várias espécies de fungos produzem $\beta-(1,3 ; 1,6)$ D-glucanos. Todos esses polímeros consistem de um esqueleto linear central de unidades de glicose ligadas na posição $\beta(1-3)$, com cadeias laterais unidas em $\beta(1-6)$ que ocorrem em variados tamanhos e intervalos (BROWN; GORDON, 2003; MAGNANI; CASTRO-GÓMEZ, 2008; COX; DALLOUL, 2010; BARSANTI et. al., 2011). Esse tipo de estrutura química (ilustrada na Figura 1) parece ser biologicamente a mais ativa. Quanto à ramificação, os polímeros com grau de ramificação entre 0,20 e 0,33 são os mais ativos (BOHN; BEMILLER, 1995).

Figura 1 - Estrutura molecular do 1,3/1,6- $\beta$-D- glucano

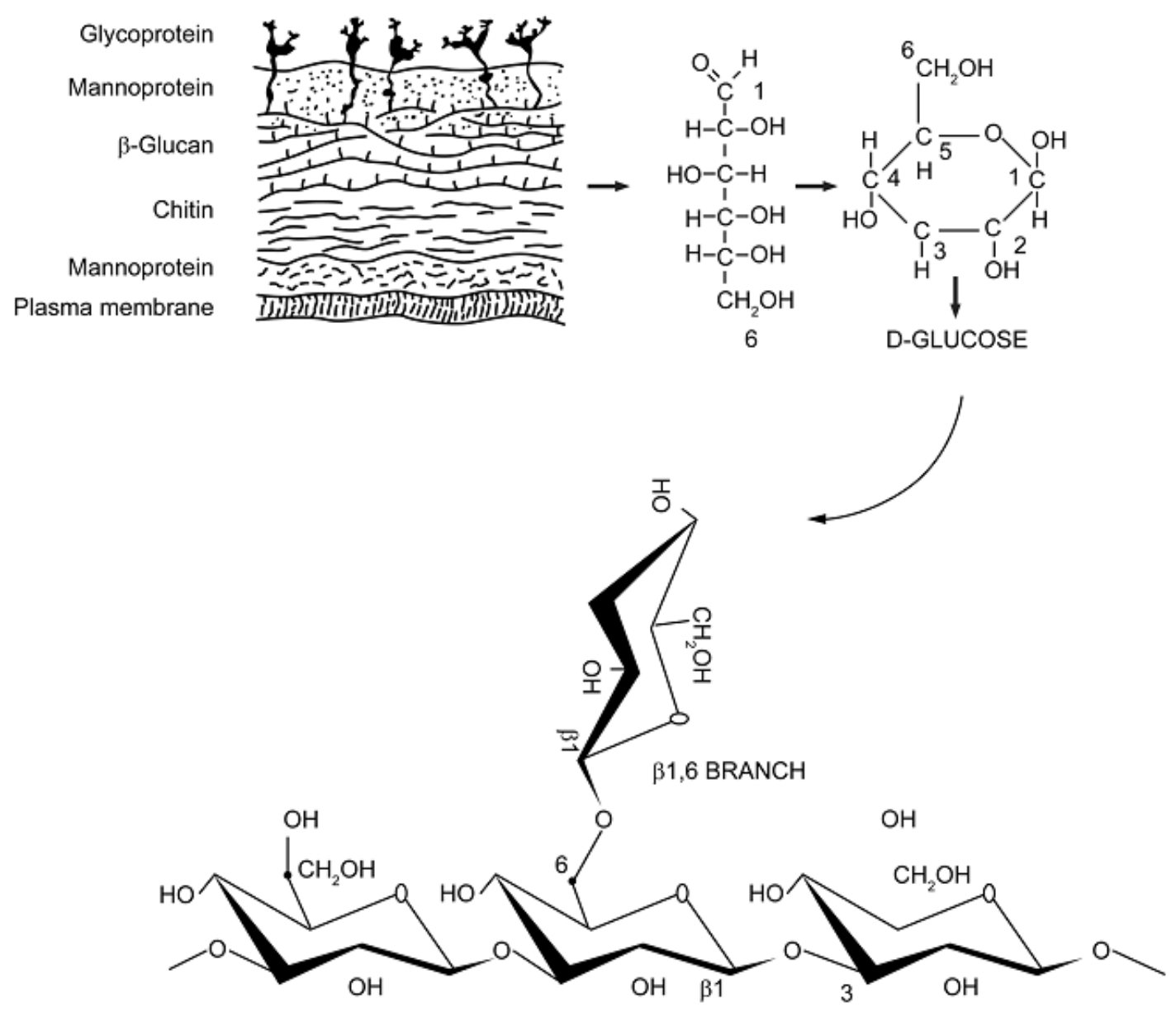

Fonte: Chan, Chan e Zse (2009) 
Quadro 1 - Fontes de $\beta$-glucano

\begin{tabular}{|c|c|c|c|}
\hline & Fonte & Nome comum & \multirow{6}{*}{$(1,3) \beta$-glucano linear } \\
\hline Bactérias & $\begin{array}{l}\text { Agrobaterium spp. } \\
\text { Rizobium spp. } \\
\text { Cellulomonas spp. } \\
\text { Bacillus spp. } \\
\text { Alcaligenes faecalis }\end{array}$ & Curdlan & \\
\hline Fungo & Poria cocos & Pachyman & \\
\hline Liquens & $\begin{array}{l}\text { Steeocaulon ramulosun } \\
\text { Ramina spp. } \\
\text { Claonia spp. }\end{array}$ & & \\
\hline Algas & $\begin{array}{l}\text { Euglena spp. } \\
\text { Astasia longa } \\
\text { Pavlova mesolychnon } \\
\text { Peranema trichophorum }\end{array}$ & Paramylon & \\
\hline Plantas & $\begin{array}{l}\text { Vitis vinifera } \\
\text { Gossypium arboretum } \\
\text { Nicotiana alata }\end{array}$ & Callose & \\
\hline Líquen & Cetralia islandica & Liquenin & \\
\hline Algas & $\begin{array}{l}\text { Ulva lactuca } \\
\text { Monodus subterraneus } \\
\text { Micrasterias spp. }\end{array}$ & & $(1,3 ; 1,4) \beta$-glucano linear \\
\hline Plantas & $\begin{array}{l}\text { Hordeum vulgare } \\
\text { Avena sativa } \\
\text { Triticum vulgare } \\
\text { Equisetum arvense }\end{array}$ & & \\
\hline Bactéria & $\begin{array}{l}\text { Streptococcus pneumoniae tipo } \\
37\end{array}$ & & $\begin{array}{l}(1,3 ; 1,6) \beta \text {-glucano cadeia- } \\
\text { lateral ramificada }\end{array}$ \\
\hline Fungo & $\begin{array}{l}\text { Auricular aurícula-judae } \\
\text { Coriolus versicolor }\end{array}$ & Krestin & $\begin{array}{l}(1,4 ; 1,6) \beta \text {-glucano cadeia- } \\
\text { lateral ramificada }\end{array}$ \\
\hline & Pleurotus ostreatus & Pleuran & \\
\hline & Lentinus edodes & Lentinan & \\
\hline & Sclerotium rolfsii & Scleroglucan & \\
\hline & Schizophyllum commune & Schizophyllan & \\
\hline & Grifola frondosa & Grifolan & \\
\hline Fungos & $\begin{array}{l}\text { Phytium apinadermatum } \\
\text { Achyla bisexualis }\end{array}$ & Mycolaminarim & $\begin{array}{l}(1,3 ; 1,6) \beta \text {-glucano cadeia- } \\
\text { lateral-ramificada }\end{array}$ \\
\hline & $\begin{array}{l}\text { Chaetoceros mulleri } \\
\text { Ochromonas spp. } \\
\text { Haramonas dimorpha } \\
\text { Phaeodactylum tricornutum } \\
\text { Coscinodiscus nobilis } \\
\text { Thalassiosira pseudonana }\end{array}$ & Chrysolaminarin & \\
\hline & $\begin{array}{l}\text { Laminaria spp. } \\
\text { Eicenia spp. }\end{array}$ & Laminarin & \\
\hline Fungos & $\begin{array}{l}\text { Sccharomyces cerevisiae } \\
\text { Schizosaccharomyces pombe } \\
\text { Aspergillus fumigatus } \\
\text { Candida albicans }\end{array}$ & & $\begin{array}{lr}1,3 ; 1,6) & \beta \text {-glucano } \\
\text { ramificação em ramificação }\end{array}$ \\
\hline Bactérias & $\begin{array}{l}\text { Agrobacterium tumefaciens } \\
\text { Sinorhizobium meliloti } \\
\text { Rhizobium meliloti } \\
\text { Mesorhizobium loti } \\
\text { Brucella spp. }\end{array}$ & & $(1,2) \beta$-glucano ciclico \\
\hline Bactérias & $\begin{array}{l}\text { Bradyhizobium japonicum } \\
\text { Rhizobium loti } \\
\text { Azorhizobium caulinodans } \\
\text { Azospirillum brasiliense }\end{array}$ & & $(1,3 ; 1,6) \beta$-glucano ciclico \\
\hline
\end{tabular}

Fonte: Adaptado de Barsanti et al. (2011) 
Apesar das diferentes estruturas químicas, esses polímeros de glicose receberam a denominação comum de $\beta$-glucanos (VETVICKA; VANCIKOVA, 2010). No entanto, sabe-se que as diferenças estruturais influenciam na atividade biológica (WILLIAMS, 1997; SOLTANIAN et al., 2009).

A levedura Sacharomyces cerevisiae, conhecida também como levedura de fermentação, é uma importante fonte de $\beta$-glucano. Sacharomyces cerevisiae é amplamente empregada nas indústrias de cervejaria, sucroalcooleira e de panificação (MAGNANI; CASTRO-GÓMEZ, 2008).

A parede celular de Saccharomyces cerevisiae corresponde em peso seco a aproximadamente 10 a $25 \%$ do peso total da célula, sendo que a parede celular pode conter de 30 a $60 \%$ de $\beta$-glucanos. Trata-se de $\beta$-(1,3;1,6)-D-glucanos, ou seja, $\beta$-(1,3)-D-glucano com ramificações $\beta$-(1,6) intercaladas. São insolúveis em água (BARSANTI et al., 2011).

A obtenção de $\beta$-glucanos purificados e solúveis é um desafio para que se possa avaliar completamente a sua estrutura e as suas propriedades. $\beta$-glucanos insolúveis podem ser submetidos à fosforilação, aminação e sulfatação para melhorar a solubilidade (TZIANABOS, 2000). A solubilização aumenta as possibilidades terapêuticas de $\beta$-glucanos por evitar efeitos nocivos de produtos particulados quando administrados de forma sistêmica (WILLIAMS et al. 1988a; WILLIAMS et al.,1991).

O ideal é que após se aumentar a solubilidade, o potencial biológico seja mantido (WILLIAMS et al. 1991). Existe relato de que a sulfatação aumenta o potencial imunoestimulante (ITOH et al., 1990).

\subsection{SISTEMA IMUNOLÓGICO E MECANISMOS DE AÇÃO DOS $\beta$-GLUCANOS}

Os benefícios terapêuticos do $\beta$-glucano como a sua ação anti-infecciosa e antitumoral foram muito estudados (BROWN; GORDON, 2003; CHEN; SEVIOUR, 2007). Os efeitos benéficos no tratamento de colesterol alto e diabetes também foram descritos (CHEN; SEVIOUR, 2007). Porém, os mecanismos que atuam para que ocorram esses efeitos ainda não são claros (BROWN; GORDON, 2003). 
A resposta imunológica inata é baseada em receptores não clonais chamados de Receptores de Reconhecimento Padrão (PRRs). Estes receptores reconhecem moléculas na superfície de micro-organismos, as quais são denominadas Padrões Moleculares Associados a Patógenos (PAMPs). Os PAMPs são moléculas conservadas, importantes para a sobrevivência e patogenicidade do microorganismo e estão presentes em diversos micro-organismos (NOVAK; VETVICKA, 2009).

Os $\beta$-glucanos não estão presentes nos animais, sendo reconhecidos pelo sistema imunológico inato, tanto de vertebrados quanto de invertebrados, como "não próprios" através de PRRs (SOLTANIAN et al., 2009).

Os mecanismos da resposta inata contra patógenos fúngicos reconhecem componentes estruturais conservados como os $\beta$-glucanos. Desta forma, entender como atua a resposta imunológica contra esses patógenos pode facilitar a compreensão da ação dos $\beta$-glucanos e possibilitar uma melhor exploração do seu potencial terapêutico (BROWN; GORDON, 2003).

A ação mais conhecida dos $\beta$-glucanos está relacionada ao aumento da fagocitose por granulócitos, macrófagos, monócitos e células dendriticas. Sendo que os macrófagos desempenham papel fundamental nas infecções tanto de bactérias quanto de vírus e parasitas (NOVAK; VETVICKA, 2009).

A resposta imunológica inata e especifica atuam em cooperação. Por exemplo, os macrófagos em resposta a um estímulo inflamatório liberam citocinas e estimulam os linfócitos específicos a se ativar a um determinado micro-organismo. Do mesmo modo, linfócitos podem liberar citocinas que ativam os macrófagos (MORGULIS, 2002).

A ação do $\beta$-glucano estimulando o sistema imunológico inato é de grande interesse por proteger contra infecções oportunistas que são muito comuns em indivíduos imunossuprimidos (CROSS et al., 2011). Quando um antígeno ultrapassa as barreiras epiteliais, os macrófagos desempenham um importante papel através da fagocitose. Os antígenos fagocitados são destruídos pelas enzimas presentes no lisossomo e, além disso, os macrófagos liberam citocinas como IL-1, IL-6, IL-8, IL12, TNF- $\alpha$ e mediadores da inflamação como óxido nítrico e peróxido de hidrogênio. Desta forma, a ativação dos macrófagos pelos $\beta$-glucanos aumenta a ação da resposta imunológica de defesa (AKRAMIENĖ et al., 2007). 
As células efetoras do sistema imunológico adaptativo são os linfócitos B e T que agem, respectivamente, através da produção de anticorpos (Imunidade humoral) e da imunidade mediada por células (CHEN; SEVIOUR, 2007). As células apresentadoras de antígenos são essenciais para que se inicie a resposta imunológica adaptativa. Estas apresentam através do MHC classe II (Complexo Principal de Histocompatibilidade), os peptídeos de antígenos extracelulares para os linfócitos T Helper (CD4+). Os antígenos intracelulares são apresentados pelo $\mathrm{MHC}$ classe I, para os linfócitos T citotóxicos (CD8+) (CHAN; CHAN; SZE, 2009).

Carboidratos são capazes de estimular a resposta imune independente das células T, sendo chamados antígenos T independentes (TZIANABOS, 2000; CHAN; CHAN; SZE, 2009). A resposta imunológica T independente é de curta duração, devido a ausência de ativação dos linfócitos T Helper, não há o desenvolvimento de memória imunológica e também não ocorre a interrupção da produção de anticorpos da classe IgM para passar a produzir a classe lgG (TZIANABOS, 2000).

Contudo, polissacarídeos que carregam cargas positivas e negativas, como os $\beta$-glucanos, ativam linfócitos CD4+ através da via endocítica. Assim, os $\beta$ glucanos são processados e apresentados pelas células apresentadoras de antígenos aos linfócitos T Helper (CHAN; CHAN; SZE, 2009).

A resposta imunológica é direcionada por citocinas que induzem a diferenciação dos linfócitos T Helper em Th1 e Th2. Sendo que o Th1 produz um perfil de citocinas que caracterizam a imunidade celular, enquanto que o Th2 produz citocinas que ativam a síntese de imunoglobulinas ou a imunidade humoral (CHEN; SEVIOUR, 2007). Dados iniciais sugeriram que a resposta ao $\beta$-glucano era direcionada a Th1, mas ainda não há um consenso em relação a isso (CHAN; CHAN; SZE, 2009). Em estudo in vitro não foi observada a polarização da resposta imunológica para Th1 ou Th2 (CHAN et al., 2007).

Os vertebrados não possuem 1,3 $\beta$-glucanases, assim, não podem degradar rapidamente esses carboidratos, por isso são metabolizados lentamente através de oxidação (NONO et al., 1991). A longa permanência do $\beta$-glucano no organismo pode ser um fator que contribua para a sua ação imunomoduladora.

Os $\beta$-glucanos considerados mais ativos possuem uma cadeia principal ligada por 1,3 $\beta$-D-glucopiranose com cadeias laterais unidas em 1,6 ou 1,4 (BOHN; BEMILLER, 1995; SOLTARIAN et al., 2009). 
A ligação de $\beta$-glucanos a receptores de macrófagos e de outros fagócitos ativa várias funções incluindo o aumento na quimiocinese, da quimiotaxia, a desgranulação, a expressão de moléculas adesivas nos macrófagos que em consequência aumenta a sua adesão ao endotélio. A ligação ao $\beta$-glucano estimula a ação de processos intracelulares caracterizados pela explosão respiratória (formação de espécies reativas de oxigênios, espécies de nitrogênio e radicais livres) (NOVAK; VETVICKA, 2009; VETVICKA, 2011).

$A$ ativação dos fagócitos inicia um processo inflamatório através de citocinas liberadas, por exemplo, IL-1, IL-9 e TNF-a. Apesar de ser essencial para a proteção do organismo, se ocorrer de forma desordenada, a inflamação pode levar a sérios danos ao tecido normal e até mesmo ao desenvolvimento de doenças auto imunes (NOVAK; VETVICKA, 2009).

Alguns receptores celulares foram reconhecidos como responsáveis pela atividade do $\beta$-glucano, são eles: Dectina-1, lactosilceramida, receptores scavenger (SR), receptores de complemento três (CR3) e receptores Toll-like 2 e 6 (TLR) (SOLTARIAN, 2009, BROWN; GORDON, 2003). Há descrição em aves do TLR-2 (FUKUI et al., 2001), dos receptores scavenger (HE et al. 2009), do receptor CR3 (MOYES et al., 1998) e da dectina-1 (NERREN E KOGUT, 2009).

$O$ receptor CR3 é também conhecido como Mac-1, $\alpha_{M} \beta_{2}$-integrina, ou ainda CD11b/CD18 (NOVAK; VETVICKA, 2009). Monócitos, neutrófilos e linfócitos NK expressam o CR3 em alta concentração, contudo é menos presente nos macrófagos (AKRAMIENĖ, 2007; CHEN; SEVIOUR, 2007). Este receptor é uma glicoproteína composta por duas (2) subunidades denominadas de CD11 ou $\alpha_{M}$ e CD18 ou $\beta_{2}$ (NOVAK; VETVICKA, 2009). Pode ser considerado o receptor mais importante em linfócitos NK, uma vez que estes não possuem a dectina-1 (CHEN; SEVIOUR, 2007).

O CR3 é uma glicoproteína que atravessa a membrana celular, pertencente a família da ß2-integrina (AKRAMIENÉ, 2007; TSONI; BROWN, 2008). Este receptor atua tanto como uma molécula de adesão que facilita a diapedese (AKRAMIENE், 2007; NOVAK; VETVICKA, 2009) em fagócitos e linfócitos NK (NOVAK; VETVICKA, 2009), como também possibilita a fagocitose e degranulação em micro-organismos opsonizados pelo iC3b (AKRAMIENĖ, 2007; NOVAK; VETVICKA, 2009). As funções citotóxicas, assim como, as de adesão são reguladas pelo domínio de lectina intracelular (AKRAMIENE், 2007). 
O receptor lactosilceramida é um glicoesfingolípede presente na membrana plasmática de muitas células (TSONI; BROWN, 2008), que se liga a células microbianas e também a $\beta$-glucanos (NOVAK; VETVICKA, 2009). É encontrado em células endoteliais e neutrófilos (CHEN; SEVIOUR, 2007, KIM et al. 2011). Consiste de um lipídeo ceramida hidrofóbico e um motivo de açucares hidrofílico e foi identificado como receptor para o $\beta$-glucano (ZIMMERMAN et al.1998). Contudo, quanto a sua capacidade de se ligar ao $\beta$-glucano, ainda não foram totalmente esclarecidas (NOVAK; VETVICKA, 2009), sabe-se que induz respostas celulares in vitro como, a produção de proteína inflamatória 2 por macrófagos (MIP-2) e do fator de necrose tumoral a (TNF- $\alpha$ ) em neutrófilos alveolares (KIM et al., 2011).

Os receptores Toll-like (TLR) são receptores que atravessam a membrana celular, são importantes na resposta imunológica inata como PRRs (NOVAK; VETVICKA, 2009). Sabe-se que o Zymosan se liga ao TLR-2 e 4. O TLR-2 aumenta as concentrações celulares de NF-kB e a produção de citocinas como TNFa e IL-12 (CHEN; SEVIOUR, 2007). A dectina-1 age em cooperação com o TLR-2 e TLR-6 (CHAN; CHAN; SZE, 2009), contudo os estudos mostrando essa cooperação não foram feitos com $\beta$-glucanos purificados, por isso ainda são necessárias comprovações (CHEN; SEVIOUR, 2007; CHAN; CHAN; SZE, 2009).

O receptor scavenger (SR) é formado por um grupo de proteínas heterogêneas com dois (02) domínios que atravessam a membrana, dois (2) intracelulares e um (1) extracelular (CHEN; SEVIOUR, 2007; NOVAK; VETVICKA, 2009). Estão presentes em células mielóides e epiteliais (CHEN; SEVIOUR, 2007) e reconhecem diferentes antígenos. Sabe-se que se ligam ao lentinam, mas ainda não foram identificados receptores scavenger exclusivos do $\beta$-glucano (NOVAK; VETVICKA, 2009). Os efeitos biológicos que podem ocorrer em consequência da ligação do $\beta$-glucano a esses receptores ainda não estão esclarecidos e não se sabe qual a sua real importância (CHEN; SEVIOUR, 2007).

O receptor dectina-1 é uma lectina, de grande importância no reconhecimento de patógenos fúngicos (NOVAK; VETVICKA, 2009). Está presente em macrófagos, algumas linhagens de neutrófilos, células dendriticas (DC) e algumas células $T$, mas não estão presentes nos linfócitos NK (CHEN; SEVIOUR, 2007). É uma proteína que atravessa a membrana celular, composta por quatro (4) componentes. Um domínio extracelular que interage com carboidratos (CRD), um caule, uma região que 
atravessa a membrana celular e uma cauda citoplasmática com o imuno receptor ITAM (tirosine-based activating motif) (NOVAK; VETVICKA, 2009).

O domínio citoplasmático da dectina-1, o imuno receptor ITAM, ativa uma tirosina-quinase que por sua vez estimula a produção de espécies reativas de oxigênio (ROS) e induz a síntese de TNF-a, IL-2, IL-10 e IL-12 (CHEN; SEVIOUR, 2007).

Segundo Brown et al. (2002) a Dectina-1 é o principal receptor em macrófagos para $\beta$-glucanos tanto solúveis como particulados. Contudo alguns trabalhos descrevem a dectina- 1 como um receptor apenas de $\beta$-glucanos particulados (GOODRIDGE; UNDERHILL; TOURET, 2012).

A presença de dectina-1 em frangos foi descrita por Nerren e Kogut (2009), eles mostraram que heterófilos e células mononucleares responderam ao estimulo por Curdlan, considerado um agonista especifico da dectina-1, através do aumento significativo da produção de espécies reativas de oxigênio. $E$, além disso, 0 tratamento das células com laminarina, que atua bloqueando a dectina-1, reduzia significativamente a produção de espécies reativas de oxigênio. Esses dados indicavam a presença da dectina-1 ativa em heterofilos e células mononucleares, contudo mais pesquisas são necessárias para determinar a ação da dectina-1 nas aves.

Assim, os $\beta$-glucanos fúngicos podem ativar diferentes populações de células imunológicas através de receptores específicos. A dectina-1 é muito importante nos macrófagos, assim como, o CR3 nos linfócitos NK. Algumas células como os neutrófilos possuem vários receptores. Efeitos coordenados entre a dectina-1 e o TLR são conhecidos, mas ainda são necessários estudos para verificar a ação conjunta de outros receptores (CHEN; SEVIOUR, 2007).

\subsection{EFEITOS BIOLÓGICOS DOS $\beta$-GLUCANOS}

Os efeitos biológicos dos $\beta$-glucanos, conforme já elucidado, são atribuídos a sua interação com receptores de macrófagos, neutrófilos e linfócitos Natural Killer (NK). Contudo, $\beta$-glucanos estruturalmente semelhantes apresentaram efeitos diferentes e isso foi ainda mais exacerbado quando os produtos apresentaram 
diferenças significativas em suas estruturas (AKRAMIENÉ et al., 2007). Muitos estudos foram conduzidos com o uso do Zymosan, que contem outros componentes além do $\beta$-glucano, o que dificulta a discussão dos efeitos biológicos dos $\beta$-glucanos (AKRAMIENE் et al., 2007).

Em relação aos efeitos desses polissacarídeos existem contradições, possivelmente pela considerável diversidade de fontes naturais de $\beta$-glucanos (NOVAK; VETVICKA, 2009). Dessa forma, a análise dos dados da literatura deve ser criteriosa, já que ainda não se tem um consenso em relação aos requerimentos estruturais básicos necessários para a atividade biológica do $\beta$-glucano (BROWN; GORDON, 2003).

De forma geral, os estudos in vitro tem sugerido que $\beta$-glucanos de alto peso molecular ativam diretamente os leucócitos, estimulando as atividades antimicrobianas, citotóxicas e a fagocitose (AKRAMIENÉ, et al. 2007). Enquanto os $\beta$-glucanos de peso molecular baixo ou intermediário são ativos in vivo, mas os seus efeitos celulares ainda não estão claros (BROWN; GORDON, 2003; AKRAMIENE் et al., 2007).

As aves comerciais sofrem diferentes tipos de estresses, tanto relativos ao ambiente quanto ao manejo. $O$ estresse influencia na imunidade e consequentemente na susceptibilidade a doenças (KOUTSOS; KLASING, 2008). O uso de $\beta$-glucano oral mostrou-se eficaz para reduzir os efeitos do estresse por frio e por restrição de movimentos em camundongos (VETVICKA; VANCIKOVA, 2010).

Um importante aspecto em relação à atividade imunológica do $\beta$-glucano foi sua ação como adjuvante, melhorando a resposta a vacinas (WILLIAMS, 1997). Pedroso (2009) observou que o $\beta$-glucano sulfatado solúvel associado à vacina contra a Doença Infecciosa da Bursa aumentou a resposta imunológica em frangos de corte.

Chae et al. (2006) realizaram um estudo avaliando o efeito da adição do $\beta$-glucano na dieta de frangos de corte e observaram que a adição na ração na dose de 0,04 \% aumentava a população de linfócitos (CD8 e TCR1).

O uso do $\beta$-glucano em diferentes concentrações na ração de frangos de corte $(0,25,50,75,100$ e $125 \mathrm{mg} / \mathrm{Kg}$ de ração) influenciava a resposta imunológica das aves. Ocorreu aumento nas concentrações de citocinas nos animais que estavam recebendo 50 e $75 \mathrm{mg} / \mathrm{Kg}$ de ração. Observou-se aumento nas concentrações séricas de $\operatorname{lgG}$ em todos os grupos que receberam 0 
$\beta$-glucano, exceto no grupo que recebeu $125 \mathrm{mg} / \mathrm{Kg}$. As concentrações de $\lg A$ intestinal foi maior em todos os grupos e houve aumento significativo nas concentrações de globulina sérica, mostrando que o $\beta$-glucano ativou a resposta imune humoral. Além disso, os autores observaram que na dose de 50 e $75 \mathrm{mg} / \mathrm{Kg}$ de ração houve um melhor ganho de peso dos animais (ZHANG; GUO; WANG, 2008).

Cox et al. (2010a) utilizaram $\beta$-glucano na ração de frangos de corte em duas doses diferentes $(0,02 \%$ e $0,1 \%)$. Os animais que receberam o $\beta$-glucano não apresentaram um aumento no ganho de peso. Quanto à resposta imune não houve diferença no peso relativo dos órgãos linfóides, assim como, no número de heterófilos, porém observou-se diferenças nas citocinas expressadas nos animais que receberam o $\beta$-glucano, mostrando que a suplementação com $\beta$-glucano alterava a produção de citocinas, interferindo na resposta imunológica.

O uso de carboximetilglucana adicionada à ração foi avaliada em diferentes doses (0\%, 0,025\%, 0,050\% e 0,075\%), em frangos de corte da linhagem COBB, um grupo de aves, de cada um dos tratamentos, recebeu a carboximetilglucana por via intramuscular. O uso da carboximetilglucana levou a diferença no ganho de peso e no consumo de ração. O peso relativo da bursa de Fabricius aumentou nas aves suplementadas com 0,025 e 0,050\% de carboximetilglucana. Observou-se também que a concentração sérica de lgG total aos 21 dias de idade foi maior nas aves que foram suplementadas. Naquelas que receberam por via intramuscular ocorreu um aumento de anticorpos específicos para a doença de Newcastle (DARPOSSOLO et al., 2010).

O uso de $\beta$-glucano na dieta de frangos aumentou a fagocitose por macrófagos e também as concentrações de anticorpos séricos específicos para hemácias de carneiro (GUO; ALI; QURESHI, 2003).

$A$ atividade do $\beta$-glucano foi testada, com modelos animais, contra infecções, especialmente por bactérias, mostrando seus efeitos em diferentes parâmetros como a redução da mortalidade e decréscimo na contagem bacteriana em animais infectados (TZIANABOS, 2000).

$\beta$-glucanos derivados da parede celular de Saccharomyces cerevisiae administrados em camundongos (0,45mg/animal) por via intravenosa, quatro (04) e sete (07) dias antes de desafiar os animais com Staphylococcus aureus $\left(1 \times 10^{9}\right.$ 
UFC/mL) aumentaram significativamente a sobrevivência dos camundongos quando comparado ao grupo controle (WILLIAMS; DI LUZIO, 1979).

Os heterófilos das aves são células equivalentes aos neutrófilos nos mamíferos. São fagócitos que exercem atividade importante na defesa inespecífica às infecções (MORGULIS, 2002). Em um estudo sobre peritonite causada por $E$. coli, camundongos tratados com $\beta$-glucano três (03) ou cinco (05) dias antes de serem desafiados por E. coli, apresentaram aumento no número de neutrófilos peritoneais e séricos. Os neutrófilos de camundongos tratados com o $\beta$-glucano mostraram aumento na fagocitose da $E$. coli in vitro (WILLIAMS et al., 1988b).

Williams et al. (1991) verificaram que o $\beta$-glucano sulfatado derivado de Saccharomyces cerevisiae aumentava a resistência de camundongos a Candida albicans, ao vírus da hepatite murina e a Escherichia coli. Além disso, ativava macrófagos, estimulava a medula óssea e exercia atividade antitumoral. Em relação a influencia na infecção bacteriana por Escherichia coli o $\beta$-glucano sulfatado foi injetado por via intraperitoneal $(250 \mathrm{mg} / \mathrm{Kg}), 24$ horas antes do desafio por via intraperitoneal com Escherichia coli $\left(1 \times 10^{8} \mathrm{UFC} / \mathrm{mL}\right)$. Observou-se aumento significativo na sobrevivência dos animais que receberam o $\beta$-glucano sulfatado, $92 \%$ comparado a $18 \%$ nos animais não tratados.

Huff et al. (2006) analisaram o efeito do uso do $\beta$-glucano na ração administrada a aves infectadas experimentalmente por Escherichia coli. A dose de $\beta$-glucano utilizada foi de 22 g/tonelada de ração, sendo que um dos tratamentos recebeu o $\beta$-glucano durante todo o período experimental (25 dias), enquanto outro tratamento recebeu o $\beta$-glucano apenas nos primeiros sete dias antes da infecção por E. coli. Cada ave recebeu, por via do saco aéreo, E. coli do sorotipo O2, na concentração de 800 UFC por ave. Os autores observaram que o uso de $\beta$-glucano na ração pode diminuir as perdas por infecção com Escherichia coli, pois as aves que receberam o $\beta$-glucano tiveram uma mortalidade menor. $O$ grupo controle apresentou uma mortalidade de $63 \%$, o grupo que recebeu o $\beta$-glucano durante todo o experimento uma mortalidade de $53 \%$ e o grupo que recebeu o $\beta$-glucano durante os primeiros 7 dias uma mortalidade de 47\% (HUFF et al., 2006).

Além disso, as aves que receberam $\beta$-glucano tiveram menos lesões causadas pela $E$. coli As aves que receberam o $\beta$-glucano durante os 7 dias antes da inoculação mantiveram o ganho de peso e a conversão alimentar. Contudo isso não ocorreu com as aves que receberam o $\beta$-glucano durante os 25 dias de criação. 
Observou-se também que as aves que receberam o $\beta$-glucano e não foram desafiadas tiveram um menor ganho de peso, sugerindo que a suplementação com o $\beta$-glucano foi eficaz para reduzir os danos causados pela infecção por $E$. coli, mas o estimulo imunológico pode resultar em diminuição na produção, em condições em que a ave não esteja sob desafio (HUFF et al., 2006).

\subsection{COLIBACILOSE}

Escherichia coli pertence à família Enterobacteriaceae. É um bastonete curto Gram negativo. As colônias geralmente são lisas ou rugosas. A temperatura de crescimento varia entre 18 a $44^{\circ} \mathrm{C}$, sendo $37^{\circ} \mathrm{C}$ a temperatura ideal (FERREIRA; KNOBL, 2009). Os sorotipos de E. coli foram classificados em 1947 por Kauffman, de acordo com os seus antígenos. Assim, a identificação dos sorogrupos é baseada na identificação dos antígenos somáticos $(\mathrm{O})$, capsulares $(\mathrm{K})$, flagelares $(\mathrm{H})$ e fimbriais (F). Existem descritos 177 antígenos somáticos, 100 antígenos capsulares e 52 antígenos flagelares (FERREIRA; KNOBL, 2009).

Os principais sorogrupos associados com colibacilose aviária são $01: K 1$, $\mathrm{O} 2: \mathrm{K} 1, \mathrm{O} 36$ e O78:K80. Contudo, também foram isolados outros sorogrupos como O4, O6, O11, O21, O50, O88, 0100 e 0119 (FERREIRA; KNOBL, 2009). No Brasil, os sorogrupos O2, O21, O36, O50, O78, O88, O119 e 0152 foram os mais prevalentes (FERREIRA, 1989; MENÃO et al., 2002).

Infecções causadas por $E$. coli acarretam grandes perdas econômicas na avicultura em todo o mundo (ANTÃO et al., 2008).

Esta bactéria pode causar doença respiratória crônica, onfalite, peritonite, septicemia, síndrome da cabeça inchada, enterite, salpingite e celulite (BRITO, 2000). Sendo geralmente associada a doenças extras intestinais, principalmente infecções respiratórias e sistêmicas (LA RAGIONE; WOODWARD, 2002).

A doença respiratória crônica se caracteriza por sinais respiratórios, ocorrendo retardo do crescimento, diminuição do consumo de ração e consequente aumento da mortalidade. As principais lesões são aerossaculite e inflamação de várias serosas, especialmente pericardite e perihepatite (ASK et al., 2006). A 
evolução da doença é rápida, comumente evolui para a septicemia, ou seja, presença de E. coli na circulação sanguínea, sendo denominada colisepticemia.

Nos abatedouros as lesões (aerossaculite, pericardite e perihepatite) são conhecidas como "tríade de condenação da carcaça" (FERREIRA; REVOLLEDO; FERREIRA, 2009).

Infecções virais, micoplasmose e fatores ambientais causadores de estresse aumentam a susceptibilidade das aves a colibacilose (LA RAGIONE; WOODWARD, 2002), uma vez que E. coli é frequentemente um agente secundário, mas também pode ser o agente primário (BARNES et al., 2008).

De maneira geral qualquer fator ambiental, infeccioso e nutricional que possa lesar o epitélio respiratório ou levar a supressão imunológica torna a ave susceptível a E. coli (FERREIRA; KNOBL, 2009).

O controle dos agentes infecciosos associados à colibacilose acompanhado de medidas gerais de melhorias no manejo reduz expressivamente a ocorrência da colibacilose, mas, ainda assim, é uma das principais doenças na avicultura (LA RAGIONE; WOODWARD, 2002).

Diante dos resultados promissores que se tem na literatura quanto à ação imunomoduladora do $\beta$-glucano, pela necessidade de mais estudos para que se possa estabelecer melhor a ação do $\beta$-glucano nas aves, e também considerando a importância da E. coli como patógeno na avicultura, este estudo foi realizado. 


\section{OBJETIVOS}

Os objetivos do presente estudo foram:

- Verificar a interferência do $\beta$-glucano solúvel aplicado em diferentes vias (oral, subcutânea e ocular) na resposta humoral das aves através da avaliação das concentrações de $\lg G$ e $\lg A$ séricas totais;

- Determinar qual via de administração é a mais eficiente com respeito à resposta imunológica e o desempenho das aves;

- Verificar se o $\beta$-glucano solúvel influência nos parâmetros zootécnicos;

- Verificar a interferência do $\beta$-glucano solúvel, na infecção por E. coli, através da redução da mortalidade e do escore de lesões em sacos aéreos, fígado e coração e também nas concentrações de anticorpos totais (lgG e $\lg A)$. 


\section{MATERIAL E MÉTODOS}

Serão descritos os materiais e a metodologia utilizados neste estudo.

\section{$4.1 \beta$-GLUCANO SOLÚVEL}

O produto utilizado para o preparo do $\beta$-glucano solúvel foi o MacroGard (Biorigin ${ }^{\circledR}$ ), que é composto por parede celular de levedura e possui no mínimo $60 \%$ de $\beta$-glucano purificado.

Para a solubilização, o produto foi sulfatado de acordo com Willians et al. (1991) com modificações feitas por Pedroso (2009). Após a solubilização o $\beta$-glucano solúvel foi liofilizado.

Cada ave recebeu no primeiro dia de idade $413,8 \mu \mathrm{g}$ do produto liofilizado, que correspondeu a $215 \mu \mathrm{g}$ de $\beta$-glucano solúvel por ave.

O $\beta$-glucano solúvel foi diluído no diluente da vacina de Marek e administrado por diferentes vias (subcutânea, ocular, e oral). Para isso o $\beta$-glucano solúvel foi pesado em balança analítica e diluído de forma que nos tratamentos que receberam $\beta$-glucano solúvel subcutâneo e oral a ave recebesse $0,1 \mathrm{~mL}$. Nas aves que receberam $\beta$-glucano solúvel por via ocular cada ave recebeu $0,03 \mathrm{~mL}$, ou seja, uma gota.

Foi feito teste de esterilidade no produto antes da liofilização e também após a aplicação do produto nas aves. O $\beta$-glucano solúvel foi semeado em BHI (Brain heart infusion) ágar e incubado a $37^{\circ} \mathrm{C}$ durante 24 horas.

\subsection{AVES}

Foram utilizadas 160 aves de corte, da linhagem comercial Ross (Aviagen ${ }^{\circledR}$ ), machos, com um dia de idade, divididas em oito (08) tratamentos com duas repetições de 10 aves em cada tratamento. 
As aves foram recebidas no primeiro dia e alojadas em dois galpões diferentes no Centro Experimental de Patologia Aviária da FMVZ-USP, em São Paulo. Os boxes para o alojamento das aves foram previamente lavados e desinfetados e o piso foi coberto com maravalha.

Para se evitar a contaminação cruzada as aves que não foram inoculadas com E. coli foram alojadas no galpão 1 (Tratamentos 1 a 4) e as que receberam E. coli, no galpão 2 (Tratamentos 5 a 8). Os boxes do galpão 1 eram de aproximadamente $1,7 \mathrm{~m}^{2}$ e os do galpão 2 de aproximadamente $1 \mathrm{~m}^{2}$.

Durante as duas primeiras semanas de vida as aves foram mantidas sob aquecimento elétrico entre 30 e $34^{\circ} \mathrm{C}$ e posteriormente a temperatura ambiente, sendo realizado o manejo das cortinas do aviário para manter o conforto térmico. As aves receberam água e ração ad libitum sendo que a ração utilizada foi comercial (Master Nutrição Animal @) e sem aditivos antimicrobianos e ou coccidiostáticos. Do primeiro dia ao $21^{\circ}$ dia de idade as aves receberam ração inicial e do $22^{\circ}$ dia até 0 $42^{\circ}$ dia de idade a ração do tipo engorda.

\subsection{DELINEAMENTO EXPERIMENTAL}

Foram realizados dois experimentos diferentes, sendo o primeiro Experimento 1 (Vias de administração) e o segundo Experimento 2 ( $\beta$-glucano e Escherichia coli).

As 160 aves foram divididas no dia 0 (zero) em oito (08) tratamentos, que foram subdivididos em duas $(02)$ repetições cada $(n=10)$. O tratamento 1 (controle negativo), foi o mesmo para os dois experimentos. Os tratamentos 2 a 4 foram do Experimento 1 (Vias de Administração), e os tratamentos 5 a 8 do Experimento 2 ( $\beta$ glucano e E. coli.) Assim, os resultados foram analisados separadamente.

Os tratamentos foram os seguintes:

\section{Controle negativo do Experimento 1 e 2:}

-Tratamento 1: não recebeu $\beta$-glucano solúvel e não foi inoculado com E. $\operatorname{coli}(\mathrm{C}-)$.

\section{Experimento 1- Vias de administração:}

- Tratamento 2: $\beta$-glucano solúvel por via subcutânea (SC);

- Tratamento 3: $\beta$-glucano solúvel por via ocular (OC) ; 
-Tratamento 4: $\beta$-glucano solúvel por via oral (VO);

\section{Experimento 2- $\beta$-glucano e Escherichia coli}

-Tratamento 5: inoculação com E. coli aos 14 dias $\left(\mathrm{C}_{+}\right)$de idade;

-Tratamento 6: $\beta$-glucano solúvel por via subcutânea e inoculação com E. coli $(\mathrm{SC}+\mathrm{EC})$ aos 14 dias de idade;

-Tratamento 7: $\beta$-glucano solúvel por via ocular e inoculação com E. coli $(\mathrm{OC}+\mathrm{EC})$ aos 14 dias de idade;

-Tratamento 8: $\beta$-glucano solúvel por via oral e inoculação com E. coli $(\mathrm{VO}+\mathrm{EC})$ aos 14 dias de idade.

De acordo com os tratamentos, as aves receberam o $\beta$-glucano solúvel no primeiro dia de idade e foram inoculadas por via saco aéreo torácico direito com $E$. coli.

\subsection{DESAFIO DAS AVES}

A infecção com E. coli foi realizada com a amostra EC341, pertencente à coleção de cultura do Laboratório de Ornitopatologia, sorotipo O119, proveniente de ave com doença respiratória crônica. As aves receberam por via do saco aéreo torácico direito, aos 14 dias de idade, $0,1 \mathrm{~mL}$ do inoculo, na concentração de $4 \times 10^{7}$ UFC E. colimL.

Escherichia coli foi semeada em ágar MacConkey e incubada a $37^{\circ} \mathrm{C}$. A partir desta cultura foram escolhidas colônias isoladas que foram inoculadas em $\mathrm{BHI}$ caldo (Braian heart infusion) sob agitação de $130 \mathrm{rpm}$ a $37^{\circ} \mathrm{C}$. Foi estabelecido previamente em qual tempo e densidade óptica, através da leitura em comprimento de onda de $625 \mathrm{~nm}$, a suspensão bacteriana possuía a concentração de $1 \times 10^{7}$ UFC E. coli/mL.

A contagem bacteriana foi feita utilizando-se 7 (sete) tubos de ensaio contendo $9 \mathrm{~mL}$ de água peptonada $0,1 \%$. Os tubos foram numerados de $10^{-1}$ até $10^{-7}$ e uma diluição em série, na base 10 , foi realizada. Uma alíquota de $100 \mu \mathrm{L}$ foi retirada dos últimos quatro (04) tubos $\left(10^{-4}\right.$ a $\left.10^{-7}\right)$ e foi semeada em ágar MacConkey, utilizando-se alça de Drigalski. As placas foram incubadas a $37^{\circ} \mathrm{C}$ por 
18 a 24 horas. O número de unidades formadoras de colônia (UFC) foi determinado nas diluições realizadas.

Através desses ensaios prévios se definiu a D.O. necessária para se obter a concentração bacteriana desejada

O inoculo foi levado até o aviário em gelo, evitando o crescimento bacteriano. Após a inoculação foi feita a contagem bacteriana para se confirmar a concentração bacteriana recebida pelas aves.

Os meios de cultura utilizados estão descritos no apêndice $A$.

\subsection{OBTENÇÃO DAS AMOSTRAS}

Nos dias 28, 35 e 42 do experimento foram colhidos aproximadamente $1 \mathrm{~mL}$ de sangue de cada ave, da veia ulnar, utilizando-se seringas de $3 \mathrm{~mL}$ e agullhas $30 \times 7$. As amostras foram colhidas a partir dos 28 dias para que não houvesse presença dos anticorpos maternos. As amostras foram deixadas em repouso sem anticoagulante, dentro da seringa à temperatura ambiente para posterior separação do soro. O soro separado foi centrifugado a 3500 x g por 10 minutos e congelado à 20ํㅡ até a realização do ensaio imunoenzimático (ELISA).

\subsection{ESCORE DE LESÃO}

No $42^{\circ}$ dia do experimento, após a colheita de sangue, as aves foram sacrificadas em câmara de $\mathrm{CO}_{2}$ e foram necropsiadas.

As aves dos grupos que receberam E. coli (T5, T6, T7 e T8) e do controle negativo (T1) foram analisadas quanto ao escore de lesão para colibacilose. Foram observadas lesões em sacos aéreos (torácico esquerdo, torácico direito e abdominal), fígado e coração. A classificação dessas lesões foi feita em um escore individual dos órgãos entre zero (menor intensidade) e quatro (maior intensidade) de acordo com Goren (1978), com algumas modificações. Depois da infecção com E. coli (14 dias), o escore de lesão também foi realizado nas aves que morreram. 
Os resultados das aves que morreram e das que foram sacrificadas foram analisados separados e também em conjunto. $\mathrm{Na}$ analise em conjunto foi feito um índice de escore de lesão. Para isso o número de aves que apresentavam determinado escore de lesão foi multiplicado pelo escore (0 a 4), posteriormente esses valores foram somados e divididos pelo $\mathrm{n}$ total.

O quadro 2 explica detalhadamente as características do escore de zero a quatro (0 a 4$)$.

Quadro 2 - Escore de lesão estabelecido para pericárdio, serosa hepática e sacos aéreos.

\begin{tabular}{|c|l|c|}
\hline Local & \multicolumn{1}{|c|}{ Descrição } & Escore \\
\hline \multirow{5}{*}{$\begin{array}{c}\text { Sacos } \\
\text { aéreos }\end{array}$} & Normal & 0 \\
& Oeve opacidade dos sacos aéreos & 1 \\
& Oxsudato localizada dos sacos aéreos e com presença de & 2 \\
& Opacidade extensa com grande quantidade de exsudato & 3 \\
& Opacidade extensa e presença de placas de fibrina & 4 \\
\hline \multirow{5}{*}{ Fígado } & Normal & 0 \\
& Presença de fibrina em pequena quantidade & 1 \\
& Presença de placas de fibrina na superfície hepática & 2 \\
& Placas de fibrina extensas e que formam aderência no tecido & 3 \\
& hepático & 4 \\
\hline \multirow{5}{*}{ Coração } & Placas extensas e espessas de fibrina em todo o fígado & 0 \\
& Normal & 1 \\
& Quantidade excessiva de fluido claro dentro do saco & \\
& Opericárdico pacidade no pericárdio ou presença de fluido turvo dentro do & 2 \\
& saco pericárdico. & 3 \\
& Presença de placas de fibrina no pericárdio & 4 \\
\hline
\end{tabular}

Fonte: Goren (1978) com modificações.

\subsection{ENSAIO IMUNOENZIMÁTICO (ELISA)}

As concentrações séricas de $\lg G$ e $\lg A$ totais, de todos os tratamentos, foram obtidas por ensaio imunoenzimático indireto (ELISA indireto) utilizando-se kits comerciais da Bethyl ${ }^{\circledR}$ (Chicken IgA ELISA Quantitation Set e Chicken IgG ELISA Set).

Foram feitos ensaios para a padronização do teste, onde várias diluições do conjugado foram testadas de maneira que se obtivesse no primeiro padrão da curva 
uma densidade ótica (D.O.) entre 1,8 e 2,2, conforme recomendado. Contudo, no ensaio de quantificação de lgG não foi possível definir a diluição ideal, uma vez que em ensaios diferentes utilizando uma mesma diluição do conjugado não eram reproduzidos os resultados. Por isso decidiu-se fazer as análises de lgG, dos soros colhidos na mesma idade, todas no mesmo ensaio, pois, assim, os possíveis erros seriam padronizados não prejudicando a comparação dos resultados.

Soros de cada tratamento foram testados em pools de soros para que fosse definida a diluição a ser padronizada nas amostras de soro, de forma que se enquadrassem na curva.

As amostras de soro foram analisadas individualmente sendo feita a média dos resultados. As analises de $\lg A$ foram feitas em duplicata, enquanto as de $\lg G$ isso não foi possível, para que todas as amostras na mesma idade pudessem ser analisadas em um mesmo ensaio.

As amostras de soro após serem descongelados foram homogeneizadas e centrifugadas a $3500 \times \mathrm{g}$, por 10 minutos para que as partículas formadas devido ao congelamento decantassem. A diluição das amostras foi feita utilizando a solução de diluição conforme recomendado pelo kit, sendo que nos testes para a quantificação de $\lg G$ as amostras foram diluídas 1:40000, e para $\lg A$ 1:2000.

As lavagens da placa foram realizadas em lavadora automática utilizando-se o tampão de lavagem, sendo o procedimento repetido cinco (05) vezes em cada lavagem. A placa era "batida" em papel absorvente para retirar todo o liquido.

Os ensaios tanto de $\lg G$ quanto de $\lg A$ foram feitos seguindo os passos recomendados pelo fabricante do kit, com algumas modificações. Segue a descrição de cada passo do ensaio. Todas as soluções utilizadas estão descritas no apêndice B.

Utilizaram-se placas de poliestireno de fundo chato (Costar®) que foram sensibilizadas com $50 \mu \mathrm{L} /$ poço de anticorpos de revestimento diluídos em tampão carbonato-bicarbonato $0,05 \mathrm{M}, \mathrm{pH} 9,6$. Em estufa a $22^{\circ} \mathrm{C}$, as placas foram incubadas durante uma (01) hora. Após a lavagem, os sítios inespecíficos da placa foram bloqueados com $200 \mu \mathrm{L} /$ poço de solução de bloqueio, por 30 minutos. Após este período foram lavadas conforme descrição acima.

Adicionou-se nas duas primeiras fileiras das placas $50 \mu \mathrm{L} /$ poço do soro padrão, diluído conforme consta nas tabelas 1 e 2 para os ensaios de $\lg A$ e $\lg G$, 
respectivamente. Nas demais fileiras, as amostras de soro já diluídas. As placas foram incubadas em estufa a $22^{\circ} \mathrm{C}$, por uma hora e em seguida, lavadas novamente.

Acrescentou-se o anticorpo conjugado a horseradish peroxidase (HRP), $50 \mu \mathrm{L} /$ poço, na concentração de 1:50000 no ensaio para IgG e de 1:26000 para a IgA. As placas foram incubadas em estufa $22^{\circ} \mathrm{C}$, por uma hora e em seguida, lavadas novamente.

Tabela 1 - Diluição do soro padrão utilizada para o ELISA de quantificação de IgA

\begin{tabular}{|c|c|c|c|}
\hline Padrão & $\mathrm{ng} / \mathrm{mL}$ & $\begin{array}{c}\text { Soro padrão } \\
(0,38 \mathrm{mg} / \mathrm{mL} \operatorname{lgA})\end{array}$ & Solução de diluição \\
\hline 1 & 1000 & $2,5 \mu \mathrm{L}$ & $950 \mu \mathrm{L}$ \\
\hline 2 & 500 & $100 \mu \mathrm{L}$ do padrão 1 & $100 \mu \mathrm{L}$ \\
\hline 3 & 250 & $100 \mu \mathrm{L}$ do padrão 2 & $100 \mu \mathrm{L}$ \\
\hline 4 & 125 & $100 \mu \mathrm{L}$ do padrão 3 & $100 \mu \mathrm{L}$ \\
\hline 5 & 62,5 & $100 \mu \mathrm{L}$ do padrão 4 & $100 \mu \mathrm{L}$ \\
\hline 6 & 31,25 & $100 \mu \mathrm{L}$ do padrão 5 & $100 \mu \mathrm{L}$ \\
\hline 7 & 15,625 & $100 \mu \mathrm{L}$ do padrão 6 & $100 \mu \mathrm{L}$ \\
\hline 8 & 0 & Branco & $100 \mu \mathrm{L}$ \\
\hline
\end{tabular}

Tabela 2 - Diluição do soro padrão utilizada para o ELISA de quantificação de lgG

\begin{tabular}{cccc}
\hline Padrão & $\mathbf{n g} / \mathbf{m L}$ & $\begin{array}{c}\text { Soro padrão } \\
(\mathbf{6 , 2 5} \mathbf{~ m g / m L} \mathbf{g G})\end{array}$ & Solução de diluição \\
\hline Inicial & 10000 & $1 \mu \mathrm{L}$ & $650 \mu \mathrm{L}$ \\
1 & 200 & $100 \mu \mathrm{L}$ do inicial & $4,9 \mathrm{~mL}$ \\
2 & 100 & $100 \mu \mathrm{L}$ do padrão 1 & $100 \mu \mathrm{L}$ \\
3 & 50 & $100 \mu \mathrm{L}$ do padrão 2 & $100 \mu \mathrm{L}$ \\
4 & 25 & $100 \mu \mathrm{L}$ do padrão 3 & $100 \mu \mathrm{L}$ \\
5 & 12,5 & $100 \mu \mathrm{L}$ do padrão 4 & $100 \mu \mathrm{L}$ \\
6 & 6,25 & $100 \mu \mathrm{L}$ do padrão 5 & $100 \mu \mathrm{L}$ \\
7 & 3,12 & $100 \mu \mathrm{L}$ do padrão 6 & $100 \mu \mathrm{L}$ \\
8 & 0 & Branco & $100 \mu \mathrm{L}$ \\
\hline
\end{tabular}

Foi adicionado $50 \mu \mathrm{L} /$ poço de TMB (Bethyl囚) durante 15 minutos no ensaio de IgA e em torno de 15 a 20 minutos no ensaio de IgG (era observada a intensidade da coloração para parar a reação). A reação foi interrompida pela adição de $50 \mu \mathrm{L} /$ poço de solução stop. A leitura foi feita no Leitor de ELISA modelo PowerWave HT (Biotec®), no comprimento de onda de $450 \mathrm{~nm}$.

O cálculo da concentração em $\mathrm{ng} / \mathrm{mL}$ foi feito utilizando o programa Masterplex® Reader Fit (Curve-fitting Software for ELISA Analysis), através da análise com quatro (04) parâmetros logísticos. O resultado obtido foi multiplicado pelo coeficiente de diluição da amostra, ou seja, para $\lg A$ foi multiplicado por 2000 e para lgG por 40000. 


\subsection{DESEMPENHO ZOOTÉCNICO}

As aves e a ração foram pesadas semanalmente. Toda ração adicionada era pesada, e no final de cada semana pesava-se a sobra da ração. Desta forma, os índices zootécnicos foram analisados por semana e no período experimental total.

Os índices analisados semanalmente foram: Peso médio das aves (PM), Ganho de Peso Médio (GP), Consumo Médio Corrigido (CM), Conversão Alimentar por Fase (CA). Durante todo o período avaliou-se o Ganho de Peso Acumulado (GP), Ganho de Peso Diário Acumulado (GPD), Conversão Alimentar Acumulada (CA), Viabilidade e Índice de Eficiência Produtiva (IEP). As formulas utilizadas para os cálculos dos parâmetros zootécnicos estão no apêndice C.

\subsection{ANÁLISES DOS RESULTADOS}

Para a análise estatística dos resultados sorológicos, o titulo foi transformado de $\mathrm{ng} / \mathrm{mL}$ para logaritmo natural $(I n)$. Os resultados foram analisados pelo programa Minitab 16, através de análise de variância (ANOVA) e do teste de Tukey, com grau de significância de 0,05 . Foram retirados dados que se mostraram muito discrepantes em relação à maioria das aves. Como as aves foram numeradas por anilhas, as aves discrepantes em uma determinada idade foram retiradas também nas demais idades.

O coeficiente de variação também foi calculado pelo programa Minitab 16, para calcular a dispersão entre as amostras.

Os parâmetros zootécnicos foram analisados de forma descritiva pela média e desvio padrão. 


\section{RESULTADOS}

Os resultados obtidos foram organizados em tabelas e gráficos para uma melhor compreensão.

Os parâmetros zootécnicos foram analisados de forma descritiva em tabelas com a média entre as repetições e o desvio padrão, uma vez que o experimento foi composto por duas repetições (2) foi inviável fazer análise de variância.

Quanto aos resultados da sorologia são apresentadas tabelas com a média das concentrações obtidas em cada tratamento em $\mathrm{ng} / \mathrm{mL}$ e também os valores em logaritmo natural (In). A análise estatística foi feita com os valores em In.

\subsection{TESTE DE ESTERILIDADE E DO $\beta$-GLUCANO SOLÚVEL}

Não houve crescimento bacteriano no teste feito antes da liofilização do produto, assim como na cultura feita com o produto que foi administrado as aves.

\subsection{RESULTADOS DO EXPERIMENTO 1: VIAS DE INOCULAÇÃO}

Primeiramente são apresentados os resultados obtidos na sorologia e dos parâmetros zootécnicos obtidos no Experimento 1 que avaliou as diferentes vias de administração do $\beta$-glucano solúvel.

\subsubsection{Resultados sorológicos}

As análises estatísticas foram feitas com o teste de Turkey e ANOVA utilizando-se o In. 
A concentração sérica de anticorpos da classe $\lg A$, aos 28 dias, foi de $291374 \mathrm{ng} / \mathrm{mL}(I n=12,6)$ nas aves do T1(C-), 234795ng/mL ( $I n=12,3)$ nas do T2(SC), $189223 \mathrm{ng} / \mathrm{mL}(I n=12,1)$ naquelas do T3(OC) e $251603 \mathrm{ng} / \mathrm{mL}(I n=12,3)$ nas do T4(VO).

Aos 35 dias as concentrações séricas foram as seguintes: $322911 \mathrm{ng} / \mathrm{mL}$ $(I n=12,6)$ nas aves do T1(C-), 321997ng $\mathrm{mL}(I n=12,7)$ nas aves do T2(SC), $295969 n g / m L(I n=12,5)$ nas aves do T3(OC) e $322571 \mathrm{ng} / \mathrm{mL}(I n=12,6)$ nas aves do T4(VO). Nessas duas idades (28 e 35 dias) a maior concentração de IgA foram nas aves do T1(C-) seguido pelas aves do T4(VO), T2(SC) e por último as do T3(OC).

Aos 42 dias os resultados foram $273192 \mathrm{ng} / \mathrm{mL}(I n=12,5)$ nas aves do T1(C-), $236880 \mathrm{ng} / \mathrm{mL}$ ( $I n=12,3)$ naquelas do T2(SC), 213612ng/mL ( $I n=12,2)$ nas do T3(OC) e $295364 \mathrm{ng} / \mathrm{mL}(12,5)$ naquelas do T4(VO). Nesta idade as aves do T4(VO) apresentaram a maior concentração de anticorpos, seguido pelas aves do T1(C-), T2(SC) e, com a menor concentração, aquelas do T3(OC). A tabela 3 e a figura 2 apresentam os resultados da quantificação de lgA.

Em relação à análise estatística da concentração sérica de $\lg A$, ao se comparar os diferentes tratamentos, com aves de mesma idade, verificou-se que aos 28 dias não houve diferença significativa $(P>0,05)$ entre as aves do $\mathrm{T} 1(\mathrm{C}-)$, aquelas do T2(SC) e as do T4(VO). Assim como, entre as aves do T2(SC), aquelas do $\mathrm{T} 3(\mathrm{OC})$ e as do $\mathrm{T} 4(\mathrm{VO})$. As concentrações séricas de IgA determinadas nas aves do T3(OC) foram significativamente menores do que as do T1(C-). Nas outras idades avaliadas, 35 e 42 dias, não existiu diferença entre as concentrações de $\lg A$ avaliadas nas aves de todos os tratamentos.

Tabela 3 - Concentrações de IgA séricas detectada por ELISA de acordo com a via de inoculação e a idade das aves (fatorial $4 \times 3$ )

\begin{tabular}{|c|c|c|c|c|c|c|}
\hline \multirow[t]{2}{*}{ Tratamento } & \multicolumn{3}{|c|}{ In (C. V. \%) } & \multicolumn{3}{|c|}{$\mathrm{ng} / \mathrm{mL}$} \\
\hline & 28 dias & 35 dias & 42 dias & 28 dias & 35 dias & 42 dias \\
\hline T1(C-) & $\begin{array}{c}12,6 \mathrm{ab} \\
(1,97)\end{array}$ & $\begin{array}{l}12,6 \mathrm{a} \\
(2,39)\end{array}$ & $\begin{array}{c}12,5 \mathrm{ab} \\
(2,12)\end{array}$ & 291374 & 322911 & 273192 \\
\hline T2(SC) & $\begin{array}{c}12,3 \mathrm{abc} \\
(2,79)\end{array}$ & $\begin{array}{l}12,7 \mathrm{a} \\
(1,45)\end{array}$ & $\begin{array}{c}12,3 \mathrm{abc} \\
(2,64)\end{array}$ & 234795 & 321997 & 236880 \\
\hline T3(OC) & $\begin{array}{l}12,1 \mathrm{c} \\
(3,52)\end{array}$ & $\begin{array}{c}12,5 \mathrm{ab} \\
(2,89)\end{array}$ & $\begin{array}{c}12,2 \mathrm{bc} \\
(2,42)\end{array}$ & 189223 & 295969 & 213612 \\
\hline T4(VO) & $\begin{array}{c}12,3 \mathrm{abc} \\
(4,01)\end{array}$ & $\begin{array}{l}12,6 \mathrm{a} \\
(2,60)\end{array}$ & $\begin{array}{c}12,5 \mathrm{ab} \\
(2,76)\end{array}$ & 251603 & 322571 & 295364 \\
\hline
\end{tabular}

Nível de significância 5\%; C.V.= Coeficiente de variação; Valores com letras diferentes tiveram diferenças significativas 
Figura 2 - Concentrações séricas de $\lg$ A nas diferentes idades e nos diferentes tratamentos

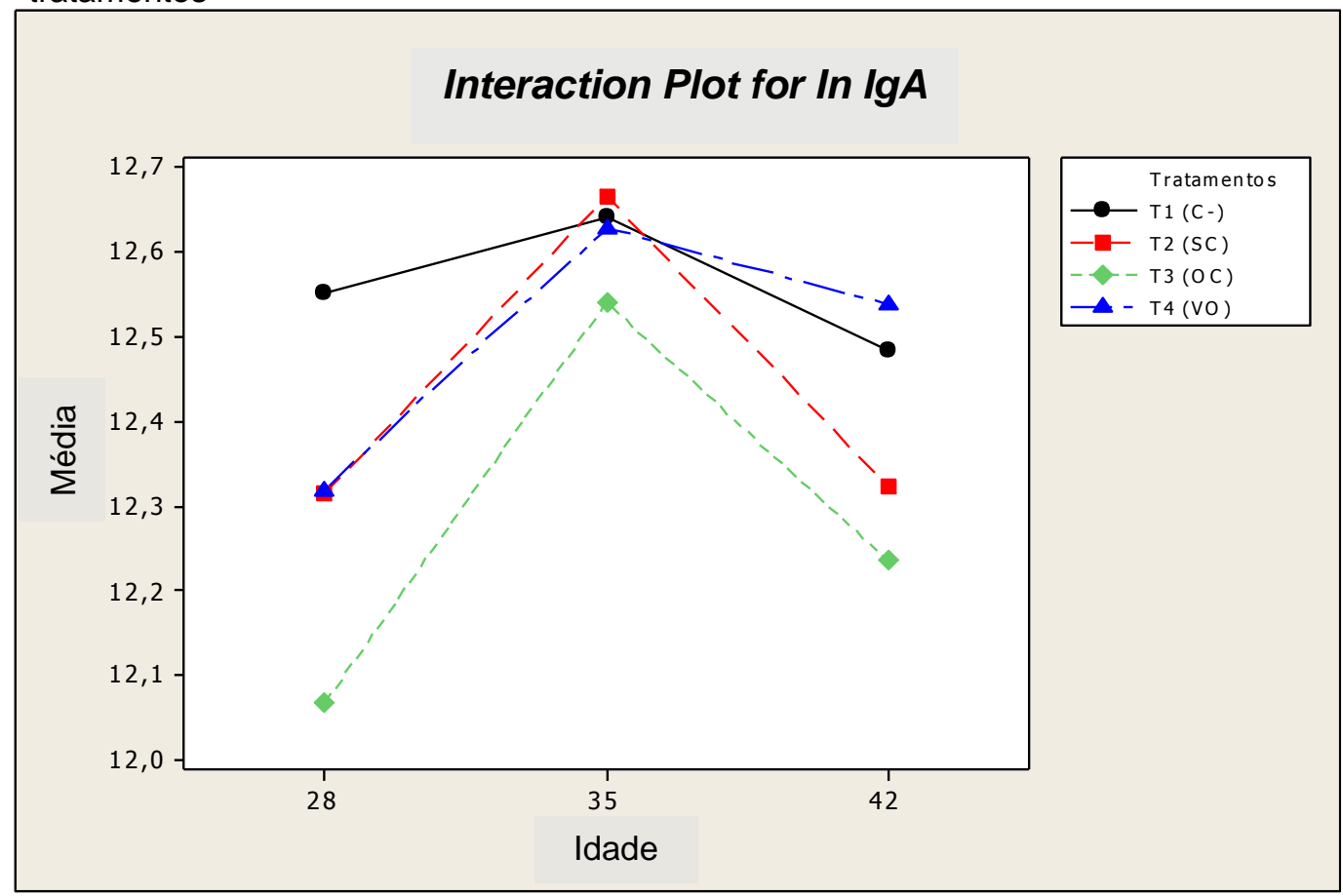

Ao desconsiderar-se a idade e comparar apenas os tratamentos, não houve diferença significativa entre as concentrações de anticorpos das aves do T1(C-), aquelas do T2(SC) e as do T4(VO). Também não ocorreu diferença entre as concentrações nas aves do $\mathrm{T} 3(\mathrm{OC})$ e naquelas do $\mathrm{T} 2(\mathrm{SC})$, assim como entre as concentrações nas aves do T4(VO) e nas aves do T2(SC). No entanto, as concentrações séricas de $\lg A$ determinadas nas aves do $\mathrm{T} 3(\mathrm{OC})$ foram significativamente menores do que aquelas obtidas nas aves do T1(C-) e naquelas do T2(SC). Estes resultados se encontram na tabela 4 e figura 3.

Tabela 4 - Concentrações de IgA sérica detectadas por ELISA (em In), considerando apenas as vias de administração

\begin{tabular}{ccc}
\hline In & C.V. (\%) \\
\hline T1(C-) & $12,6 \mathrm{a}$ & 2,18 \\
T2(SC) & $12,4 \mathrm{ab}$ & 2,67 \\
T3(OC) & $12,3 \mathrm{~b}$ & 3,32 \\
T4(VO) & $12,5 \mathrm{a}$ & 3,29 \\
\hline
\end{tabular}

Nível de significância 5\%; C.V.= Coeficiente de variação; Valores com letras diferentes tiveram diferenças significativas

Analisando-se apenas a diferença entre as idades e desconsiderando os diferentes tratamentos, observou-se que o título de 28 dias é significativamente 
menor do que aos 35 dias. Aos 42 dias o título diminuiu sendo estatisticamente menor que aos 35 dias. A tabela 5 e figura 5 mostram estes resultados.

Tabela 5 - Concentrações de IgA sérica detectadas por ELISA (em In) considerando apenas as diferentes idades

\begin{tabular}{ccc}
\hline Idades & In & C.V. (\%) \\
\hline $\mathbf{2 8}$ dias & $12,3 \mathrm{~b}$ & 3,37 \\
$\mathbf{3 5}$ dias & $12,6 \mathrm{a}$ & 2,34 \\
$\mathbf{4 2}$ dias & $12,4 \mathrm{~b}$ & 2,65 \\
\hline
\end{tabular}

Nível de significância 5\%; C.V.= Coeficiente de variação; Valores com letras diferentes tiveram diferenças significativas

Figura 3 - Efeitos principais nas concentrações séricas de $\operatorname{lgA}$ em relação a idade e ao tratamento

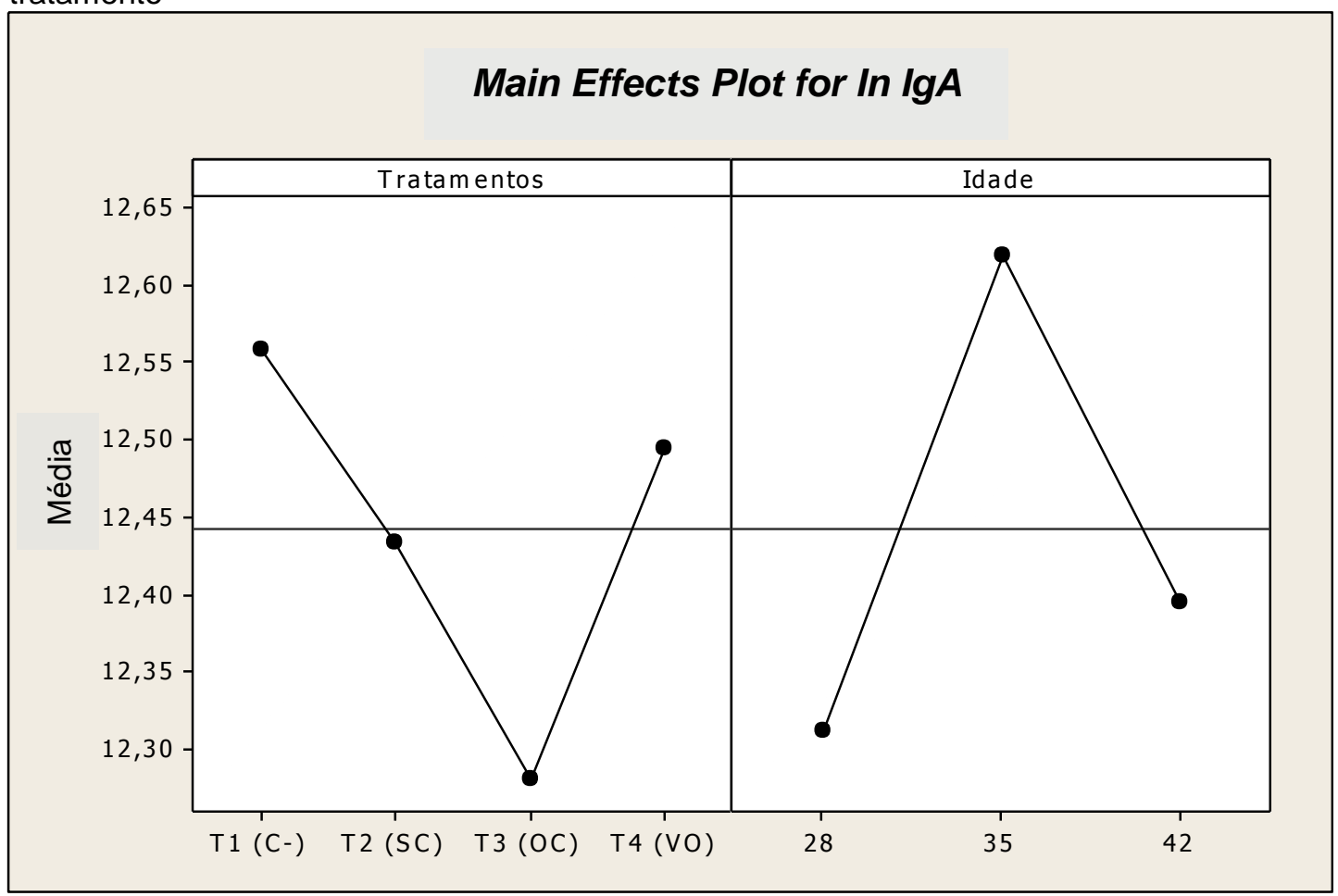

A concentrações sérica de $\lg G$ aos 28 dias nas aves do T1(C-) foi de $1020182 \mathrm{ng} / \mathrm{mL}(/ n=13,7)$, nas aves do T2(SC) 1017004ng/mL $(/ n=13,7)$, naquelas do T3(OC) $1061622 \mathrm{ng} / \mathrm{mL}(I n=13,7)$ e nas aves do T4(VO) $1271162 \mathrm{ng} / \mathrm{mL}(I n=14,0)$. Sendo a maior concentração nas aves do T4(VO) seguido pelas aves do T3(OC), T1(C-) e T2(SC).

Em ordem da maior para a menor concentração sérica de IgG aos 35 dias os resultados foram: $2139848 \mathrm{ng} / \mathrm{mL}(I n=14,5)$ nas aves do T4(VO), $1749581 \mathrm{ng} / \mathrm{mL}$ $(I n=14,3)$ nas aves do T2(SC), $1740035 \mathrm{ng} / \mathrm{mL}(I n=14,3)$ nas aves do T3(OC) e $1675993 \mathrm{ng} / \mathrm{mL}(\mathrm{In=14,2)}$ nas aves do T1(C-). No fim do experimento, aos 42 dias, as aves do T4(VO) apresentaram a concentração de 2379506ng/mL (In=14,6), aquelas 
do T1(C-) 2084991ng/mL (In=14,5), as aves do T2(SC) $2035408 \mathrm{ng} / \mathrm{mL}(I n=14,4)$ e aquelas do T3(OC) $1846949 \mathrm{ng} / \mathrm{mL}(/ n=14,3)$.

Nas quantificações de $\lg G$ não foram encontradas diferenças significativas quando se observa os valores obtidos em uma mesma idade nos diferentes tratamentos. A tabela 6 apresenta os resultados da quantificação de $\mathrm{lgG}$ em ng/mL e em logaritmo natural (In), os resultados estão ilustrados na figura 4.

Tabela 6 - Concentrações de IgG sérica detectadas por ELISA de acordo com a via de inoculação e a idade das aves (fatorial $4 \times 3$ )

\begin{tabular}{ccccccc}
\hline & \multicolumn{3}{c}{$\mathbf{I n}(\mathbf{C} . \mathbf{V .} \%)$} & \multicolumn{3}{c}{$\mathbf{n g} / \mathbf{m L}$} \\
\cline { 2 - 7 } & $\mathbf{2 8}$ dias & $\mathbf{3 5}$ dias & $\mathbf{4 2}$ dias & $\mathbf{2 8}$ dias & 35 dias & 42 dias \\
\hline T1(C-) & $13,7 \mathrm{de}$ & $14,2 \mathrm{abcd}$ & $14,5 \mathrm{ab}$ & 1.020 .182 & 1.675 .993 & 2.084 .991 \\
& $(3,78)$ & $(2,91)$ & $(3,00)$ & & & \\
T2(SC) & $13,7 \mathrm{e}$ & $14,3 \mathrm{abc}$ & $14,4 \mathrm{ab}$ & 1.017 .004 & 1.749 .581 & 2.035 .408 \\
& $(4,23)$ & $(3,20)$ & $(2,94)$ & & & \\
T3(OC) & $13,7 \mathrm{cde}$ & $14,3 \mathrm{abcd}$ & $14,3 \mathrm{ab}$ & 1.061 .622 & 1.740 .035 & 1.846 .949 \\
& $(3,98)$ & $(3,56)$ & $(3,31)$ & & & \\
T4(VO) & $14,0 \mathrm{bcde}$ & $14,5 \mathrm{a}$ & $14,6 \mathrm{a}$ & 1.271 .162 & 2.139 .848 & 2.379 .506 \\
& $(3,34)$ & $(3,24)$ & $(2,89)$ & & &
\end{tabular}

Nível de significância 5\%; C.V.= Coeficiente de variação; Valores com letras diferentes tiveram diferenças significativas

Figura 4 - Concentrações séricas de lgG nas diferentes idades e nos diferentes tratamentos

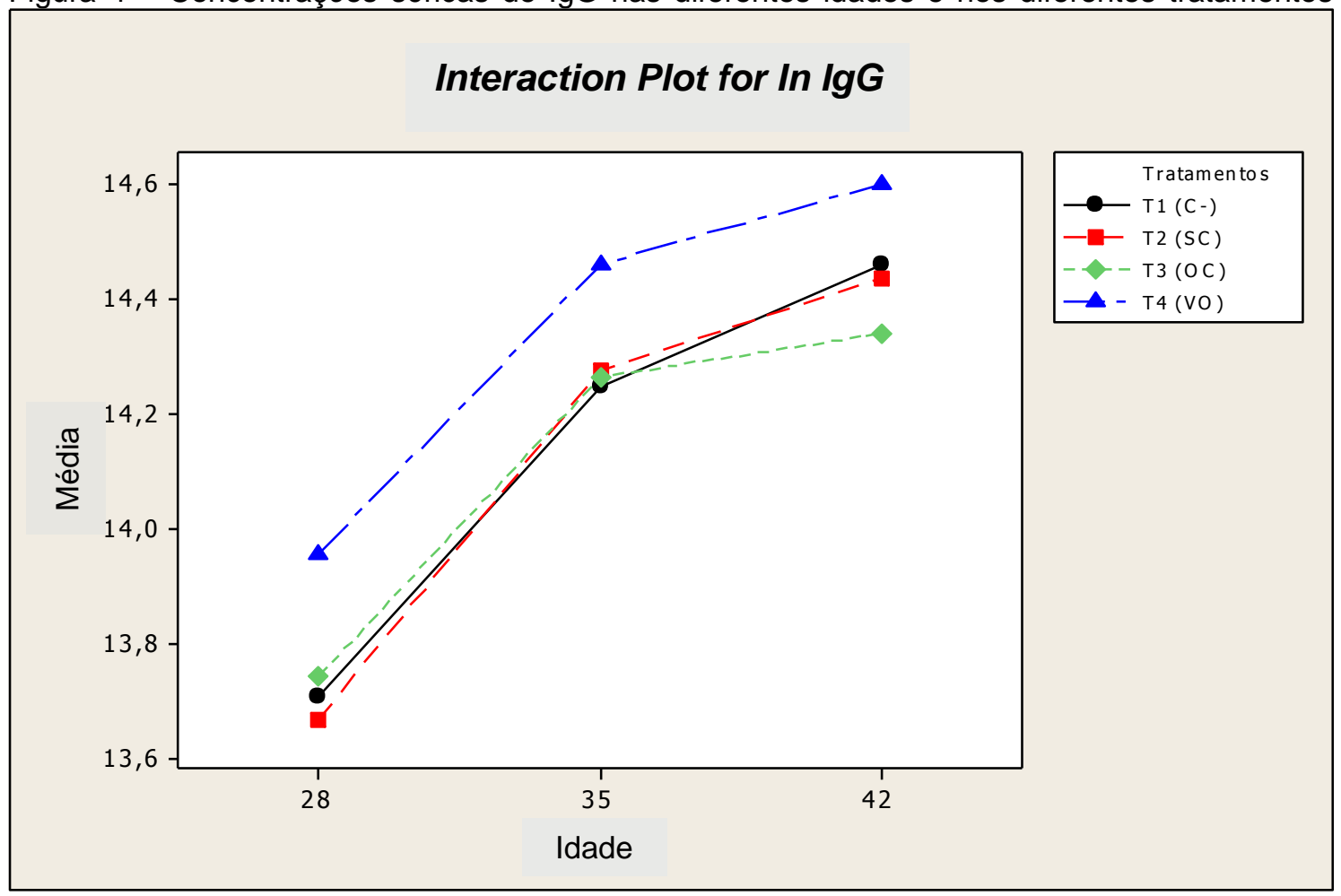

Quando se compara os diferentes tratamentos, sem considerar a idade das aves, também não foram encontradas diferenças estatísticas nas concentrações de 
anticorpos entre os grupos de aves estudadas. Estes resultados se encontram na tabela 7 e na figura 5.

Tabela 7 - Concentrações séricas de IgG detectados por ELISA (em In), considerando apenas as vias de administração

\begin{tabular}{ccc}
\hline Iratamento & In & C.V. (\%) \\
\hline T1(C-) & $14,1 \mathrm{a}$ & 3,90 \\
T2(SC) & $14,1 \mathrm{a}$ & 4,18 \\
T3(OC) & $14,1 \mathrm{a}$ & 4,02 \\
T4(VO) & $14,3 \mathrm{a}$ & 3,66 \\
\hline
\end{tabular}

Nível de significância 5\%; C.V.= Coeficiente de variação; Valores com letras diferentes tiveram diferenças significativas

Avaliando-se apenas as idades, as concentrações séricas de lgG obtidas aos 28 dias foram significativamente menores do que aos 35 e 42 dias. Aos 42 de idade foram obtidos valores maiores que aos 35 , contudo não foram estatisticamente diferentes. A tabela 8 e a figura 5 ilustram estes resultados.

Tabela 8 - Concentrações séricas de IgG detectadas por ELISA (em In), considerando apenas as diferentes idades.

\begin{tabular}{rcc}
\hline In & C.V. (\%) \\
\hline $\mathbf{2 8}$ dias & $13,8 \mathrm{~b}$ & 3,85 \\
$\mathbf{3 5}$ dias & $14,3 \mathrm{a}$ & 3,22 \\
$\mathbf{4 2}$ dias & $14,5 \mathrm{a}$ & 3,03 \\
\hline
\end{tabular}

Nível de significância 5\%; C.V.= Coeficiente de variação; Valores com letras diferentes tiveram diferenças significativas

Figura 5 - Efeitos principais nas concentrações séricas de $\lg G$ em relação a idade e ao tratamento

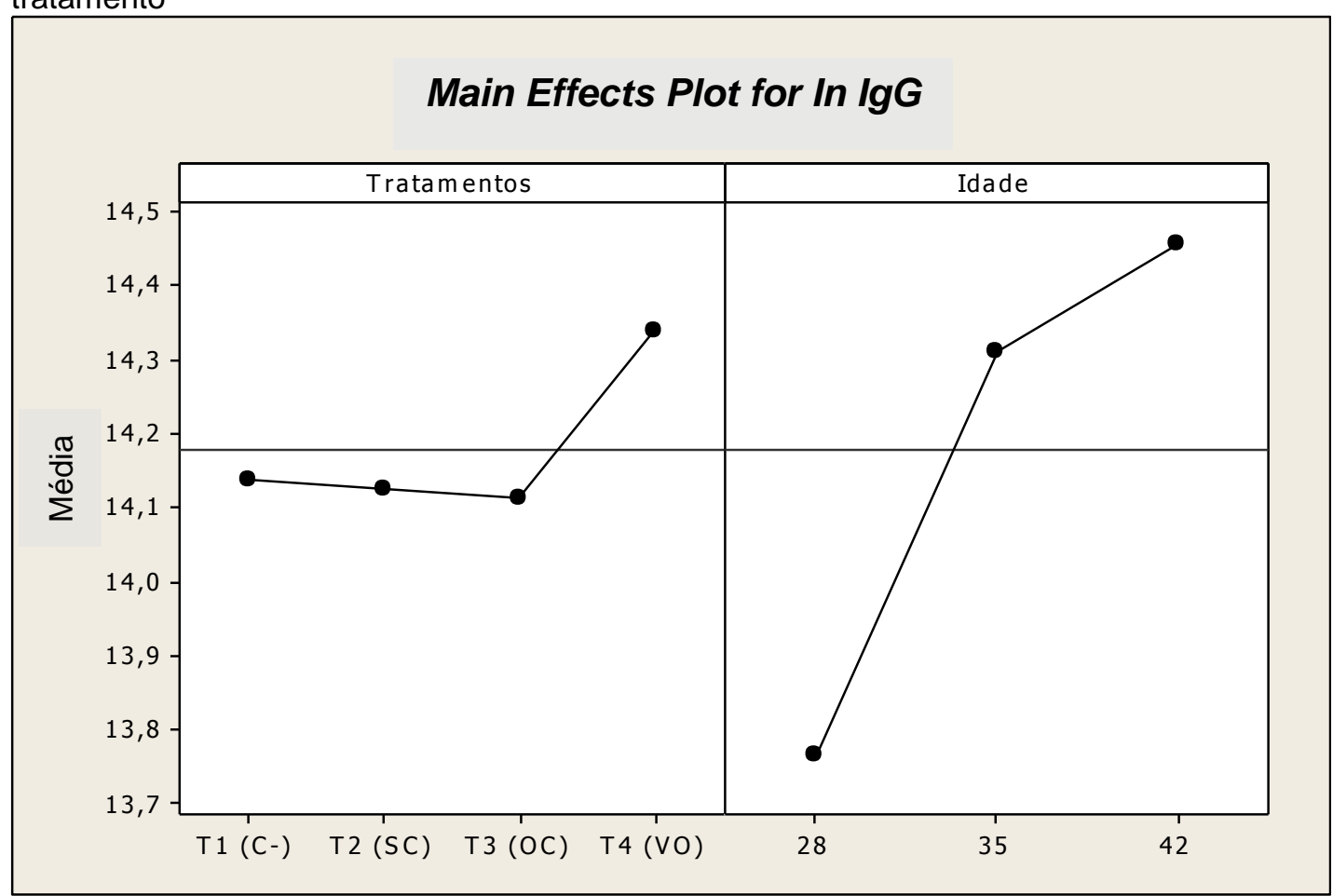


Ao se comparar por análise de variância simples (ANOVA) os dados obtidos, considerando as vias de inoculação e a idade, não existia diferença significativa $(P>$ 0,05). Contudo, existiu diferença tanto para $\lg A$ quanto para $\lg G$ ao se considerar apenas as vias de inoculação $(P<0,05)$. Também ocorreu diferença significativa quando se comparou apenas as diferentes idades $(P<0,05)$ tanto para IgA quanto para IgG. Estes resultados se encontram na tabela 9.

Tabela 9 - Valor de P obtido na Análise de Variância Simples ANOVA

\begin{tabular}{ccc}
\hline Análise de variância simples & \multicolumn{2}{c}{ Valor de $\mathbf{P}$} \\
\cline { 2 - 3 } & $\lg A$ & $\operatorname{lgG}$ \\
\hline Via de inoculação & 0,001 & 0,037 \\
Idade & 0,000 & 0,000 \\
Via de inoculação X idade & 0,179 & 0,988 \\
\hline
\end{tabular}

Nível de significância 5\%

Quando se comparou as concentrações séricas de $\lg A$ e $\lg G$ determinadas nas aves estudadas, verificou-se que o titulo de IgG sérico foi maior do que o de lgA (figura 6).

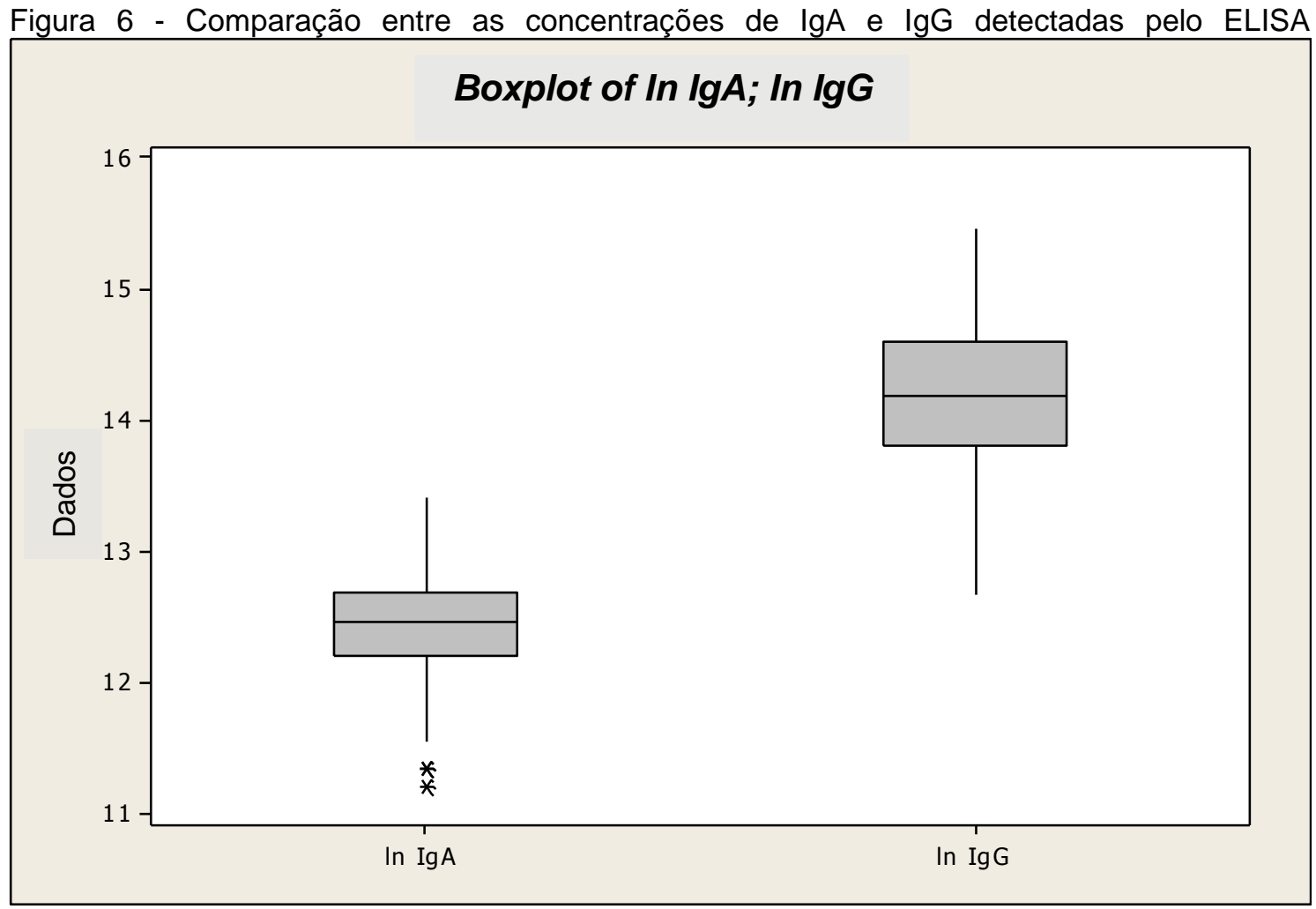




\subsubsection{Resultados dos parâmetros zootécnicos}

Os parâmetros zootécnicos: peso médio (PM), ganho de peso semanal (GP semanal), consumo médio corrigido (CM corrigido) e conversão alimentar por fase (CA por fase) foram analisados semanalmente.

Na primeira semana experimental (Tabela 10) o peso médio das aves variou entre 148,06g no T3(OC) e 153,3g no T2(SC). O T1(C-) apresentou peso médio de $152,75 \mathrm{~g}$ e o T4(VO) 153,3g. Quanto ao ganho de peso semanal em ordem decrescente as aves dos tratamentos apresentaram os seguintes resultados: as do T2(SC) ganharam 108,55g, as do T4(VO) 106g, as do T1(C-) 105,9g e as do T3(OC) 100,36g.

O consumo médio de ração foi de $161,7 \mathrm{~g}$ nas aves do $\mathrm{T1}(\mathrm{C}-), 173,4 \mathrm{~g}$ nas aves do T2(SC), 173,3 nas aves do T3(OC) e 174,85g nas aves do T4(VO). A conversão alimentar nas aves do $\mathrm{T} 1(\mathrm{C}-)$ foi de 1,53, naquelas do T2(SC) apresentou a menor conversão alimentar, esses dados estão na tabela 10 .

\begin{tabular}{|c|c|c|c|c|}
\hline Tratamento & PM (g) & GP (g) & CM (g) & CA \\
\hline T1(C-) & $152,75 \pm 3,89$ & $105,90 \pm 2,40$ & $161,7 \pm 15,1$ & $1,53 \pm 0,11$ \\
\hline T2(SC) & $153,8 \pm 9,19$ & $108,55 \pm 7,71$ & $173,40 \pm 1,41$ & $1,44 \pm 0,13$ \\
\hline T3(OC) & $148,06 \pm 9,99$ & $100,36 \pm 9,71$ & $173,3 \pm 28,7$ & $1,59 \pm 0,06$ \\
\hline T4(VO) & $153,3 \pm 10,04$ & $106,00 \pm 6,93$ & $174,85 \pm 7,85$ & $1,65 \pm 0,18$ \\
\hline
\end{tabular}

$\mathrm{Na}$ segunda semana de criação as aves do T4(VO) tiveram o maior peso médio, 378,6g, em ordem decrescente de peso as aves do T2(SC) tiveram peso médio de $370,9 \mathrm{~g}$, seguido pelas aves do T1(C-) com 367,10g e as do T3(OC) com 359,2g (Tabela11). Quanto ao ganho de peso as aves do T4(VO) ganharam 225,3g, as do T2(SC) 217,1g, aquelas do T1(C-) 214,35g e as aves do T3(OC) 211,1g.

O consumo médio de ração variou entre 463,5g nas aves do T4(VO) e 497,9g naquelas do T3(OC), enquanto as aves do T2 consumiram em média 464,8g de ração por ave e as aves do T1(C-) 489,8g. A melhor conversão alimentar obtida nessa semana foram das aves do T4(VO), 2,08, em seguida as aves do T2(SC) apresentaram índice de 2,13, enquanto as aves do T1(C-) tiveram 2,28 e aquelas do T3(OC) 2,35. 
Tabela 11 - Análise descritiva dos parâmetros zootécnicos da segunda semana (média entre as repetições \pm desvio padrão)

\begin{tabular}{ccccc}
\hline Tratamento & PM (g) & GP (g) & CM & CA \\
\hline T1(C-) & $367,10 \pm 2,97$ & $214,35 \pm 0,92$ & $489,8 \pm 49,6$ & $2,28 \pm 0,24$ \\
T2(SC) & $370,9 \pm 27,1$ & $217,1 \pm 17,9$ & $464,8 \pm 87,6$ & $2,13 \pm 0,23$ \\
T3(OC) & $359,2 \pm 31,9$ & $211,1 \pm 21,9$ & $497,9 \pm 77,4$ & $2,35 \pm 0,12$ \\
T4(VO) & $378,6 \pm 28,9$ & $225,3 \pm 18,9$ & $463,5 \pm 61,0$ & $2,08 \pm 0,44$ \\
\hline PM=peso médio; GP=ganho de peso; CM=consumo médio; CA=conversão alimentar
\end{tabular}

Os dados zootécnicos relativos à terceira semana de experimento estão expostos na tabela 12. Quanto ao peso médio das aves observou-se maior peso, 763,9g nas aves do T4(VO). Com valores bastante próximos aos das aves do $\mathrm{T} 2(\mathrm{SC})$ e as do $\mathrm{T} 3(\mathrm{OC})$ que tiveram, respectivamente, 742,3 e 743,6g de peso médio. As aves do T1(C-) tiveram peso médio de 738,9g.

O ganho de peso semanal na terceira semana foi de $371,8 \mathrm{~g}$ nas aves do T1 (C-), 371,4g naquelas do T2(SC), 384,44g nas aves do T3(OC) e 385,4g nas aves do T4(VO). Com relação ao consumo médio de ração este foi de $655,5 \mathrm{~g}$ nas aves do T1 (C-), 684,45g nas aves do T2(SC), 704,5g nas aves do T3(OC) e 663,2g nas aves do T4(VO). A conversão alimentar apresentou o melhor índice nas aves do T4(VO), 1,72, e naquelas do T1(C-), 1,76. As aves do T3(OC) tiveram índice de 1,83 e aquelas do T2(SC) de 1,85 .

Tabela 12 - Análise descritiva dos parâmetros zootécnicos da terceira semana (média entre as repetições \pm desvio padrão)

\begin{tabular}{ccccc}
\hline Tratamento & PM (g) & GP (g) & CM (g) & CA \\
\hline T1(C-) & $738,9 \pm 16,3$ & $371,8 \pm 19,2$ & $655,5 \pm 17,9$ & $1,76 \pm 0,04$ \\
T2(SC) & $742,3 \pm 47,7$ & $371,4 \pm 20,6$ & $684,45 \pm 2,33$ & $1,85 \pm 0,11$ \\
T3(OC) & $743,6 \pm 41,7$ & $384,44 \pm 9,81$ & $704,5 \pm 62,5$ & $1,83 \pm 0,12$ \\
T4(VO) & $763,9 \pm 55,0$ & $385,4 \pm 26,1$ & $663,2 \pm 27,9$ & $1,72 \pm 0,04$ \\
\hline PM=peso médio; GP=ganho de peso; CM=consumo médio; CA=conversão alimentar
\end{tabular}

$\mathrm{Na}$ quarta semana experimental as aves do T4(VO) apresentavam o maior peso médio, 1237g. As aves do T1(C-) tinham em média 1219,8g, aquelas do T2(SC) $1216,6 \mathrm{~g}$ e as do T3(OC) $1206,4 \mathrm{~g}$. Entre os tratamentos a ordem decrescente do ganho de peso nesta semana foi a seguinte: as aves do T1 ganharam 480,9g, aquelas do T2(SC) 474,34g, as do T4(VO) 473,1 g e aquelas do T3(OC) 462,8g.

O consumo médio de ração foi maior nas aves do T3(OC), 1057,6, as aves do T1(C-) consumiram 983g, seguido pelas aves do T4(VO) com consumo de 979,6g e pelas aves do T2(SC) que consumiram 968,7g. Em relação à conversão alimentar as 
aves do T1(C-) tiveram índices próximos ao das aves do T4(VO), 2,04 e 2,08, respectivamente. As aves do T2(SC) apresentaram conversão alimentar de 2,17 e aquelas do T3(OC) 1,35. Os dados zootécnicos da quarta semana são mostrados na tabela 13.

Tabela 13 - Análise descritiva dos parâmetros zootécnicos da quarta semana (média entre as repetições \pm desvio padrão)

\begin{tabular}{ccccc}
\hline Tratamento & PM (g) & GP $(\mathbf{g})$ & CM $(\mathbf{g})$ & CA \\
\hline T1(C-) & $1219,8 \pm 41,7$ & $480,9 \pm 25,5$ & $983,0 \pm 30,3$ & $2,04 \pm 0,04$ \\
T2(SC) & $1216,6 \pm 57,7$ & $474,34 \pm 9,99$ & $968,7 \pm 87,4$ & $2,17 \pm 0,04$ \\
T3(OC) & $1206,4 \pm 65,7$ & $462,8 \pm 23,9$ & $1057,6 \pm 65,2$ & $2,35 \pm 0,12$ \\
T4(VO) & $1237,0 \pm 116,5$ & $473,1 \pm 61,5$ & $979,6 \pm 73,5$ & $2,08 \pm 0,11$ \\
\hline PM=peso médio; GP=ganho de peso; CM=consumo médio; CA=conversão alimentar
\end{tabular}

O peso médio das aves na quinta semana de criação das aves, em ordem do maior para o menor, foram os seguintes: T3(OC) 1847,5g, T2(SC) 1782,1g, T1(C-) 1780,8g e T4(VO)1779g. As aves ganharam nesta semana entre 641,1g, no T3(OC), e $542 \mathrm{~g}$ no T4(VO). As aves do T1(C-) e do T2(SC) ganharam, respectivamente, $560,95 \mathrm{~g}$ e $565,51 \mathrm{~g}$. O consumo médio foi de $1300,1 \mathrm{~g}$ nas aves do T1(C-), 1265,2g nas do T2(SC), 1420,3g naquelas do T3(OC) e 1240,0 nas aves do T4(VO), ou seja, as aves do T3(OC) foram as que consumiram mais ração nesta semana. A conversão alimentar ficou entre 2,32 nas aves do T1(C-) e 2,24 nas aves do T2(SC). As aves do T3(OC) e do T4(VO) apresentaram índice de 2,29.

Tabela 14 - Análise descritiva dos parâmetros zootécnicos da quinta semana (média
entre as repetições \pm desvio padrão)
\begin{tabular}{ccccc}
\hline Tratamento & PM (g) & GP (g) & CM (g) & CA \\
\hline T1(C-) & $1780,8 \pm 34,4$ & $560,95 \pm 7,28$ & $1300,1 \pm 7,57$ & $2,32 \pm 0,02$ \\
T2(SC) & $1782,1 \pm 66,6$ & $565,51 \pm 8,89$ & $1265,2 \pm 52,8$ & $2,24 \pm 0,06$ \\
T3(OC) & $1847,5 \pm 37,0$ & $641,1 \pm 28,6$ & $1420,3 \pm 57,7$ & $2,29 \pm 0,25$ \\
T4(VO) & $1779,0 \pm 136,8$ & $542,0 \pm 20,2$ & $1240,0 \pm 102,8$ & $2,29 \pm 0,10$ \\
\hline PM=peso médio; GP=ganho de peso; CM=consumo médio; CA=conversão alimentar
\end{tabular}

Na sexta semana, ultima semana experimental, o peso médio das aves foi de 2426,3g no T1(C-), 2422,7g no T2(SC), 2523,8g no T3(OC) e 2413,3g no T4(VO). Desta forma as aves do T3(OC) terminaram o experimento com maior peso médio.

O ganho de peso foi maior nas aves do T3(OC), que ganharam em média 676,2g. As aves do T1(C-) tiveram ganho de peso de 645,5g, as do T2(SC) de $640,6 \mathrm{~g}$ e aquelas do T4(VO) $634,3 \mathrm{~g}$. O consumo de ração foi de $1561 \mathrm{~g}$ nas aves do T1(C-), 1552,3g nas aves do T2(SC), 1701,7 nas aves do T3(OC) e de 1553,4g naquelas do $\mathrm{T} 4(\mathrm{VO})$, portanto as aves do $\mathrm{T} 3(\mathrm{OC})$ foram as que consumiram a maior 
quantidade de ração nesta semana. A conversão alimentar das aves do T1(C-), T2(SC) e T4(VO) foi de 2,42, 2,43 e 2,45, respectivamente. Nas aves do T3(OC) o índice foi de 2, 51 .

\begin{tabular}{|c|c|c|c|c|}
\hline Tratamento & PM (g) & $\begin{array}{c}\text { GP } \\
\text { Semanal }\end{array}$ & CM corrigido & $\begin{array}{l}\text { CA por } \\
\text { fase }\end{array}$ \\
\hline T1(C-) & $2426,3 \pm 24,5$ & $645,5 \pm 9,9$ & $1561,0 \pm 8,06$ & $2,42 \pm 0,02$ \\
\hline T2(SC) & $2422,7 \pm 31,3$ & $640,6 \pm 35,3$ & $1552,3 \pm 57,6$ & $2,43 \pm 0,22$ \\
\hline T3(OC) & $2523,8 \pm 70,0$ & $676,2 \pm 33,0$ & $1701,7 \pm 124,7$ & $2,51 \pm 0,06$ \\
\hline T4(VO) & $2413,3 \pm 115,5$ & $634,3 \pm 21,2$ & $1553,4 \pm 30,7$ & $2,45 \pm 0,13$ \\
\hline
\end{tabular}

Desta forma, os resultados quanto ao peso médio das aves nas diferentes semanas apresentaram resultados similares nos tratamentos avaliados. Na primeira semana o maior peso médio foi encontrado com as aves do T2(SC) e na segunda com aquelas do $\mathrm{T} 4(\mathrm{VO})$, sendo nessas duas semanas o menor peso médio determinado nas aves do T3(OC).

$\mathrm{Na}$ terceira semana as aves do $\mathrm{T} 1(\mathrm{C}-)$ tiveram o menor peso médio e na quarta semana as aves do T3(VO) foram as que apresentaram o menor peso médio. Nessas duas (2) semanas as aves do T4(VO) obtiveram o maior peso médio.

$\mathrm{Na}$ quinta semana as aves do T1(C-) tiveram o menor peso médio e na sexta semana as aves do T4(VO) foram as que apresentaram o menor peso médio. Nessas duas semanas as aves do T3(OC) apresentaram o maior peso médio quando este foi comparado com os demais tratamentos e esse tratamento foi o que apresentou o menor peso médio na primeira semana. Esses dados são mostrados na figura 7 .

Os resultados em relação ao ganho de peso correspondem ao peso médio. Assim, na quinta e na sexta semana experimental as aves do T3(OC) apresentaram um ganho de peso maior do que as aves dos demais tratamentos, conforme ilustrado na figura 8. Nas demais semanas ocorreram pequenas diferenças no ganho de peso entre as aves dos diferentes tratamentos. 
Figura 7 - Peso médio (PM) semanal nos diferentes tratamentos

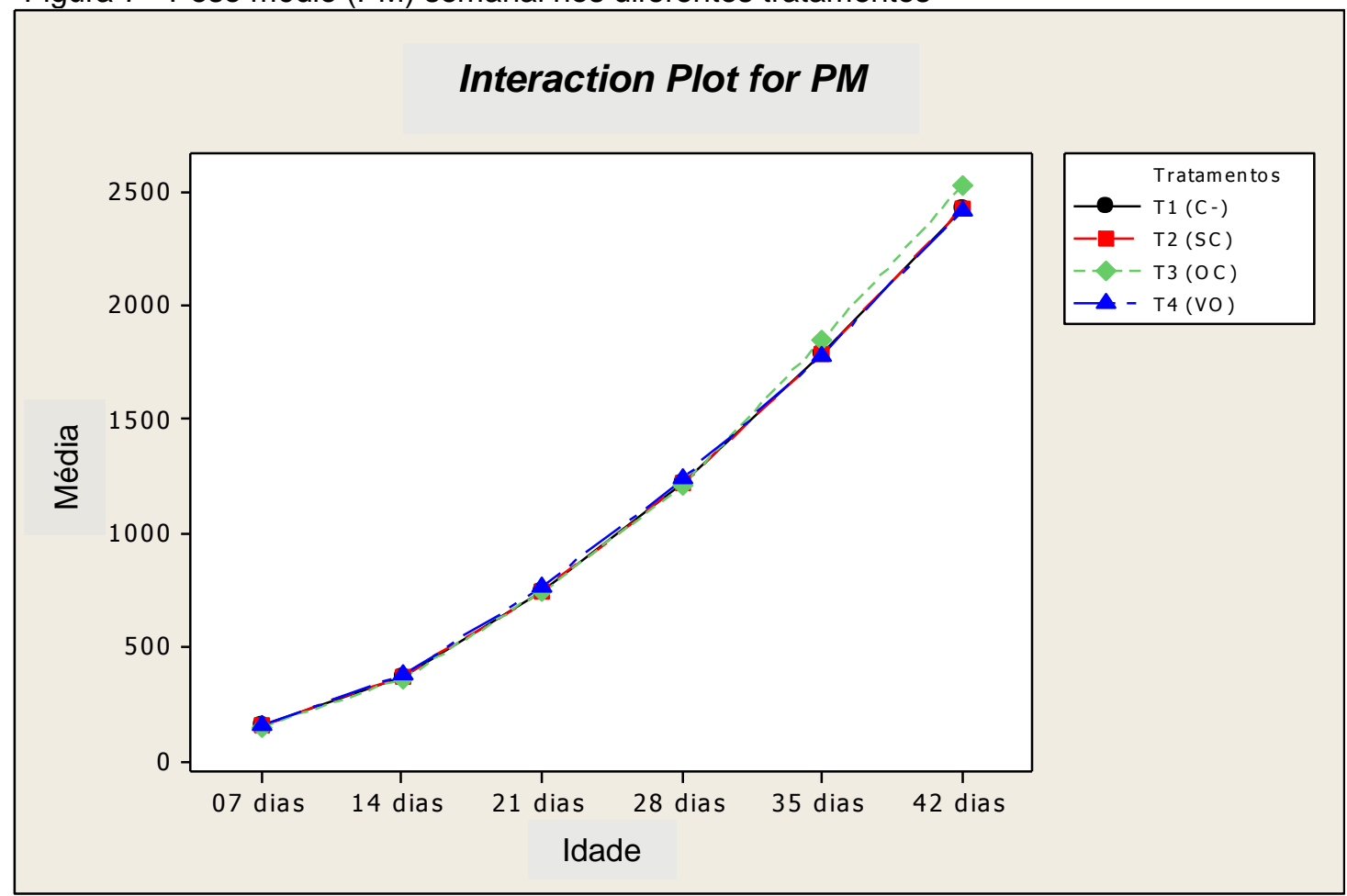

Figura 8 - Ganho de peso (GP) semanal nos diferentes tratamentos

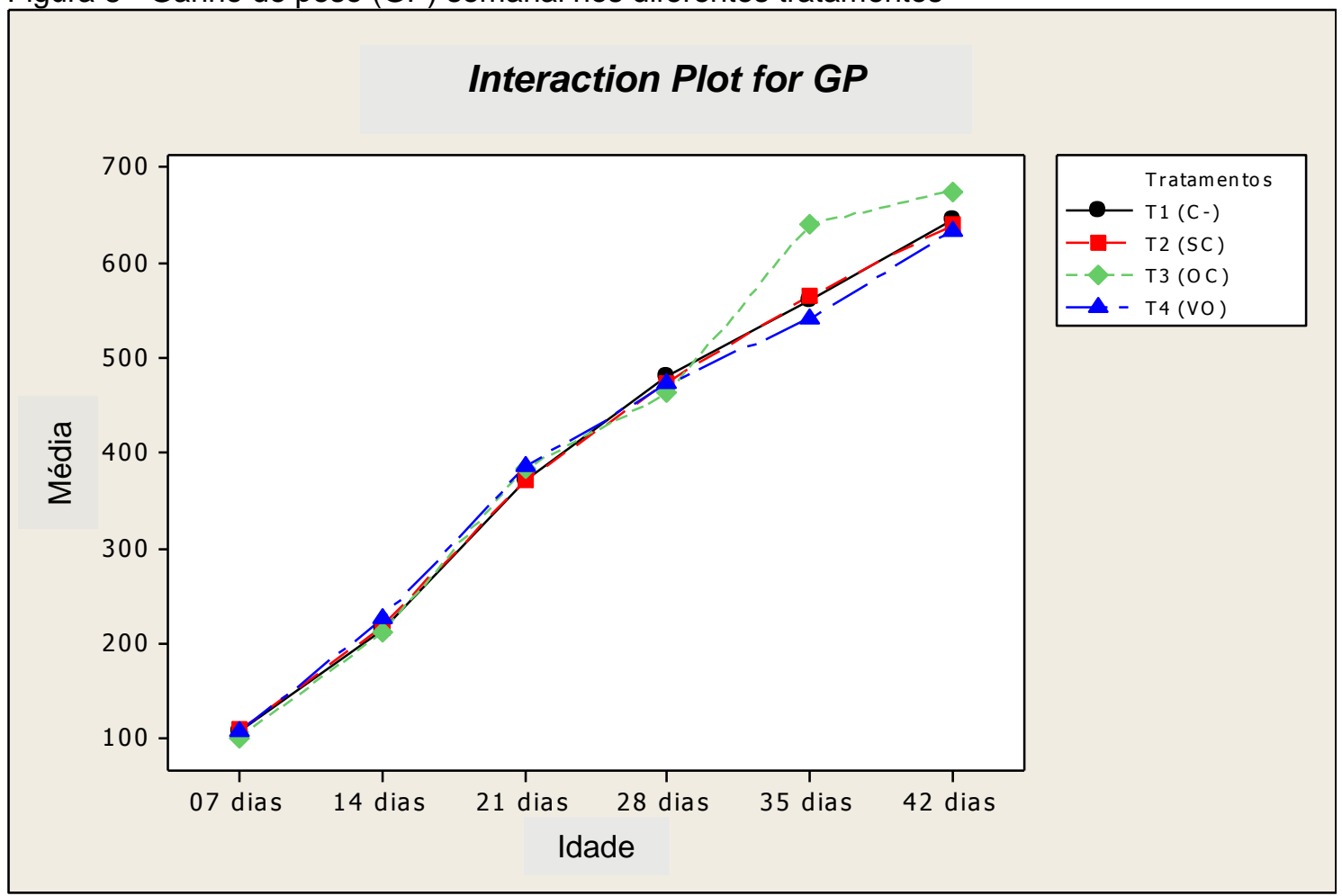

Em relação ao consumo de ração médio corrigido as aves do grupo $T 3(\mathrm{OC})$ apresentaram um consumo maior a partir da segunda semana quando comparado 
ao consumo das aves dos demais tratamentos e isso se manteve até o fim do experimento. $O$ consumo de ração entre os demais tratamentos foi semelhante entre eles. A figura 9 mostra estes resultados.

Quanto à conversão alimentar semanal (Figura 10) ocorreu uma variação nos tratamentos que obtiveram a melhor conversão em cada semana, sendo que as aves do T3(OC) foram as que apresentaram uma conversão alimentar maior na maioria dos períodos. Observou-se um aumento na conversão alimentar na semana dois (02), sendo que na semana três (03) os valores diminuíram e posteriormente aumentaram até o fim do experimento, com a exceção das aves do T3(OC) que diminuíram este índice da semana quatro (4) para a semana cinco (5).

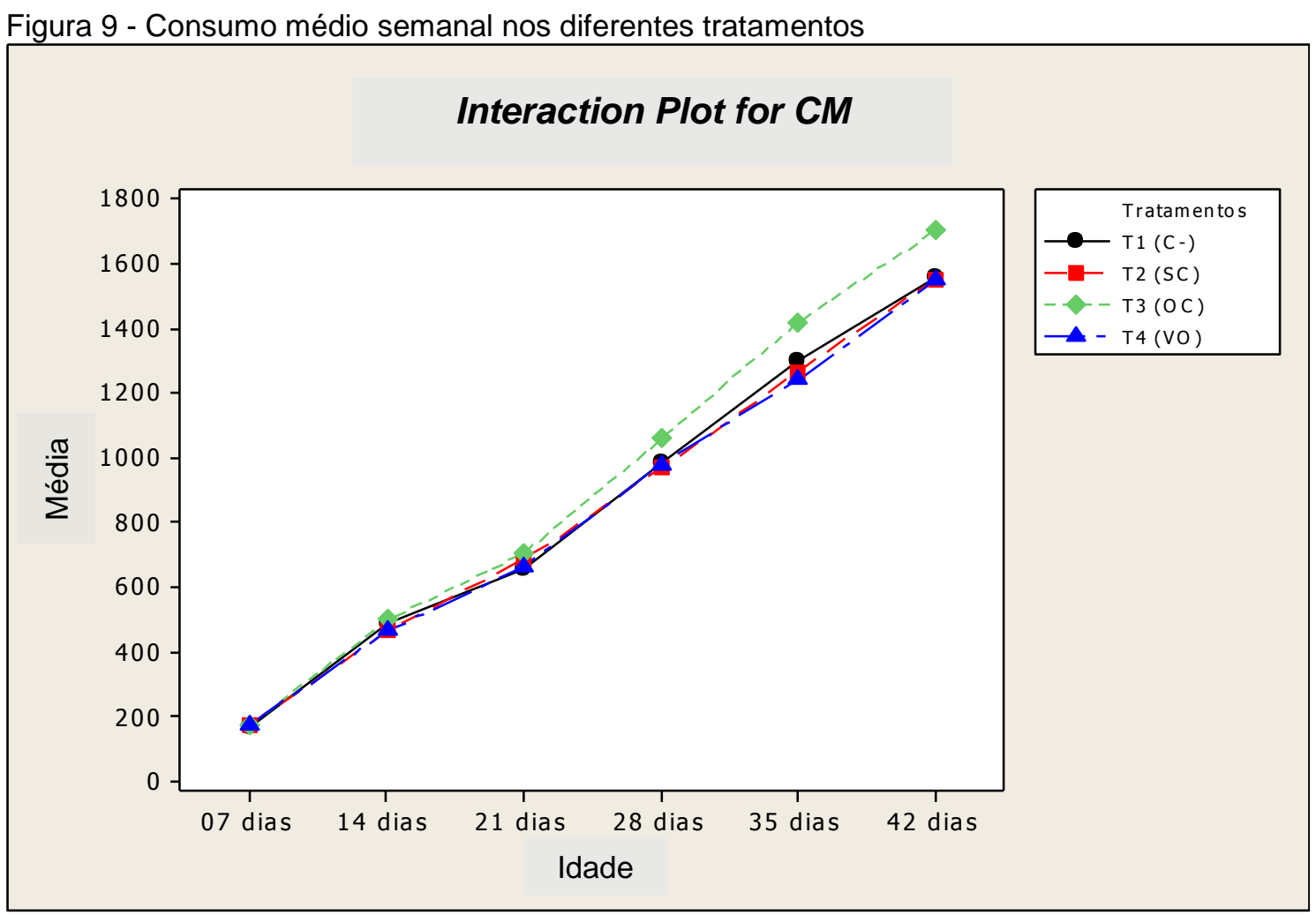




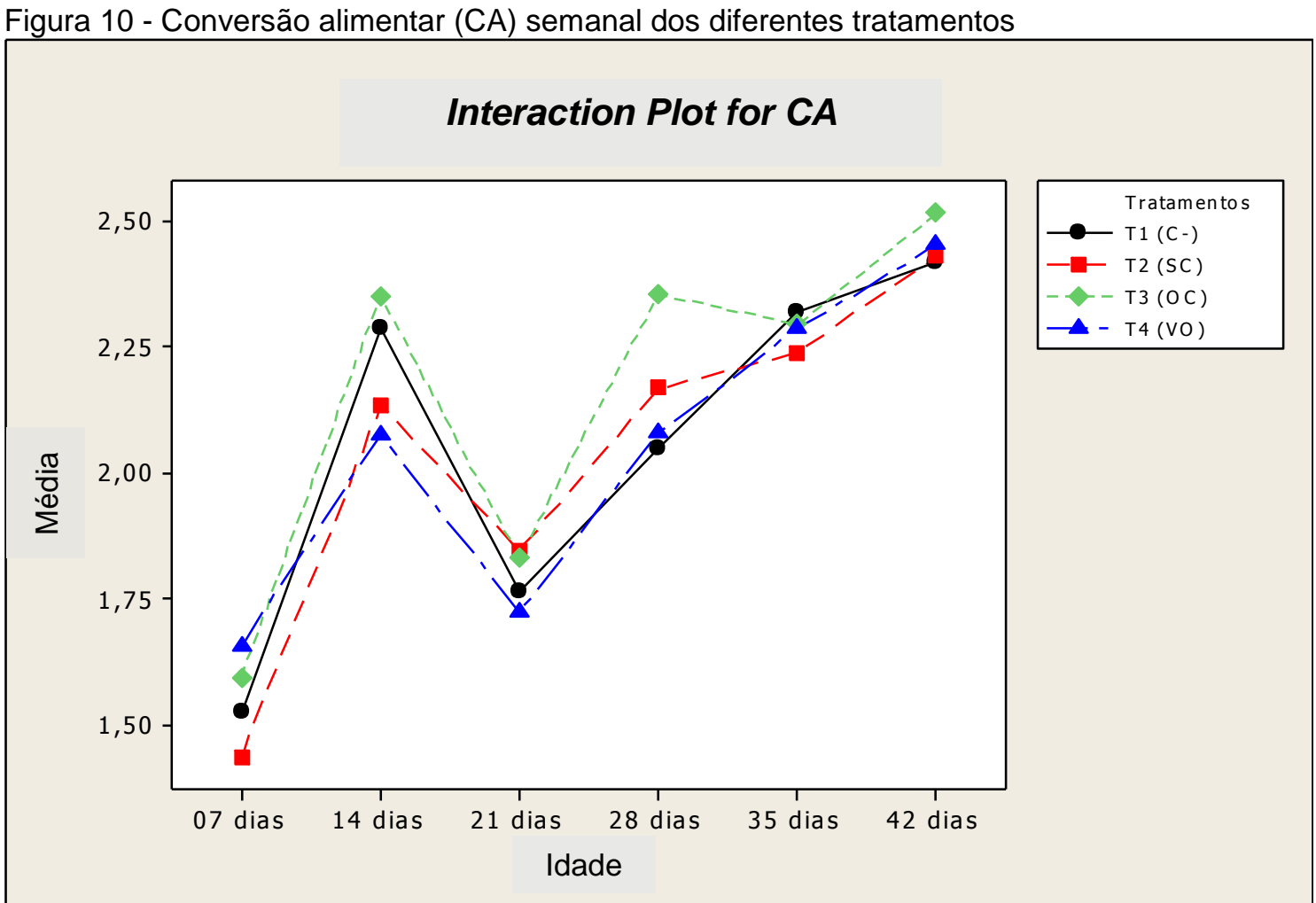

Avaliou-se o ganho de peso, o ganho de peso diário, a conversão alimentar, a viabilidade e o índice de eficiência produtiva (IEP) relativos a todo o período experimental (1 a 42 dias). Os resultados são apresentados na tabela 16.

Tabela 16 - Análise descritiva dos parâmetros zootécnicos relativos a todo o período experimental (média entre as repetições \pm desvio padrão)

\begin{tabular}{cccccc}
\hline Tratamento & GP $(\mathbf{g})$ & GPD $(\mathbf{g})$ & CA & $\begin{array}{c}\text { Viabilidade } \\
(\%)\end{array}$ & IEP \\
\hline T1(C-) & $2379,4 \pm 26,0$ & $56,65 \pm 0,62$ & $2,16 \pm 0,04$ & $100,0 \pm 0,0$ & $261,73 \pm 7,35$ \\
T2(SC) & $2377,4 \pm 29,8$ & $56,60 \pm 0,71$ & $2,16 \pm 0,07$ & $95,0 \pm 7,07$ & $248,66 \pm 13,13$ \\
& & & & & \\
T3(OC) & $2476,1 \pm 69,8$ & $58,95 \pm 1,66$ & $2,29 \pm 0,05$ & $80,0 \pm 14,1$ & $206,0 \pm 34,8$ \\
T4(VO) & $2366,0 \pm 112,4$ & $56,33 \pm 2,68$ & $2,15 \pm 0,03$ & $100,0 \pm 0,0$ & $262,7 \pm 16,4$ \\
\hline
\end{tabular}

$\mathrm{PM}=$ peso médio; $\mathrm{GP}=$ ganho de peso; $\mathrm{GPD}=$ ganho de peso diário; $\mathrm{CA}=$ conversão alimentar, $\mathrm{IEP}=$ Indice de eficiência produtiva

As aves do T3(OC) apresentaram o maior ganho de peso, 2379,4g, e as aves do T4(VO) apresentaram o menor ganho de peso, 2366g. As aves do T1(C-) e as do T2(SC) tiveram ganho de peso de $2379,4 \mathrm{~g}$ e $2377,4 \mathrm{~g}$, respectivamente. Os resultados são ilustrados na figura 11 . O ganho de peso diário foi de 56,65g nas 
aves do T1(C-), 56,6g nas do T2(SC), 58,95g naquelas do T3(OC) e de 56,33g nas aves do T4(SC).

Figura 11 - Média do ganho de peso acumulado entre as repetições

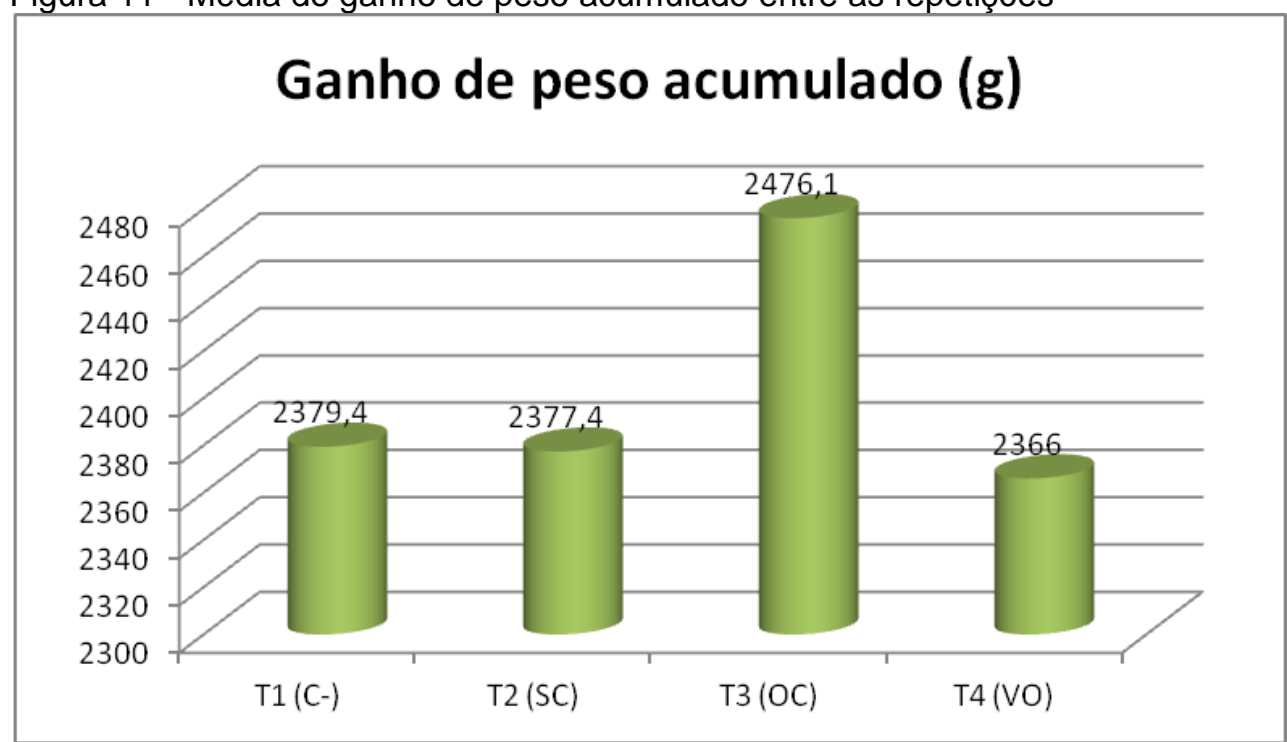

Quanto à conversão alimentar acumulada, os resultados foram muito parecidos entre as aves do T1(C-), T2(SC) e T4(VO), com índice de 2,16 tanto nas aves do T1(C-) quanto naquelas do T2(SC) e de 2,15 nas aves do T4(VO). As aves do T3(OC) foram as que apresentaram a maior conversão alimentar, 2,29. Os resultados são mostrados na figura 12.

Figura 12 - Conversão alimentar (CA) relativa a todo o período experimental

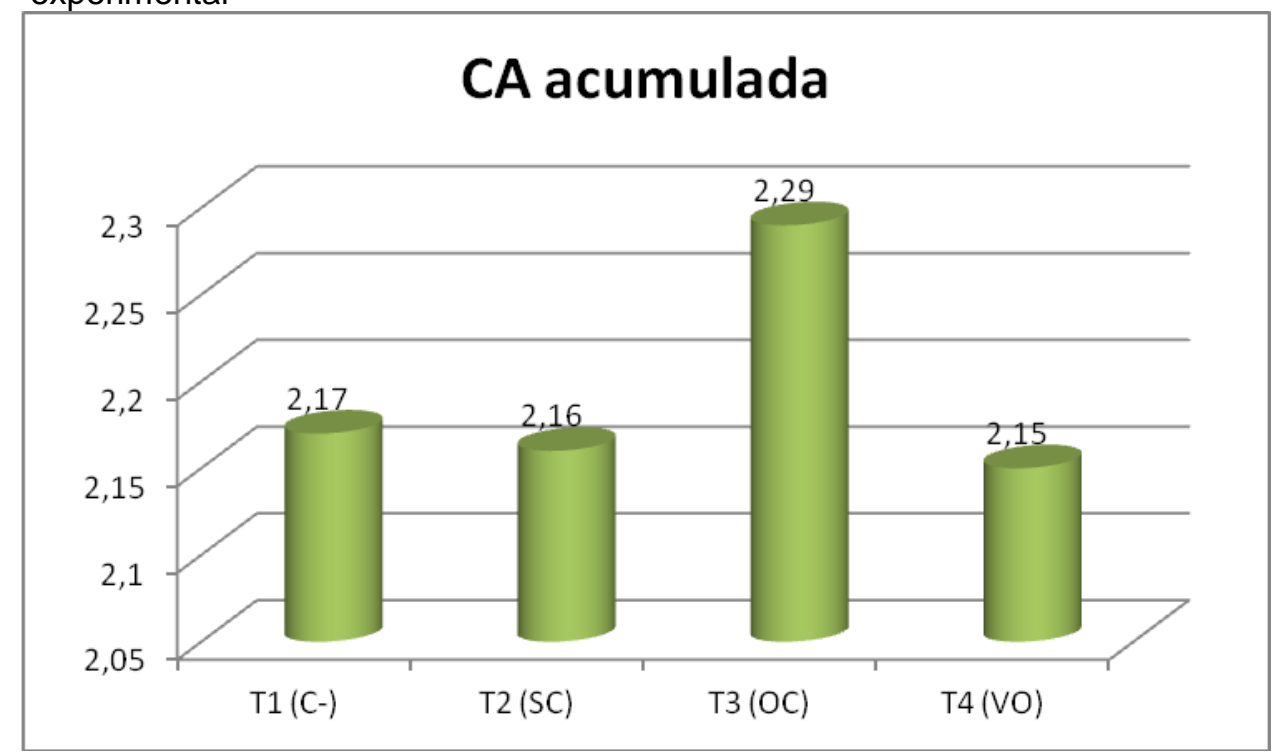


Nas aves dos tratamentos T1(C-) e T4(VO) a viabilidade foi de 100\%. Ocorreu uma viabilidade de $95 \%$ e $80 \%$, respectivamente, nas aves do T2(SC) e naquelas do T3(OC). Os resultados são ilustrados na figura 13.

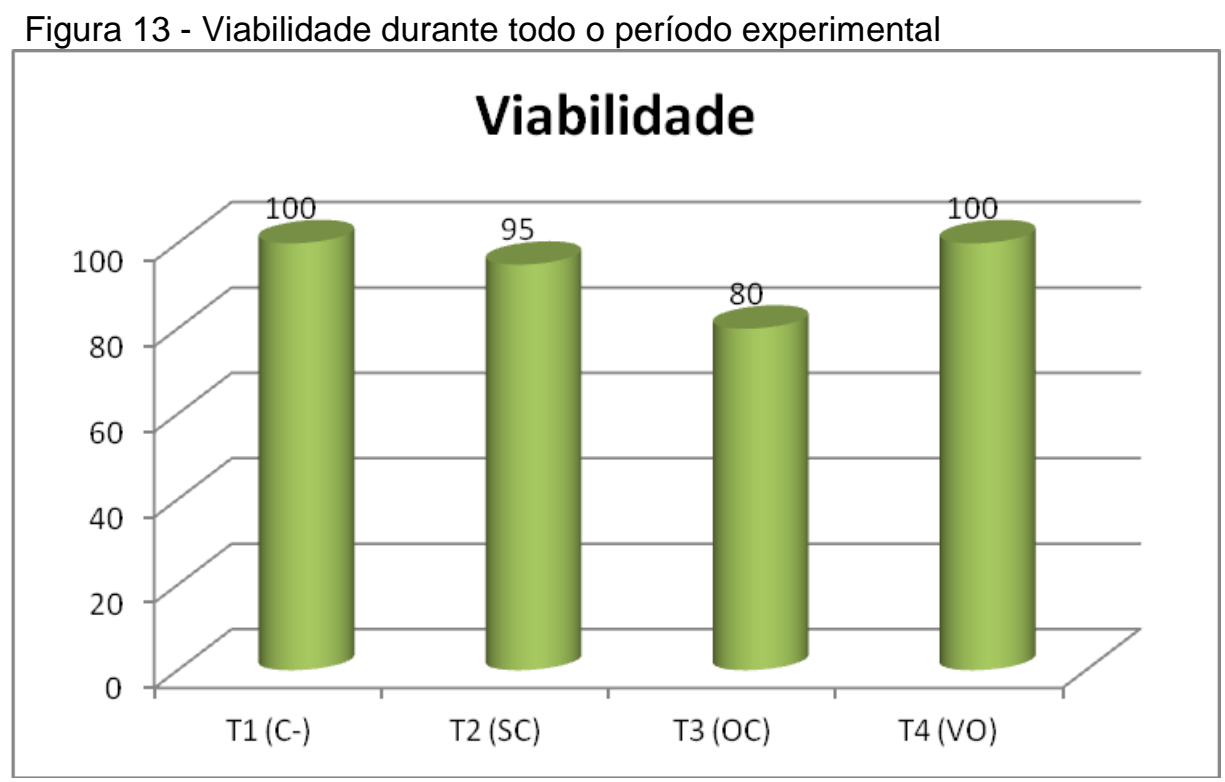

O índice de eficiência produtiva foi calculado levando-se em consideração a viabilidade, o ganho de peso e a conversão alimentar. As aves do T1(C-) tiveram índice de 261,73; aquelas do T2(SC) de 248,66; as do T3(OC) de 206,02 e as do T4(VO) de 262,68. Assim, o menor índice ocorreu nas aves do T3(OC) e o maior nas aves do T4(VO). A figura 14 mostra os resultados obtidos no Índice de Eficiência Produtiva.

Figura 14 - Índice de eficiência produtiva (IEP)

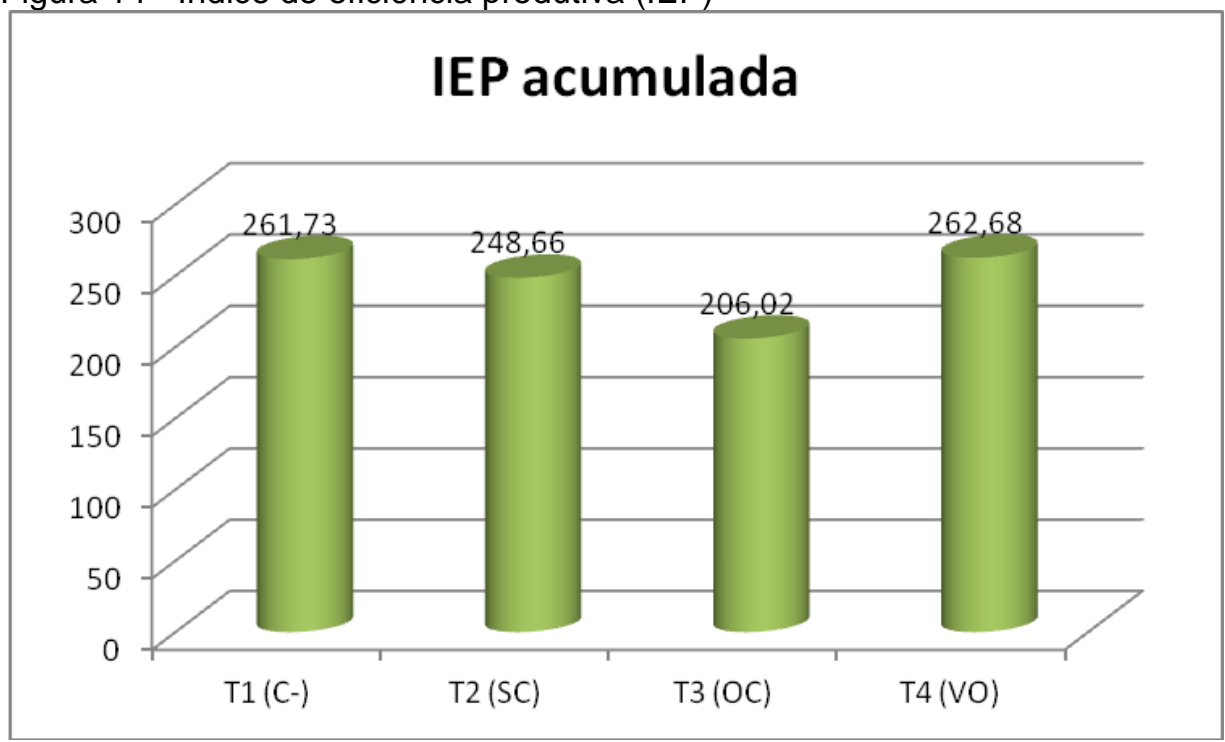




\subsection{RESULTADOS DO EXPERIMENTO 2: $\beta$-GLUCANO e ESCHERICHIA COLI}

Neste capítulo se apresentam os resultados da concentração bacteriana no inoculo, sorologia, dos parâmetros zootécnicos e escore de lesão obtidos no experimento que avaliou a influencia do $\beta$-glucano, administrado por diferentes vias, na infecção por Escherchia coli.

\subsubsection{Produção do inoculo}

Nos ensaios prévios à inoculação, se observou que na D.O. de 0,097, em comprimento de $625 \mathrm{~nm}$, se obtinha a contagem bacteriana desejada.

Após a inoculação foi feita a contagem bacteriana confirmando a concentração bacteriana recebida pelas aves que foi de $4 \times 10^{6} \mathrm{UFC} /$ ave. A figura 15 mostra as placas de ágar MacConkey, da contagem bacteriana feita após a inoculação das aves.

Figura 15 - Contagem bacteriana realizada após a inoculação das aves. Da esquerda para direita as placas correspondentes a $10^{4}, 10^{5}$ e $10^{6} \mathrm{UFC} / 100 \mu \mathrm{L}$. O resultado da contagem foi $4 \times 10^{6}$ UFC $/ 100 \mu \mathrm{L}$.

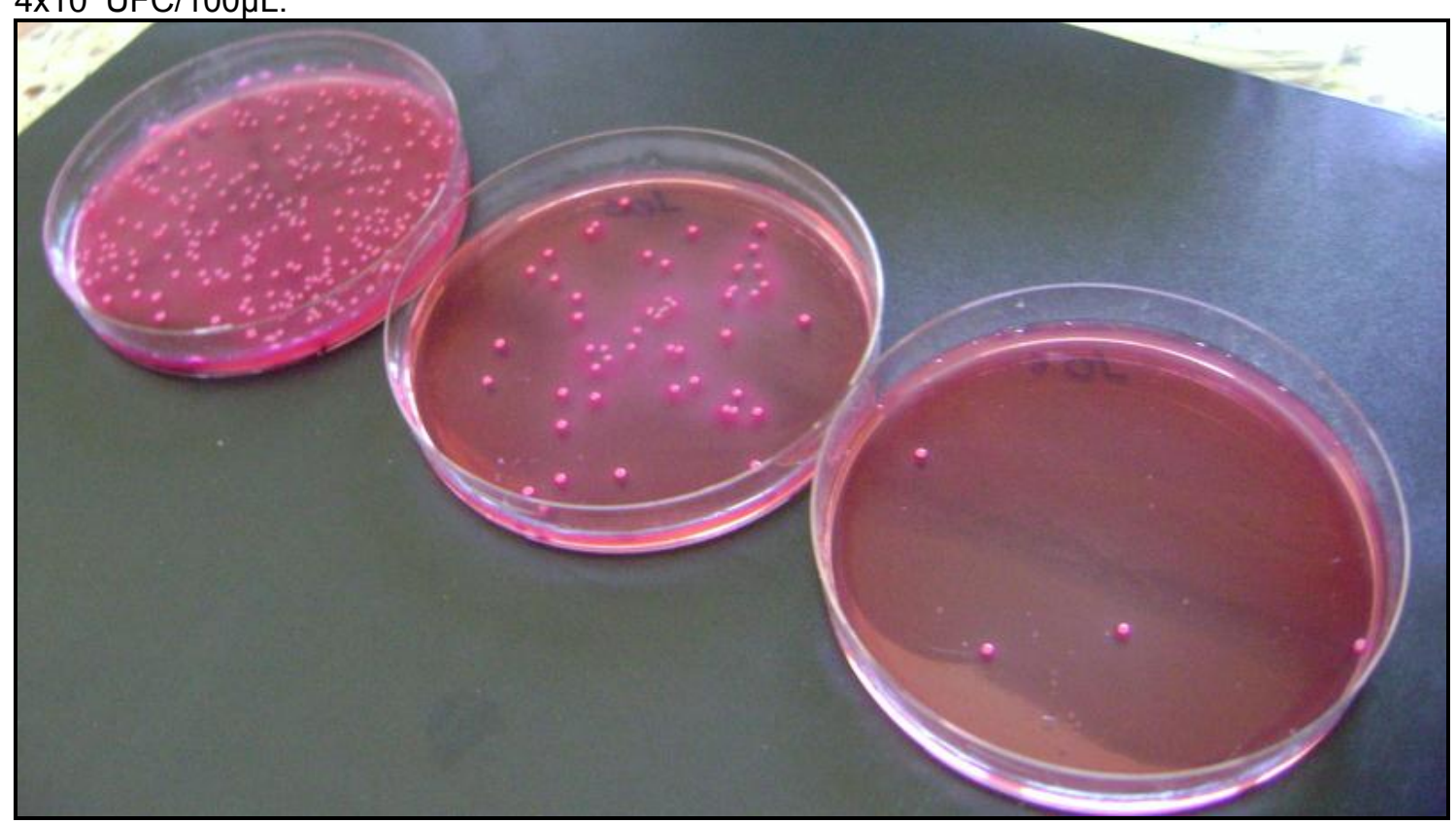




\subsubsection{Resultados sorológicos}

As concentrações séricas de imunoglobulinas se apresentam em $\mathrm{ng} / \mathrm{mL}$. Os resultados foram transformados em logaritmo natural $(I n)$ para serem usados nas análises estatísticas com o teste de Turkey e ANOVA.

Aos 28 dias de idade, 14 dias após o desafio com $E$. coli as aves do T6(SC+EC) apresentaram a concentração sérica de $\operatorname{lgA}$ de $312000 \mathrm{ng} / \mathrm{mL}(/ n=12,6)$, a maior quando comparada as aves dos demais tratamentos. As aves do T1(C-) apresentaram a segunda maior concentração de $\operatorname{lgA}, 291374 \mathrm{ng} / \mathrm{mL} \quad(\ln =12,6)$ seguido pelas aves do $\mathrm{T} 5\left(\mathrm{C}_{+}\right), 286474,3 \mathrm{ng} / \mathrm{mL}(I n=12,4)$. Quanto as aves do T5(VO+EC) e do T7(OC+EC) o resultado foi 276353,3ng/mL $(I n=12,5)$ e 239416,7 $(I n=12,6)$, respectivamente.

No $35^{\circ}$ dia de idade, em ordem da maior para a menor concentração sérica obteve-se os seguintes resultados: $365082,2 \mathrm{ng} / \mathrm{mL}(I n=12,8)$ nas aves do T8(VO+EC), 351995ng/mL (In=12,7) naquelas do T6(SC+EC), 329503,3mg/mL $(I n=12,7)$ nas aves do $\mathrm{T} 5(\mathrm{C}+), 322919,6 \mathrm{ng} / \mathrm{mL}(I n=12,6)$ nas aves do T1(C-) e $285338,9 \mathrm{mg} / \mathrm{mL}(\mathrm{In}=12,5)$ naquelas do T7(OC+EC).

No final do experimento, aos 42 dias, as aves do T1(C-) apresentaram o maior título de IgA sérico, 273191,8ng/mL $(I n=12,5)$ e aquelas do T7(OC+EC) apresentaram a concentração de $165655,3 \mathrm{ng} / \mathrm{mL}(I n=12,0)$, e mantiram nas demais idades analisadas, a menor concentração de anticorpos quando comparada as aves dos outros tratamentos. Os demais tratamentos apresentaram as seguintes concentrações: $214273,3(I n=12,1)$ nas aves do T5(C+), 251300ng/mL $(I n=12,4)$ naquelas do T6(SC+EC) e 198548,9ng/mL $(I n=12,2)$ nas aves do T8(VO+EC). A tabela 17 apresenta esses resultados. 
Tabela 17 - Concentrações séricas de IgA detectadas por ELISA nos diferentes tratamentos e idades (fatorial $5 \times 3$ )

\begin{tabular}{|c|c|c|c|c|c|c|}
\hline \multirow{2}{*}{ Tratamento } & \multicolumn{3}{|c|}{ In (C. V. \%) } & \multicolumn{3}{|c|}{$\mathrm{ng} / \mathrm{mL}$} \\
\hline & 28 dias & 35 dias & 42 dias & 28 dias & 35 dias & 42 dias \\
\hline T1(C-) & $\begin{array}{c}12,6 \mathrm{ab} \\
(1,97)\end{array}$ & $\begin{array}{l}12,6 \mathrm{a} \\
(2,39)\end{array}$ & $\begin{array}{c}12,5 \mathrm{abc} \\
(2,12)\end{array}$ & 291374,0 & 322910,6 & 273191,8 \\
\hline $\mathrm{T} 5(\mathrm{C}+)$ & $\begin{array}{c}12,4 \mathrm{abc} \\
(3,69)\end{array}$ & $\begin{array}{l}12,7 \mathrm{a} \\
(1,80)\end{array}$ & $\begin{array}{c}12,1 \mathrm{~cd} \\
4,54\end{array}$ & 286474,3 & 329503,3 & 214273,3 \\
\hline $\mathrm{T} 6(\mathrm{SC}+\mathrm{EC})$ & $\begin{array}{c}12,6 a b \\
(3,12)\end{array}$ & $\begin{array}{l}12,7 a \\
(1,96)\end{array}$ & $\begin{array}{c}12,4 \text { abcd } \\
(3,07)\end{array}$ & 312000,0 & 351995,0 & 251300,0 \\
\hline $\mathrm{T} 7(\mathrm{OC}+\mathrm{EC})$ & $\begin{array}{c}12,3 \mathrm{abcd} \\
(2,72)\end{array}$ & $\begin{array}{c}12,5 \mathrm{abc} \\
(2,31)\end{array}$ & $\begin{array}{l}12,0 \mathrm{~d} \\
(2,37)\end{array}$ & 239416,7 & 285338,9 & 165655,3 \\
\hline T8(VO+EC) & $\begin{array}{c}12,5 \mathrm{abc} \\
(1,89)\end{array}$ & $\begin{array}{l}12,8 \mathrm{a} \\
(2,81)\end{array}$ & $\begin{array}{c}12,2 \mathrm{bcd} \\
(2,66)\end{array}$ & 276353,3 & 365082,2 & 198548,9 \\
\hline
\end{tabular}

A análise estatística dos resultados nos diferentes tratamentos, com aves de mesma idade, revelou não existir diferenças significativas nas concentrações sérica de $\lg A$ aos 28 e 35 dias. Aos 42 dias as aves do T7(OC+EC) apresentaram titulo significativamente menor do que as aves do T1(C-). A figura 18 mostra esses resultados.

Figura 16 - Concentrações séricas de IgA determinadas nas diferentes idades e nos diferentes tratamentos

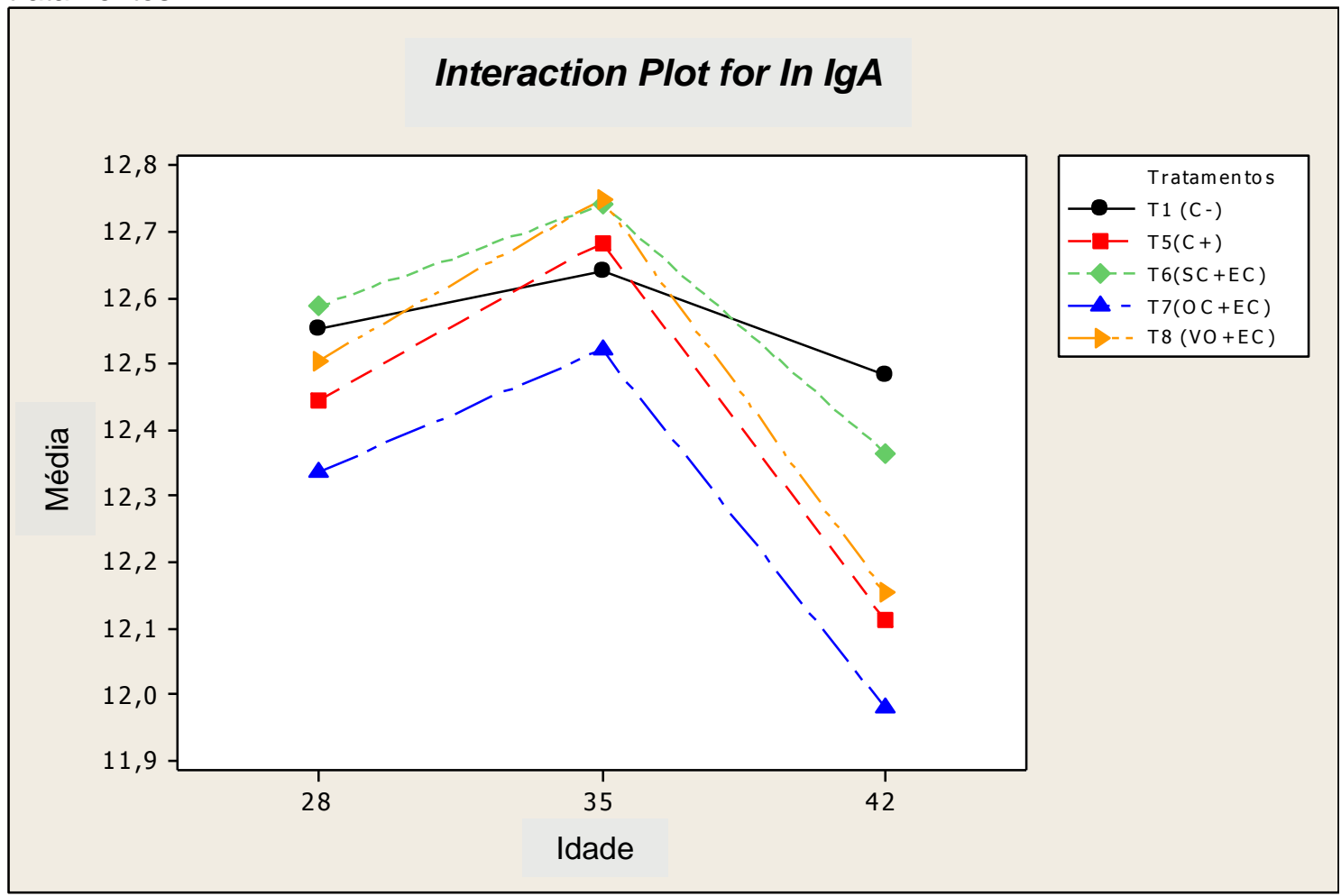

Desconsiderando os efeitos da idade verificou-se que nas aves do $\mathrm{T7}(\mathrm{OC}+\mathrm{EC})$ as concentrações séricas de IgA foram significativamente menores que 
as do T1(C-) e as do T6(SC+EC). A tabela 18 mostra estes resultados. Ao se avaliar apenas a idade constatou-se diferenças significativas entre as três idades analisadas. Aos 35 dias a concentração de anticorpos foi a maior. Aos 42 dias de idade a concentração de $\lg A$ foi menor do que aos 28 dias, ou seja, observou-se que o titulo aumentou do dia 28 para o dia 35, e diminuiu aos 42 dias de idade. Estes resultados se encontram na tabela 19 e na figura 17.

Tabela 18 - Concentrações séricas de IgA detectadas por ELISA (em In) considerando apenas as vias de administração

\begin{tabular}{ccc}
\hline Tratamento & In & C.V. (\%) \\
\hline T1(C-) & $12,6 \mathrm{a}$ & 2,18 \\
T5(C+) & $12,4 \mathrm{ab}$ & 3,89 \\
T6(SC+EC) & $12,6 \mathrm{a}$ & 2,94 \\
T7(OC+EC) & $12,3 \mathrm{~b}$ & 3,05 \\
T8(VO+EC) & $12,5 \mathrm{ab}$ & 3,12 \\
\hline
\end{tabular}

Nível de significância 5\%; C.V.= Coeficiente de variação; Valores com letras diferentes tiveram diferenças significativas

Tabela 19 - Concentrações séricas de IgA detectadas por ELISA (em In) considerando apenas as diferentes idades

\begin{tabular}{ccc}
\hline Idades & In & C.V. (\%) \\
\hline $\mathbf{2 8}$ dias & $12,5 \mathrm{~b}$ & 2,81 \\
$\mathbf{3 5}$ dias & $12,7 \mathrm{a}$ & 2,30 \\
$\mathbf{4 2}$ dias & $12,2 \mathrm{c}$ & 3,30 \\
\hline
\end{tabular}

Nível de significância 5\%; C.V.= Coeficiente de variação; Valores com letras diferentes tiveram diferenças significativas

Figura 17 - Concentrações séricas de IgA considerando os diferentes tratamentos e as diferentes idades

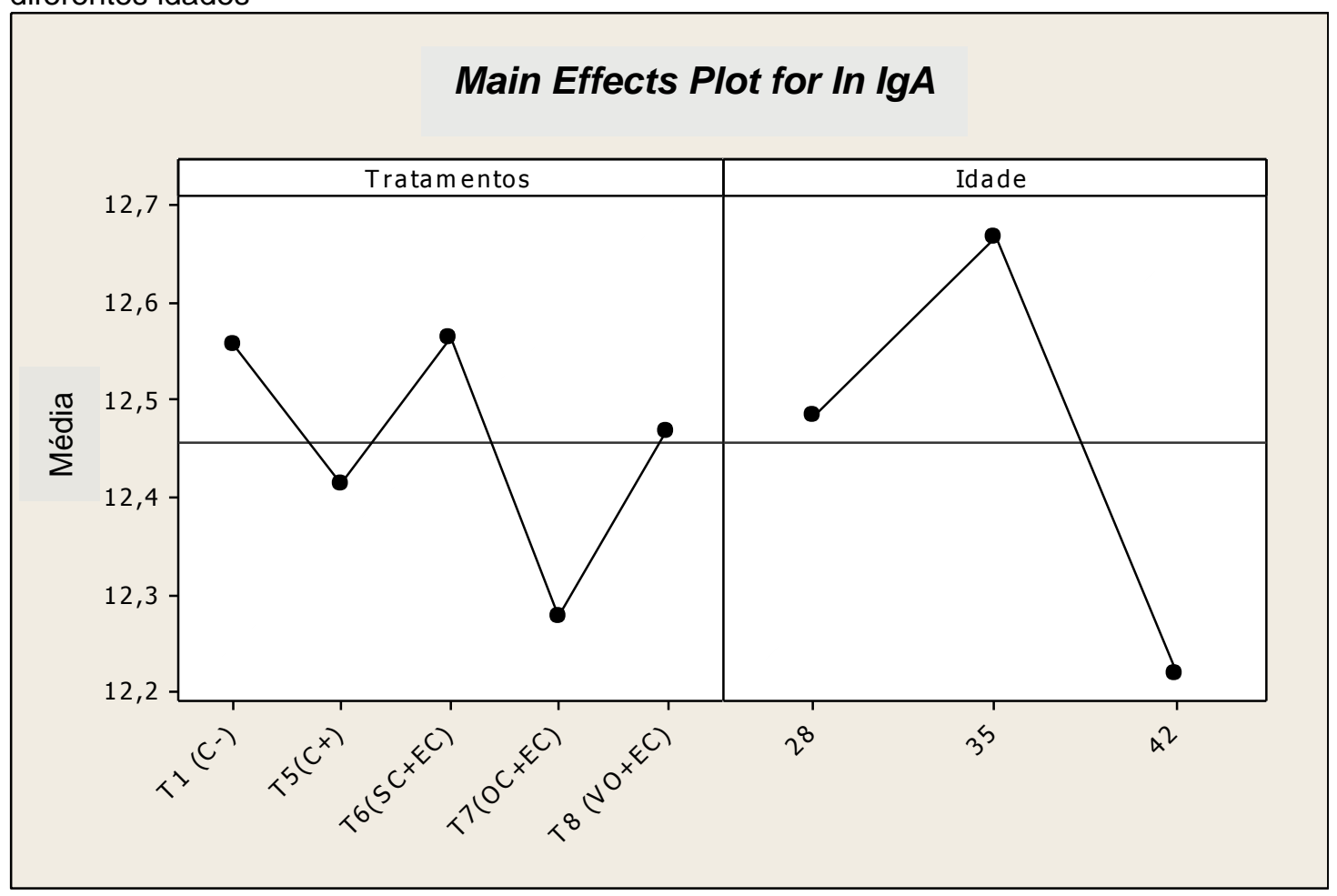


A concentração de IgG sérica nas aves com 28 dias de idade apresentou o menor resultado nas aves do T1(C-), 1020182ng/mL (In=13,7). Os demais resultados foram: nas aves do T8(VO+EC) $1243227 \mathrm{ng} / \mathrm{mL}(I n=13,9)$, naquelas do T7(OC+EC) $1248567 \mathrm{ng} / \mathrm{mL}$ ( $/ n=13,9)$, nas aves do T6(SC+EC) $1717489 \mathrm{ng} / \mathrm{mL}$ $(I n=14,3)$ e naquelas do $\mathrm{T} 5\left(\mathrm{C}_{+}\right) 1858946 \mathrm{ng} / \mathrm{mL}(I n=14,3)$, sendo esta a maior concentração.

Aos 35 dias de idade as aves do $\mathrm{T} 7(\mathrm{OC}+\mathrm{EC})$ passaram a ter a menor concentração entre os tratamentos, $1658244 \mathrm{ng} / \mathrm{mL} \quad(I n=14,3)$. As demais concentrações foram: $1675993 \mathrm{ng} / \mathrm{mL}(I n=14,2)$ nas aves do T1(C-), $1896760 \mathrm{ng} / \mathrm{mL}$ (In=14,4), naquelas do T8(VO+EC), 2341567ng/mL (In=14,6), nas aves do T5(C+), e, a maior concentração, $255660 \mathrm{ng} / \mathrm{mL}(I n=14,7)$ nas aves doT6(SC+EC).

Ao final do experimento, aos 42 dias de idade, foram esses os resultados em ordem da menor para a maior concentração: nas aves do T8(VO+EC) $1749800 \mathrm{ng} / \mathrm{mL}(/ n=14,3)$, naquelas do $T 7(\mathrm{OC}+\mathrm{EC}) 1769522 \mathrm{ng} / \mathrm{mL}$, nas aves do T1(C-) 2084991ng/mL ( $I n=14,5)$, naquelas do T5(C+) $2421060 \mathrm{ng} / \mathrm{mL}$ e nas aves do T6(SC+EC) 2565102ng/mL ( $/ n=14,6)$.

Comparando as concentrações séricas de lgG encontradas nas aves do T1(C-) com as aves dos demais grupos estudados, verificou-se que estas foram estatisticamente iguais aos 28 dias de idade com as aves do T7(OC+EC) e do T8(VO+EC). Também não ocorreram diferenças entre as aves que foram infectadas com E. coli. Contudo, as aves do $\mathrm{T} 1(\mathrm{C}-)$ apresentaram concentrações estatisticamente menores do que as do T3 $\left(\mathrm{C}_{+}\right)$e do $\mathrm{T} 6(\mathrm{SC}+\mathrm{EC})$. Aos 35 e 42 dias de idade não houve diferença significativa na concentração de IgG sérica entre os grupos estudados. A tabela 20 e a figura 18 mostram os resultados relativos a concentração sérica de lgG. 
Tabela 20 - Concentrações séricas de IgG detectadas por ELISA nos diferentes tratamentos e idade das aves (fatorial $5 \times 3$ )

\begin{tabular}{|c|c|c|c|c|c|c|}
\hline \multirow[t]{2}{*}{ Tratamento } & \multicolumn{3}{|c|}{ In (C. V. \%) } & \multicolumn{3}{|c|}{$\mathrm{ng} / \mathrm{mL}$} \\
\hline & 28 dias & 35 dias & 42 dias & 28 dias & 35 dias & 42 dias \\
\hline T1(C-) & $\begin{array}{l}13,7 d \\
(3,78)\end{array}$ & $\begin{array}{c}14,2 \text { abcd } \\
(2,91)\end{array}$ & $\begin{array}{c}14,5 \mathrm{ab} \\
(3,00)\end{array}$ & 1020182 & 1675993 & 2084991 \\
\hline T5(C+) & $\begin{array}{c}14,3 \text { abc } \\
(3,78)\end{array}$ & $\begin{array}{c}14,6 \mathrm{ab} \\
(3,30)\end{array}$ & $\begin{array}{c}14,6 \mathrm{ab} \\
(3,75)\end{array}$ & 1858946 & 2341567 & 2421060 \\
\hline T6(SC+EC) & $\begin{array}{c}14,3 a b c \\
(2,29)\end{array}$ & $\begin{array}{l}14,7 a \\
(2,21)\end{array}$ & $\begin{array}{c}14,6 a b \\
(3,35)\end{array}$ & 1717489 & 2556630 & 2565102 \\
\hline $\mathrm{T} 7(\mathrm{OC}+\mathrm{EC})$ & $\begin{array}{c}13,9 \mathrm{~cd} \\
(3,38)\end{array}$ & $\begin{array}{c}14,3 \mathrm{abcd} \\
(2,65)\end{array}$ & $\begin{array}{c}14,3 \mathrm{abc} \\
(3,12)\end{array}$ & 1248567 & 1658244 & 1769522 \\
\hline T8(VO+EC) & $\begin{array}{c}14,0 \mathrm{bcd} \\
(1,60)\end{array}$ & $\begin{array}{c}14,4 a b c \\
(2,10)\end{array}$ & $\begin{array}{c}14,3 \text { abcd } \\
(3,24)\end{array}$ & 1243227 & 1896760 & 1749800 \\
\hline
\end{tabular}

Nível de significância 5\%; C.V.= Coeficiente de variação; Valores com letras diferentes tiveram diferenças significativas

Figura 18 - Concentrações séricas de IgG determinadas nas diferentes idades e nos diferentes tratamentos

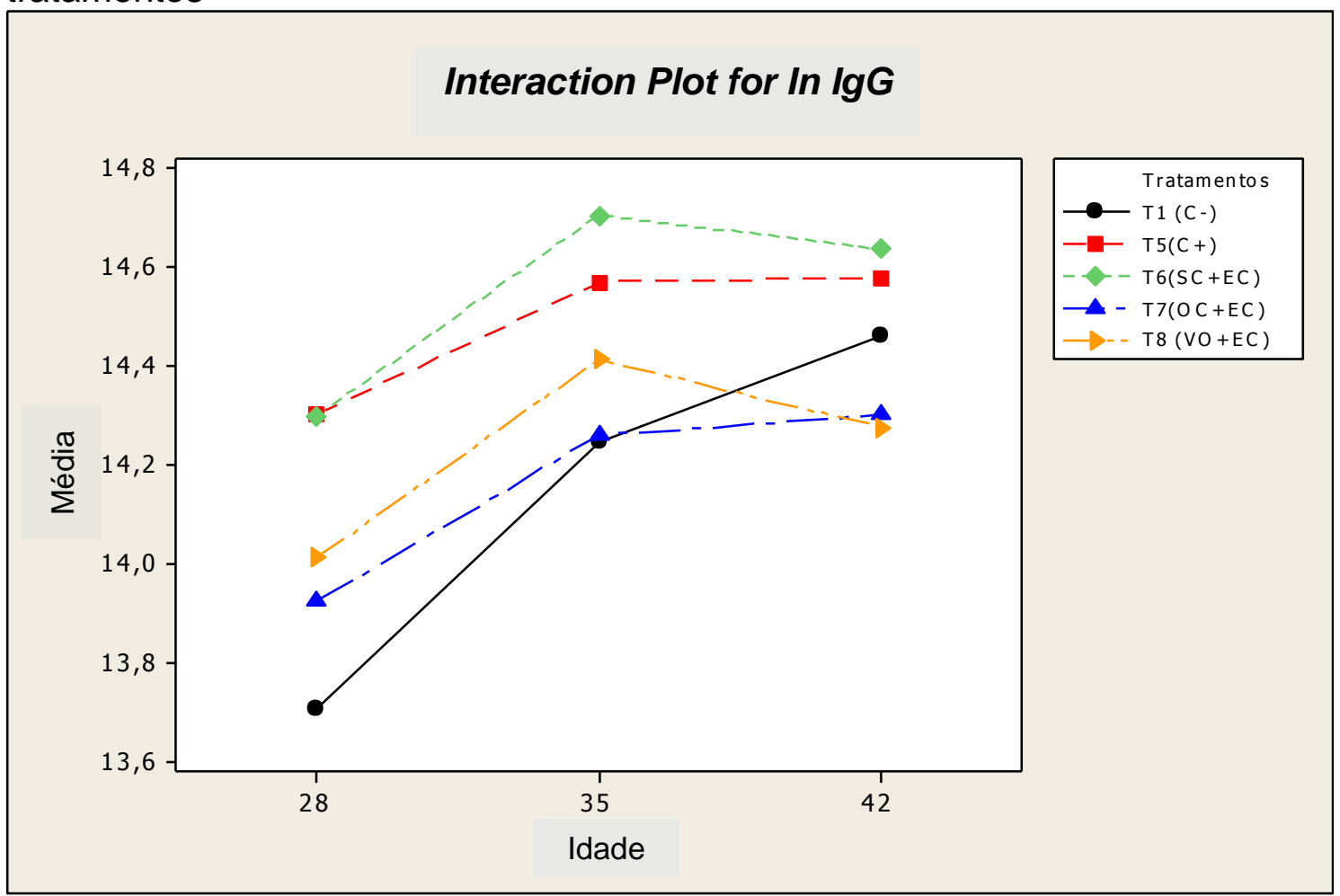

Analisando as concentrações séricas de IgG nos diferentes tratamentos, sem considerar as idades, os resultados mostraram que o menor título foi o das aves do T1(C-), que apresentou concentrações de IgG significativamente menores do que as do $T 5\left(C_{+}\right)$e do $T 6(S C+E C)$, mas não houve diferença significativa em relação ao título das aves do $\mathrm{T} 7(\mathrm{OC}+\mathrm{EC})$ e do $\mathrm{T} 8(\mathrm{VO}+\mathrm{EC})$. O título encontrado nas aves do 
$\mathrm{T} 5(\mathrm{C}+)$ não apresentou diferenças significativas com relação ao título das aves do T6(SC+EC) e do T8(VO+EC). As aves do T6(SC+EC) apresentaram concentrações de $\lg$ maiores do que as do $\mathrm{T} 8(\mathrm{VO}+\mathrm{EC})$, sendo esta estatisticamente significante. A tabela 21 e a figura 19 apresentam estes resultados.

Tabela 21 - Concentrações de séricas de IgG detectadas por ELISA (em In) considerando apenas as vias de administração

\begin{tabular}{ccc}
\hline In & C.V. (\%) \\
\hline Tratamento & $14,1 \mathrm{c}$ & 3,90 \\
\hline T1(C-) & $14,5 \mathrm{ab}$ & 3,64 \\
T5(C+) & $14,5 \mathrm{a}$ & 2,85 \\
T6(SC+EC) & $14,2 \mathrm{C}$ & 3,23 \\
T7(OC+EC) & $14,2 \mathrm{bc}$ & 2,61 \\
\hline T8(VO+EC) &
\end{tabular}

Nível de significância 5\%; C.V.= Coeficiente de variação; Valores com letras diferentes tiveram diferenças significativas

Considerando apenas as idades estudadas verificou-se que as concentrações séricas de lgG aumentaram de acordo com a idade. As aves com 28 dias de idade apresentaram concentrações significativamente menores do que as aves com 35 e 42 dias de idade, Não existiu diferença significativa entre as aves com 35 e 42 dias de idade. A tabela 22 e a figura 19 mostram estes resultados.

Tabela 22 - Concentrações séricas de IgG detectadas por ELISA (em In) considerando apenas as diferentes idades

\begin{tabular}{ccc}
\hline Idades & In & C.V. (\%) \\
\hline $\mathbf{2 8}$ dias & $14,0 \mathrm{~b}$ & 3,57 \\
$\mathbf{3 5}$ dias & $14,4 \mathrm{a}$ & 2,91 \\
$\mathbf{4 2}$ dias & $14,5 \mathrm{a}$ & 3,31 \\
\hline
\end{tabular}

Nível de significância 5\%; C.V.= Coeficiente de variação; Valores com letras diferentes tiveram diferenças significativas 
Figura 19 - Efeitos principais nas concentrações séricas de $\lg G$ em relação a idade e ao tratamento

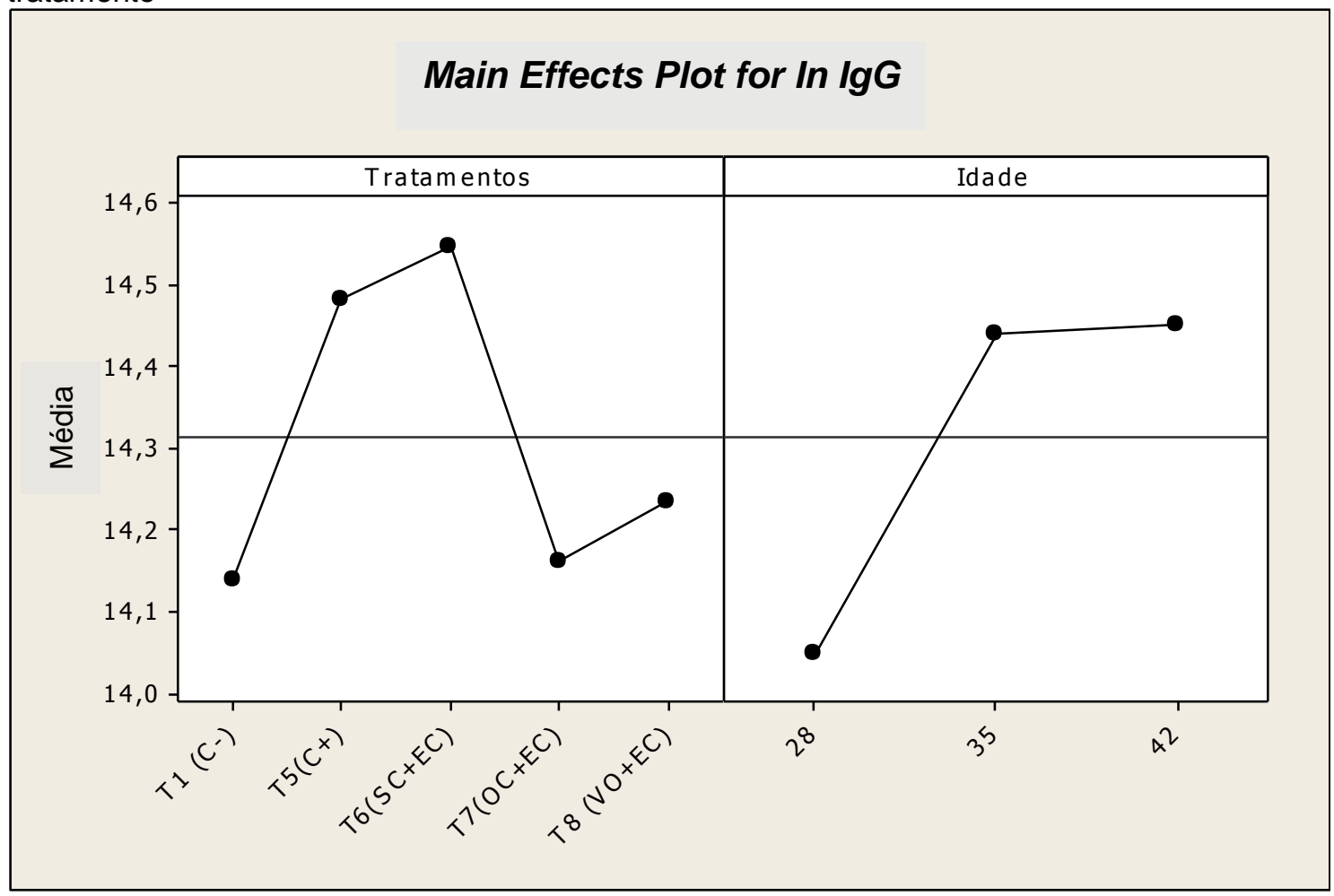

Os resultados foram submetidos à análise de variância simples (ANOVA), com um nível de significância de 5\%. Esta análise demonstrou que não houve diferença significativa das concentrações séricas de imunoglobulinas entre os grupos estudados ao se considerar as diferentes idades e os diferentes tratamentos $(P>0,05)$. Levando-se em consideração apenas as idades, as diferenças foram significativas tanto para IgA quanto para $\lg G(P<0,05)$. Da mesma forma ao se considerarem apenas os diferentes tratamentos a diferença foi significativa $(P<0,05)$. A tabela 23 mostra os resultados da análise de variância simples (ANOVA).

Tabela 23 - Valor de P obtido na análise de variância simples ANOVA

\begin{tabular}{lcc}
\hline \multirow{2}{*}{ Análise de variância simples } & \multicolumn{2}{c}{ Valor de $\mathbf{P}$} \\
\cline { 2 - 3 } & IgA & IgG \\
\hline Tratamentos & 0,000 & 0,000 \\
Idade & 0,000 & 0,000 \\
Via de inoculação X idade & 0,304 & 0,541 \\
\hline
\end{tabular}

Nível de significância 5\%; C.V.= Coeficiente de variação; Valores com letras diferentes tiveram diferenças significativas 
Ao se comparar as concentrações séricas de imunoglobulinas dos diferentes grupos de aves estudadas, verificou-se que as concentrações de $\lg A$ foram menores do que as de lgG. A figura 20 mostra a comparação entre as concentrações de $\lg A$ e $\lg G$.

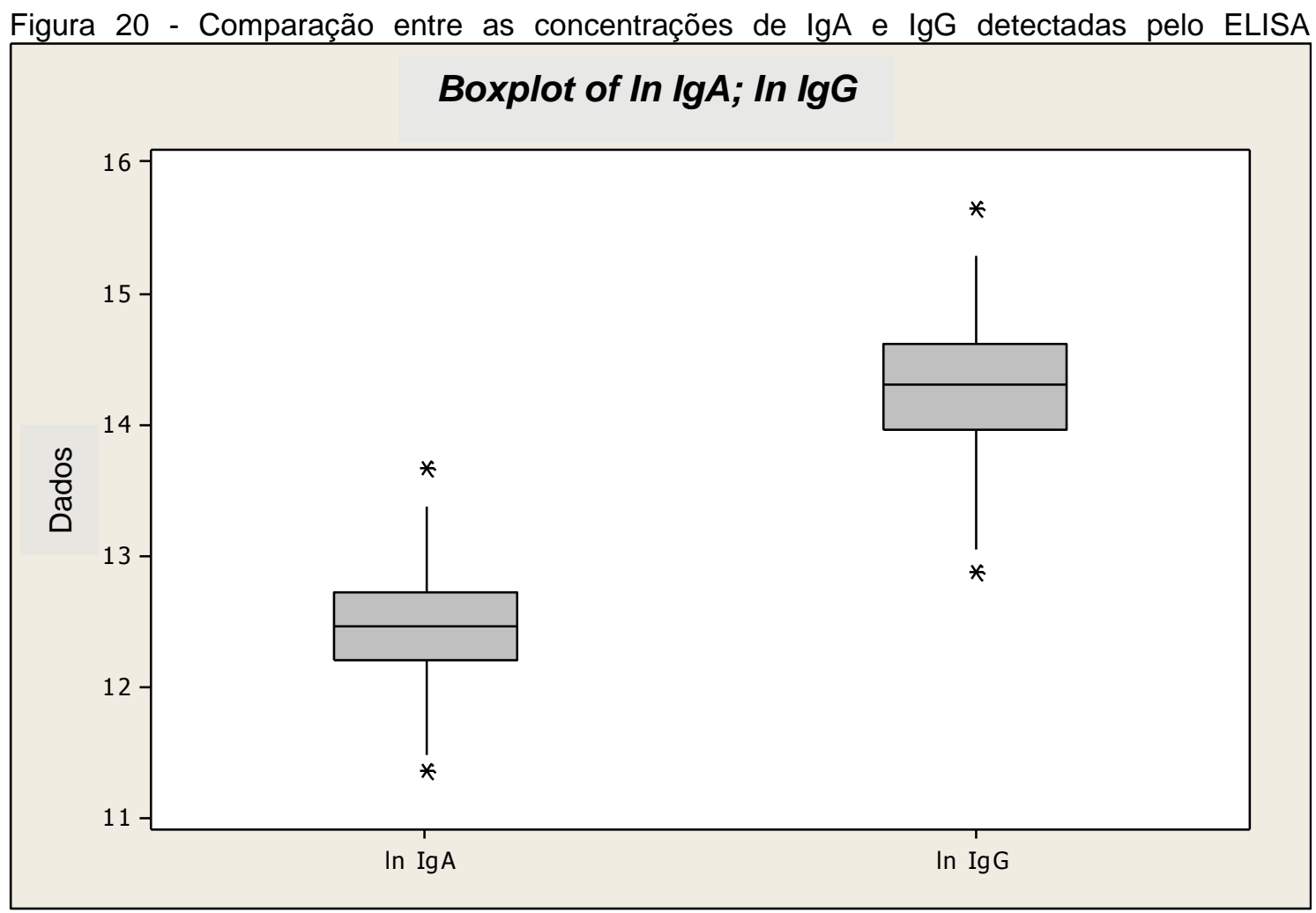

\subsubsection{Resultados dos parâmetros zootecnicos}

O desempenho zootécnico das aves na primeira semana de criação está exposto na tabela 24. Observou-se que o peso médio das aves variou entre $146,75 \mathrm{~g}[\mathrm{~T} 5(\mathrm{C}+)]$ e 160,25g [T8(OC+EC)]. Os resultados das aves nos demais tratamentos foram: $152,75 \mathrm{~g}$ no T1(C-), 157,88g no T6(SC+EC) e 158,5g no T8(VO+EC). Quanto ao ganho de peso médio os resultados foram os seguintes: as aves do $\mathrm{T} 5(\mathrm{C}+)$ ganharam 101,6g, aquelas do $\mathrm{T} 1(\mathrm{C}-) 152,75 \mathrm{~g}$, as do T6(SC+EC) 109,23g, aquelas do T8(VO+EC) $111,15 \mathrm{~g}$ e as aves do T7(OC+EC) 113,65g. As 
aves que receberam o $\beta$-glucano ganharam mais peso e tiveram maior ganho de peso nesta semana.

O consumo médio de ração, em ordem do tratamento que menos consumiu para o que mais consumiu, foi de $161,7 \mathrm{~g}$ no $\mathrm{T} 1(\mathrm{C}-), 162,4 \mathrm{~g}$ no $\mathrm{T} 2(\mathrm{C}+), 168,5 \mathrm{~g}$ no T8(VO+EC), 176,8g no T7(OC+EC) e 185,59g no T6(SC+EC). A conversão alimentar foi melhor nas aves do T8(VO+EC) que teve índice de 1,52. As aves do T1(C-) tiveram conversão de 1,53, aquelas do T7(OC+EC) 1,55, as do T5(C+) 1,6 e aquelas do T6(SC+EC), com o pior resultado, 1,67.

Tabela 24 - Análise descritiva dos parâmetros zootécnicos na primeira semana de idade (médias \pm desvio padrão)

\begin{tabular}{ccccc}
\hline Tratamento & PM $(\mathbf{g})$ & $\mathbf{G P}(\mathbf{g})$ & $\mathbf{C M}$ (g) & CA \\
\hline T1(C-) & $152,75 \pm 3,89$ & $105,90 \pm 2,4$ & $161,7 \pm 10,7$ & $1,53 \pm 0,11$ \\
T5(C+) & $146,75 \pm 2,47$ & $101,6 \pm 2,55$ & $162,4 \pm 4,38$ & $1,60 \pm 0,00$ \\
T6(SC+EC) & $157,88 \pm 1,72$ & $109,23 \pm 0,66$ & $185,59 \pm 13,7$ & $1,67 \pm 0,09$ \\
T7(OC+EC) & $160,25 \pm 0,49$ & $113,65 \pm 1,2$ & $176,8 \pm 16,2$ & $1,55 \pm 0,13$ \\
T8(VO+EC) & $158,5 \pm 0,14$ & $111,15 \pm 0,35$ & $168,5 \pm 2,97$ & $1,52 \pm 0,02$ \\
\hline PM=peso médio; GP=ganho de peso; CM=consumo médio; CA=conversão alimentar
\end{tabular}

$\mathrm{Na}$ segunda semana experimental o peso médio das aves nos diferentes tratamentos foi de $367,10 \mathrm{~g}$ no $\mathrm{T} 1(\mathrm{C}-), 346,4 \mathrm{~g}$ no $\mathrm{T} 5(\mathrm{C}+), 374,36 \mathrm{~g}$ no T6(SC+EC), $397,55 \mathrm{~g}$ no T7(OC+EC) e 387,2g no T8(VO+EC). O ganho de peso nessa semana foi de 214,35g nas aves do $\mathrm{C}_{+}, 199,6 \mathrm{~g}$ nas aves do $\mathrm{T5}(\mathrm{C}+), 216,5 \mathrm{~g}$ nas aves do T6(SC+EC), 237,3g naquelas do T7(OC+EC) e $228,7 \mathrm{~g}$ nas aves do $\mathrm{T} 8(\mathrm{OC}+\mathrm{EC})$. Nesta semana, assim como, na primeira, as aves que receberam o $\beta$ glucano tiveram o maior peso médio e também ganho de peso.

Quanto ao consumo médio de ração foram esses os resultados: $489,8 \mathrm{~g}$ nas aves do T1(C-), 455,2g; nas aves do T2(C+), 492,36; naquelas do T6(SC+EC), 486,45g; nas aves do T7(OC+EC) e 429,4 naquelas do T8(VO+EC). A conversão alimentar foi melhor nas aves do T8(VO+EC), 1,89, seguido pelas aves do T7(OC+EC) com índice de 2,05. As aves do T1(C-) e do T6(SC+EC) apresentaram a mesma conversão alimentar, 2,28 e as aves do $\mathrm{T} 5(\mathrm{C}+), 2,29$.

Os dados zootécnicos da segunda semana de criação das aves são mostrados na tabela 25. 
Tabela 25 - Análise descritiva dos parâmetros zootécnicos na segunda semana de idade (médias \pm desvio padrão)

\begin{tabular}{ccccc}
\hline Tratamento & PM (g) & GP (g) & CM (g) & CA \\
\hline T1(C-) & $367,10 \pm 2,97$ & $214,35 \pm 0,92$ & $489,8 \pm 35,0$ & $2,28 \pm 0,24$ \\
T5(C+) & $346,4 \pm 18,6$ & $199,6 \pm 21,1$ & $455,2 \pm 0,85$ & $2,29 \pm 0,24$ \\
T6(SC+EC) & $374,36 \pm 13,80$ & $216,5 \pm 15,5$ & $492,36 \pm 10,25$ & $2,28 \pm 0,21$ \\
T7(OC+EC) & $397,55 \pm 4,17$ & $237,3 \pm 4,67$ & $486,45 \pm 14,07$ & $2,05 \pm 0,10$ \\
T8(VO+EC) & $387,2 \pm 16,9$ & $228,7 \pm 16,7$ & $429,4 \pm 19,7$ & $1,89 \pm 0,07$ \\
\hline PM=peso médio; GP=ganho de peso; CM=consumo médio; CA=conversão alimentar
\end{tabular}

Aos 14 dias de idade foi feito o desafio com E. coli, portanto na semana 3 as aves do T5 ao T8 estavam infectadas e observou-se resultados com diferenças expressivas em relação as aves do $\mathrm{T} 1(\mathrm{C}-)$.

$\mathrm{O}$ peso médio nas aves do T1(C-) na terceira semana foi de $738,9 \mathrm{~g}$ e naquelas do T2 $\left(\mathrm{C}_{+}\right), 578 \mathrm{~g}$. As aves dos tratamentos que receberam o $\beta$-glucano e foram desafiados tiveram os seguintes resultados: T6(SC+EC), 572,65g; T7(OC+EC), 586,0g e o T8(VO+EC), 574,8g.

O ganho de peso médio foi: $371,8 \mathrm{~g}$ nas aves do T1(C-), $232 \mathrm{~g}$ nas aves do T5(C+), 198,29g nas aves do T6(SC+EC), 188,5g nas aves do T7(OC+EC), e 187,7g nas aves do T8(VO+EC). O consumo de ração nas aves do T1(C-) foi de 655,5g, nas aves do T5(C+) de 316,6g. As aves do T6(SC+EC) consumiram em média 332,8 $\mathrm{g}$, aquelas do T7(OC+EC) 395,9g, e as do T8(OC+EC), 393,5g.

Em relação à conversão alimentar nas aves do $\mathrm{T1}$ (C-) foi de 1,76, nas aves do $\mathrm{T} 5\left(\mathrm{C}_{+}\right) 2,06$, sendo está a melhor conversão dentre os grupos desafiados. As aves dos tratamentos $\mathrm{T} 6(\mathrm{SC}+\mathrm{EC}), \mathrm{T} 7(\mathrm{OC}+\mathrm{EC})$ e $\mathrm{T} 8(\mathrm{VO}+\mathrm{EC})$ tiveram índices de $2,25,2,11$ e 2,57, respectivamente. Os dados relativos a esta semana estão descritos na tabela 26 .

Tabela 26 - Análise descritiva dos parâmetros zootécnicos na terceira semana de idade (médias \pm desvio padrão)

\begin{tabular}{ccccc}
\hline Tratamento & $\mathbf{P M}(\mathbf{g})$ & $\mathbf{G P}(\mathbf{g})$ & $\mathbf{C M}(\mathbf{g})$ & $\mathbf{C A}$ \\
\hline T1(C-) & $738,9 \pm 16,3$ & $371,8 \pm 19,2$ & $655,5 \pm 12,7$ & $1,76 \pm 0,04$ \\
T5(C+) & $578,0 \pm 125,3$ & $232 \pm 144$ & $316,6 \pm 39,9$ & $2,06 \pm 1,47$ \\
T6(SC+EC) & $572,65 \pm$ & $198,29 \pm 3,22$ & $332,8107,9$ & $2,25 \pm 0,09$ \\
T7(OC+EC) & $586,0 \pm 19,2$ & $188,5 \pm 23,4$ & $395,9 \pm 18,6$ & $2,11 \pm 0,16$ \\
T8(VO+EC) & $574,8 \pm 34,4$ & $187,7 \pm 17,5$ & $393,5 \pm 16,0$ & $2,57 \pm 0,40$ \\
\hline
\end{tabular}

$\mathrm{PM}=$ peso médio; $\mathrm{GP}=$ ganho de peso; $\mathrm{CM}=$ consumo médio; $\mathrm{CA}=$ conversão alimentar

$\mathrm{Na}$ quarta semana as aves do controle negativo tiveram peso médio de $1219 \mathrm{~g}$ e conversão alimentar de 2,04. Quanto as aves dos tratamentos desafiados o peso 
médio foi: $937,1 \mathrm{~g}$ no T5(C+), 1040g no T6(SC+EC), $1064 \mathrm{~g}$ no T7(OC+EC) e 1094,7g no T8(VO+EC).

O tratamento que menos ganhou peso nesta a semana foram as aves do $\mathrm{T} 5(\mathrm{C}+)$, 359,1g. As aves do T6(SC+EC) ganharam 467,4g, aquelas do T7(OC+EC), $478,0 \mathrm{~g}$ e as do T8(VO+EC), 519,8g. O consumo médio de ração pelas aves do $\mathrm{T} 5(\mathrm{C}+)$ foi $842 \mathrm{~g}$ e pelas aves do T6(SC+EC), 959,8g. Nas aves do T7(SC+EC) e do T8(VO+EC) o consumo foi de 875,9 e 892,6g, respectivamente.

A conversão alimentar foi de 2,42 nas aves do $T 5(C+), 2,05$; nas aves do T6(SC+EC), 1,83; nas aves do T7(OC+EC) e 1,72 nas aves do T8(VO+EC). Os resultados são mostrados na tabela 27 .

Tabela 27 - Análise descritiva dos parâmetros zootécnicos na quarta semana de idade (médias \pm desvio padrão)

\begin{tabular}{ccccc}
\hline Tratamento & PM (g) & GP $(\mathbf{g})$ & CM $(\mathbf{g})$ & CA \\
\hline T1(C-) & $1219,8 \pm 41,7$ & $480,9 \pm 25,5$ & $983,0 \pm 21,5$ & $2,04 \pm 0,04$ \\
T5(C+) & $937,1 \pm 23,1$ & $359,1 \pm 102,1$ & $842,0 \pm 57,6$ & $2,42 \pm 0,53$ \\
T6(SC+EC) & $1040,0 \pm 0,41$ & $467,4 \pm 10,99$ & $959,8 \pm 18,0$ & $2,05 \pm 0,09$ \\
T7(OC+EC) & $1064,0 \pm 0,6$ & $478,0 \pm 19,8$ & $875,9 \pm 26,1$ & $1,83 \pm 0,13$ \\
T8(VO+EC) & $1094,7 \pm 56,8$ & $519,8 \pm 22,4$ & $892,6 \pm 58,5$ & $1,72 \pm 0,04$ \\
\hline PM=peso médio; GP=ganho de peso; CM=consumo médio; CA=conversão alimentar
\end{tabular}

Na quinta semana experimental as aves do T1(C-) apresentavam peso médio de $1780,8 \mathrm{~g}$. Os resultados zootécnicos desta semana foram descritos na tabela 28. O peso médio das aves nos tratamentos desafiados foi: $1287 \mathrm{~g}$ no T2(C+), 1525,6 no T6(SC+EC), 1527,3g no T7(OC+EC) e 1605,5g no T8(VO+EC). O ganho de peso foi de 581,8g nas aves do T2(C+), 485,6g; nas aves do T6(SC+EC), 463,3g; nas aves do T7(OC+EC) e de 510,9g nas aves do T8(VO+EC).

As aves do T6(SC+EC) consumiram mais ração nesta semana, $1450 \mathrm{~g}$. Em ordem decrescente os demais consumos foram: 1416,7g nas aves do T8(VO+EC), 1300,1g; nas aves do T1(C-), 1050,0g; nas aves do T7(OC+EC) e 932g nas aves do $\mathrm{T} 5(\mathrm{C}+)$. Quanto à conversão alimentar as aves do T1(C-) tiveram índice de 2,32, aquelas do $\mathrm{T} 5(\mathrm{C}+)$ 2,84, as do $\mathrm{T} 6(\mathrm{SC}+\mathrm{EC}) 3,15$, as aves do $\mathrm{T} 7(\mathrm{OC}+\mathrm{EC}) 2,28 \mathrm{e}$ aquelas do T8(VO+EC) 2,77, sendo, portanto o melhor resultado o encontrado com as aves do $\mathrm{T} 7(\mathrm{OC}+\mathrm{EC})$. 
Tabela 28 - Análise descritiva dos parâmetros zootécnicos na quinta semana de idade (médias \pm desvio padrão)

\begin{tabular}{ccccc}
\hline Tratamento & PM (g) & GP $(\mathbf{g})$ & CM $(\mathbf{g})$ & CA \\
\hline T1(C-) & $1780,8 \pm 34,4$ & $560,95 \pm 7,28$ & $1300,1 \pm 5,35$ & $2,32 \pm 0,02$ \\
T5(C+) & $1287 \pm 176$ & $581,8 \pm 129,5$ & $932,0 \pm 501$ & $2,84 \pm 0,30$ \\
T6(SC+EC) & $1525,6 \pm 45,2$ & $485,6 \pm 45,6$ & $1450,0 \pm 70,7$ & $3,15 \pm 0,23$ \\
T7(OC+EC) & $1527,3 \pm 64,2$ & $463,3 \pm 64,8$ & $1050,0 \pm 70,7$ & $2,28 \pm 0,17$ \\
T8(VO+EC) & $1605,5 \pm 36,5$ & $510,9 \pm 20,3$ & $1416,7 \pm 117,9$ & $2,77 \pm 0,12$ \\
\hline PM=peso médio; GP=ganho de peso; CM=consumo médio; CA=conversão alimentar
\end{tabular}

Na última semana de criação as aves do T1(C-) tinham peso médio de $2426 \mathrm{~g}$, do T5(C+) 2105g, do T6(SC+EC) 1968,3g, do T7(OC+EC) 2067,6g e as do T8(VO+EC) 2233,9g. Com relação ao ganho de peso as aves do T8(VO+EC) foram as que ganharam mais peso dentre os tratamentos desafiados $(540,3 \mathrm{~g})$. As aves do T6(SC+EC) ganharam menos peso esta semana, $443 \mathrm{~g}$, sendo que as aves do T5(C+) tiveram ganho de $586 \mathrm{~g}$ e aquelas do T7 540,3g de ganho de peso médio.

O consumo médio de ração foi de $1561 \mathrm{~g}$ nas aves do T1(C-). Nas aves dos demais tratamentos variaram o consumo médio entre 1098,71g no T5(C+) e 1435,7g no T7(OC+EC). Nas aves do T6(SC+EC) o consumo foi de 1115,2 e naquelas do T8(VO+EC) de 1265,4g. A conversão alimentar foi melhor nas aves do T5(C+) com índice de 1,98. As aves do T8(VO+EC) tiveram conversão de 2,01, aquelas do $\mathrm{T} 6$ (SC+EC) 2,05, as aves do T1(C-) 2,42 e aquelas do $\mathrm{T} 7(\mathrm{OC}+\mathrm{EC}) 2,89$. Os resultados estão expostos na tabela 29.

\begin{tabular}{|c|c|c|c|c|}
\hline Tratamento & PM (g) & GP (g) & CM (g) & CA (g) \\
\hline T1(C-) & $2426,3 \pm 24,5$ & $645,5 \pm 9,9$ & $1561,0 \pm 5,70$ & $2,42 \pm 0,02$ \\
\hline T5(C+) & $2105 \pm 221$ & $586,0 \pm 68,1$ & $1098,71,82$ & $1,98 \pm 0,08$ \\
\hline T6(SC+EC) & $\begin{array}{c}1968,3 \pm \\
122,3\end{array}$ & $443 \pm 167$ & $\begin{array}{c}1115,2 \pm \\
127,2\end{array}$ & $2,05 \pm 0,02$ \\
\hline \multirow{2}{*}{$\begin{array}{l}\text { T7(OC+EC) } \\
\text { T8(VO+EC) }\end{array}$} & $2067,6 \pm 12,2$ & $540,3 \pm 76,4$ & $1435,7 \pm 2,54$ & $2,89 \pm 0,08$ \\
\hline & $2233,9 \pm 29,9$ & $628,33 \pm 6,6$ & $\begin{array}{c}1265,4 \pm \\
116,8\end{array}$ & $2,01 \pm 0,21$ \\
\hline
\end{tabular}

Pode-se observar que as aves do $\mathrm{T} 5\left(\mathrm{C}_{+}\right)$apresentaram menor peso médio nas duas primeiras semanas de idade, enquanto o maior peso médio foram o das aves do $\mathrm{T} 7(\mathrm{OC}+\mathrm{EC})$. As tabelas 24 e 25 mostram estes resultados. Após o desafio com E. coli, partir da terceira semana de idade, as aves do T1(C-) mantiveram o maior peso médio até o fim do experimento. Dentre os grupos de aves infectadas com E. coli, na terceira semana de idade, o maior peso médio foi obtido com as aves 
do $\mathrm{T} 7(\mathrm{OC}+\mathrm{EC})$ e o menor com as aves do $\mathrm{T} 6(\mathrm{SC}+\mathrm{EC})$, estes resultados se encontram na tabela 26.

$\mathrm{Na}$ quarta, quinta e sexta semana de idade o maior peso médio dentre os grupos desafiados foi obtido com as aves do T8(VO+EC). As aves do T5(C+) apresentaram o menor peso médio tanto na quarta quanto na quinta semana de idade. Na sexta semana de idade as aves do T2 (SC+EC) foram as que apresentaram o menor peso. Os resultados relativos aos pesos médios das aves estão ilustrados na figura 21.

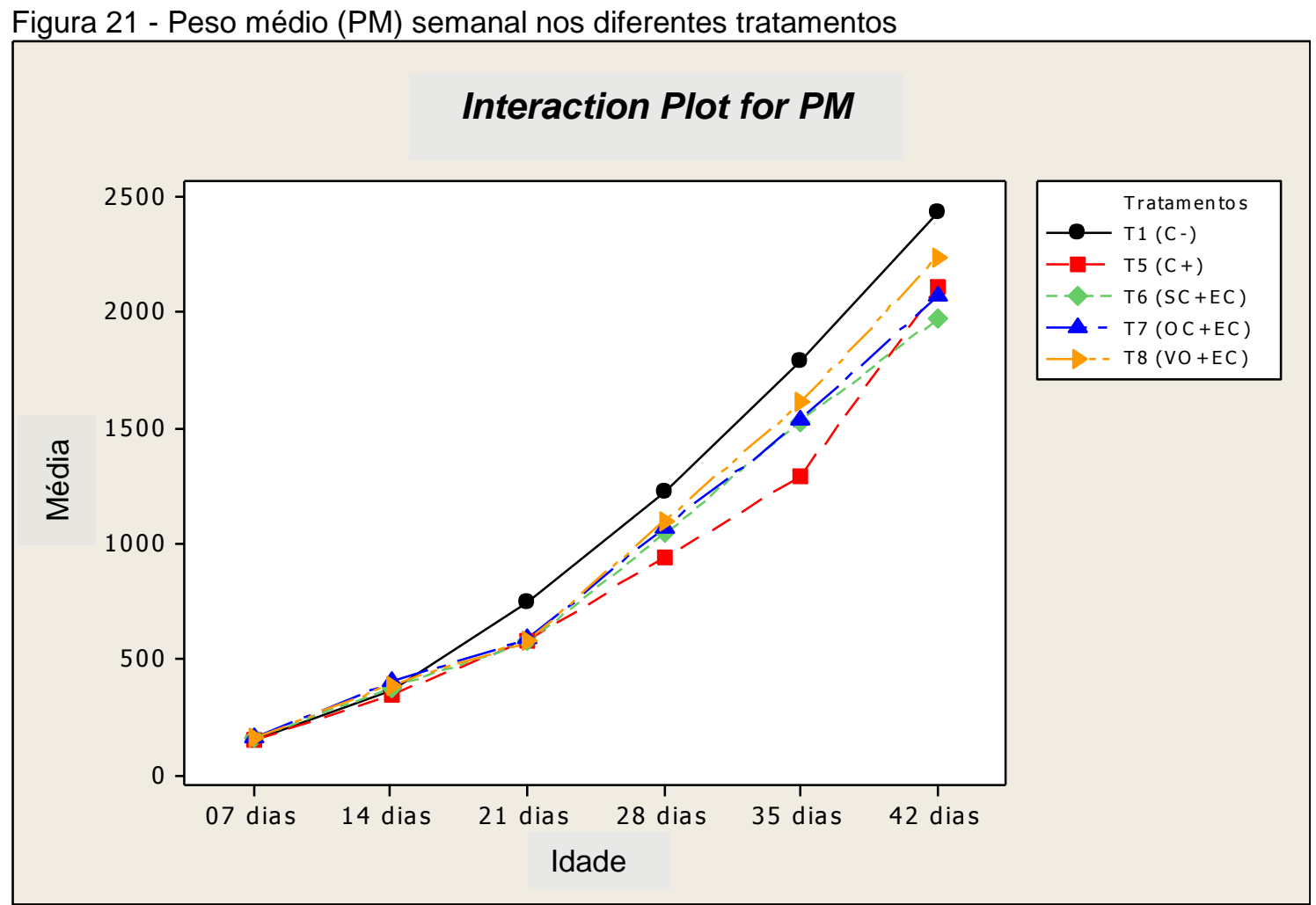

Ocorreu uma grande variação de pesos entre os grupos estudados quanto ao ganho de peso semanal das aves, especialmente após a terceira semana de idade quando as aves haviam sido inoculadas com E. coli. A figura 22 mostra a cinética de ganho de peso das aves.

Nas duas primeiras semanas de idade as aves do T6(SC+EC) foram as que tiveram o maior consumo médio de ração (Tabelas 24 e 25). Nas demais semanas do experimento as aves do T1(C-) consumiram mais ração. A figura 23 mostra a variação de consumo médio de ração entre as aves que foram infectadas com $E$. coli. 
Figura 22 - Ganho de peso (GP) semanal nos diferentes tratamentos

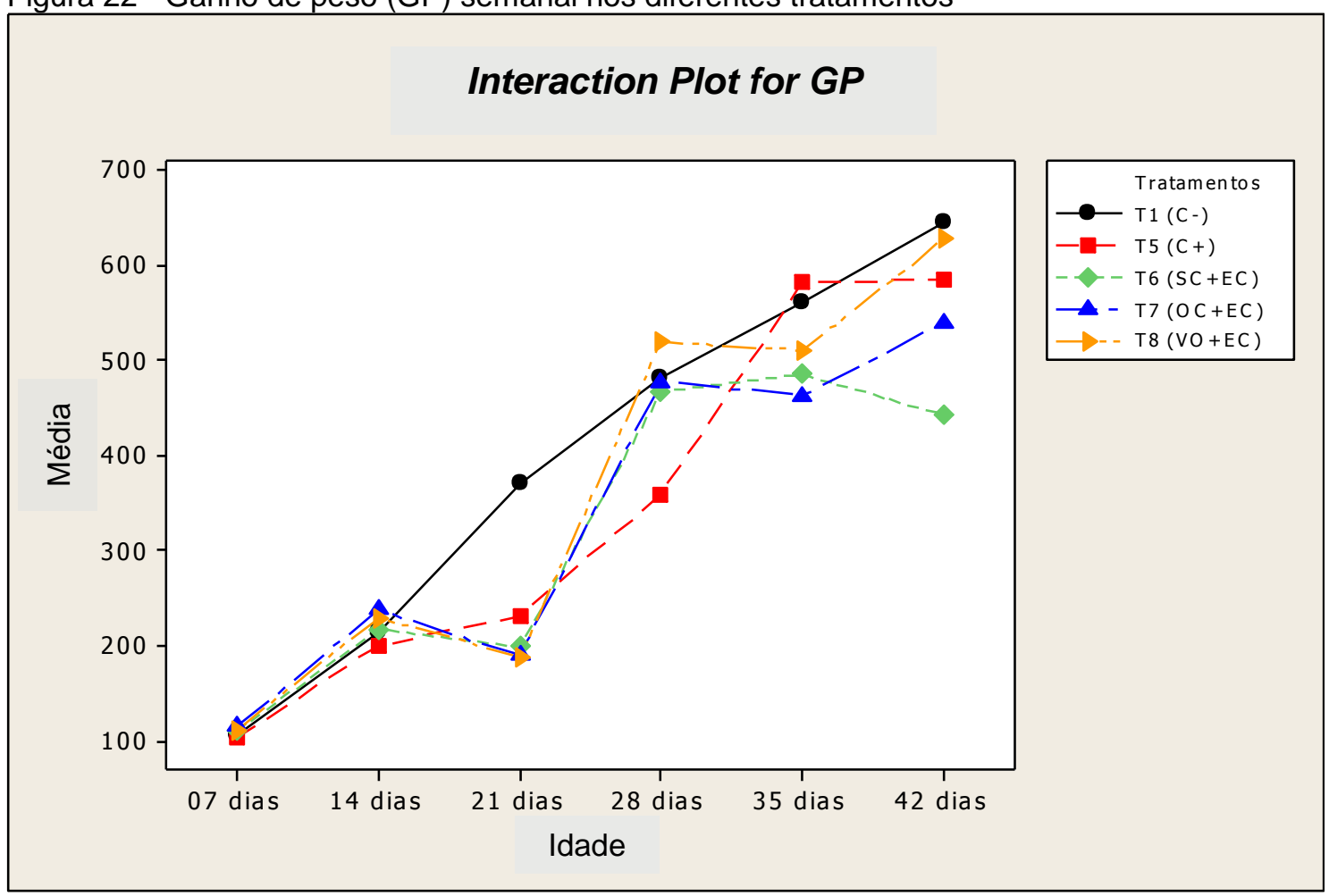

Figura 23 - Consumo médio (CM) semanal nos diferentes tratamentos

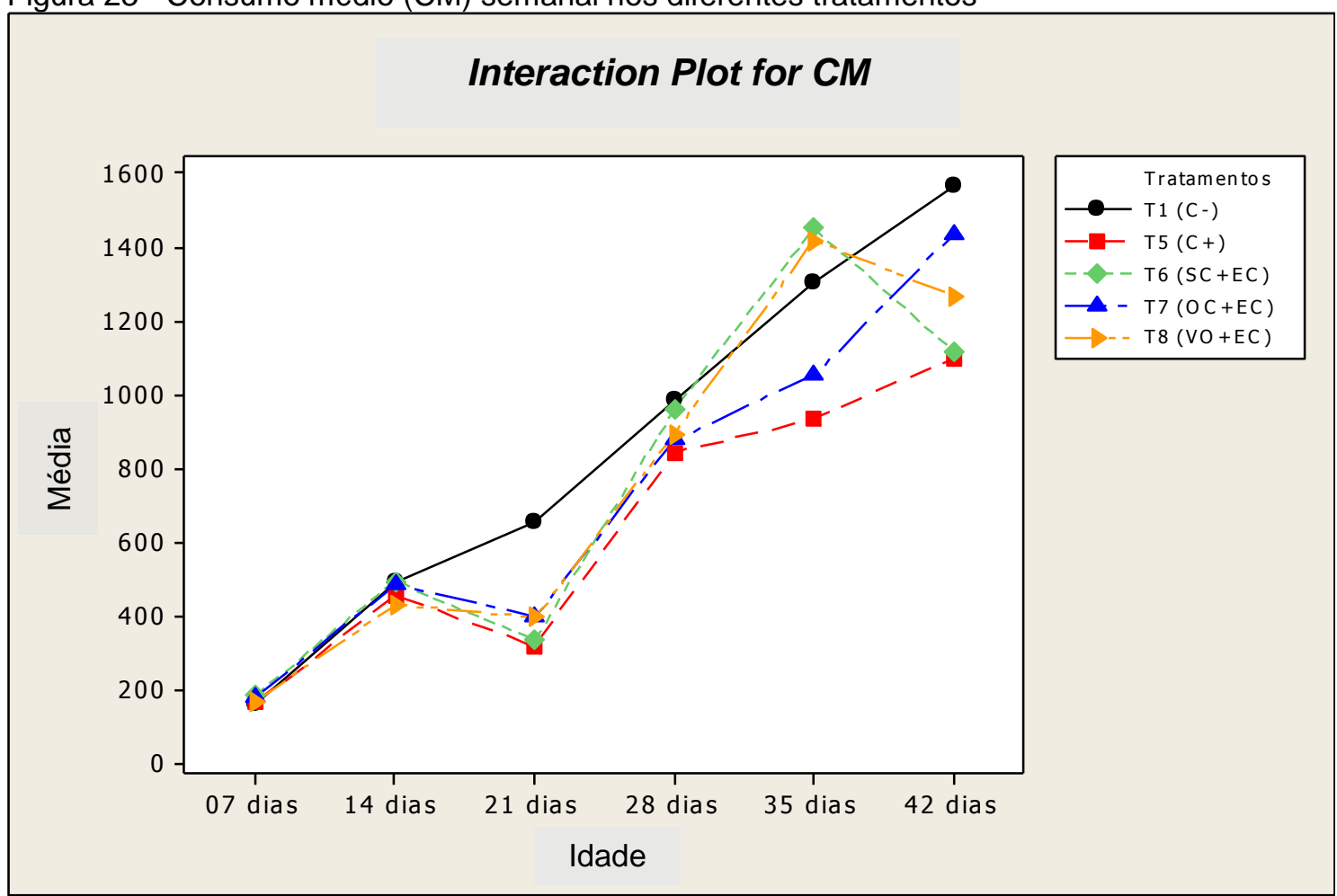


Os resultados semanais relativos a conversão alimentar são mostrados na figura 24. Os resultados dos parâmetros zootécnicos relativos a todo o período experimental estão apresentados na tabela 30 .

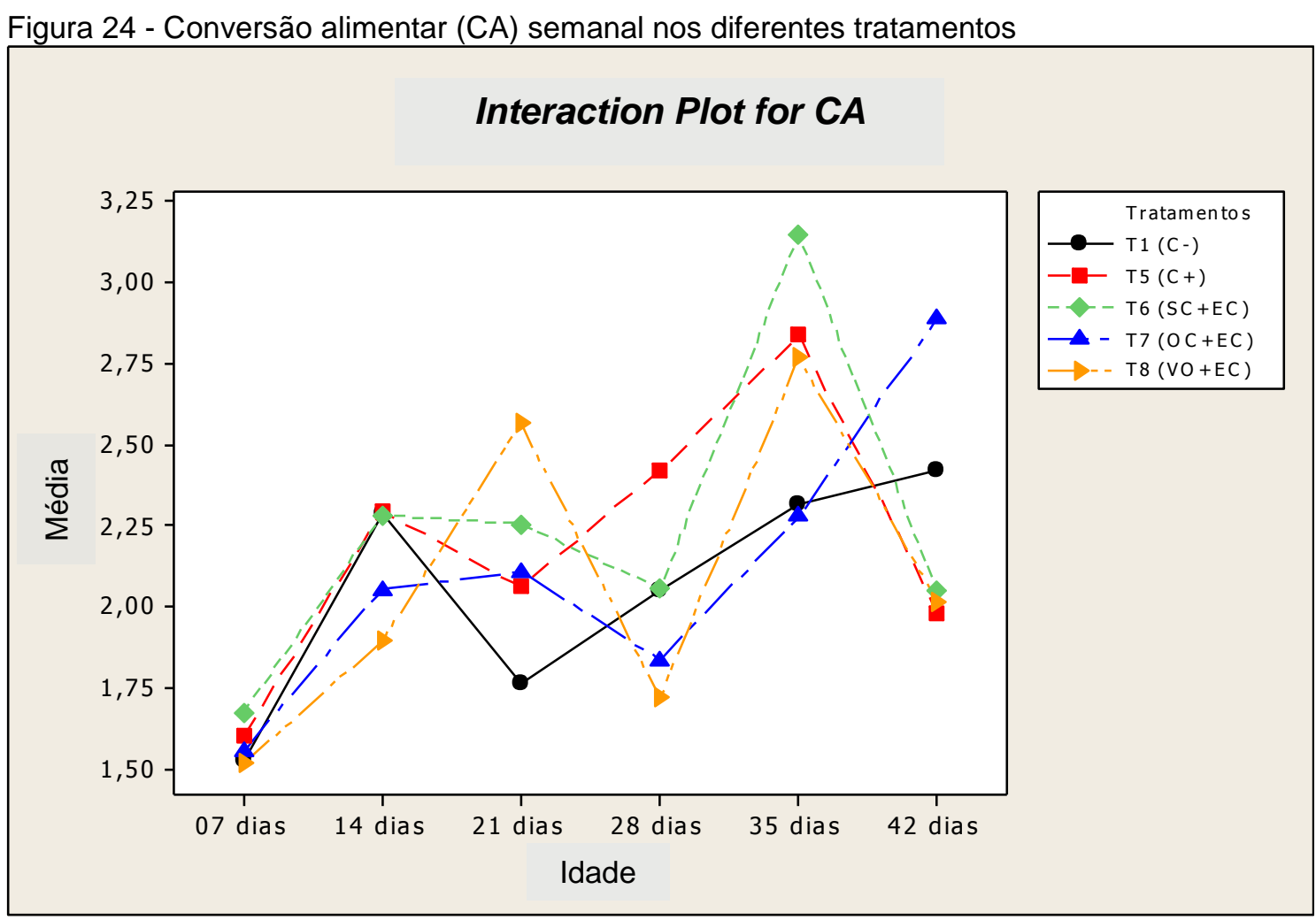

Tabela 30 - Análise descritiva dos parâmetros zootécnicos relativos a todo período experimental (médias das repetições \pm desvio padrão)

\begin{tabular}{cccccc}
\hline Tratamento & GP (g) & GPD (g) & CA & Viabilidade (\%) & IEP \\
\hline T1(C-) & $2379,4 \pm 26,0$ & $56,65 \pm 0,62$ & $2,16 \pm 0,04$ & $100,0 \pm 0,0$ & $261,73 \pm 7,35$ \\
T5(C+) & $2060 \pm 221$ & $49,04 \pm 5,26$ & $2,19 \pm 0,03$ & $60,0 \pm 14,1$ & $132,2 \pm 15,2$ \\
T6(SC+EC) & $1919,7 \pm 121,2$ & $45,71 \pm 2,89$ & $2,31 \pm 0,07$ & $65,0 \pm 21,2$ & $127,8 \pm 37,6$ \\
T7(OC+EC) & $2021,0 \pm 11,5$ & $48,12 \pm 0,27$ & $2,23 \pm 0,03$ & $90,0 \pm 14,1$ & $194,3 \pm 26,9$ \\
T8(VO+EC) & $2186,5 \pm 30,1$ & $52,06 \pm 0,72$ & $2,07 \pm 0,02$ & $50,0 \pm 14,1$ & $125,7 \pm 36,2$ \\
\hline
\end{tabular}

$\mathrm{PM}=$ peso médio; $\mathrm{GP}=$ ganho de peso; $\mathrm{GPD}=$ ganho de peso diário; $\mathrm{CA}=$ conversão alimentar, IEP=Indice de eficiência produtiva

O maior ganho de peso foi encontrado nas aves do T1(C-). Nos grupos desafiados com E. coli, as aves do T8(VO+EC) foram as que apresentaram o maior ganho de peso, 2186,5g. As aves do T5(C+) tiveram ganho de peso de $2060 \mathrm{~g}$, as do T6(SC+EC) 1919,7g e as do T7(OC+EC) 2021 g. A figura 25 mostra os resultados do ganho de peso. Quanto ao ganho de peso diário os resultados foram: $56,65 \mathrm{~g}$ nas 
aves do T1(C-), 49,04g; nas aves do T5(C+), 45,71g; nas aves do T6(SC+EC), 48,12g; nas aves do T7(OC+EC) e 52,06 g nas aves do T8(VO+EC).

Figura 25 - Ganho de peso relativo a todo o período experimental

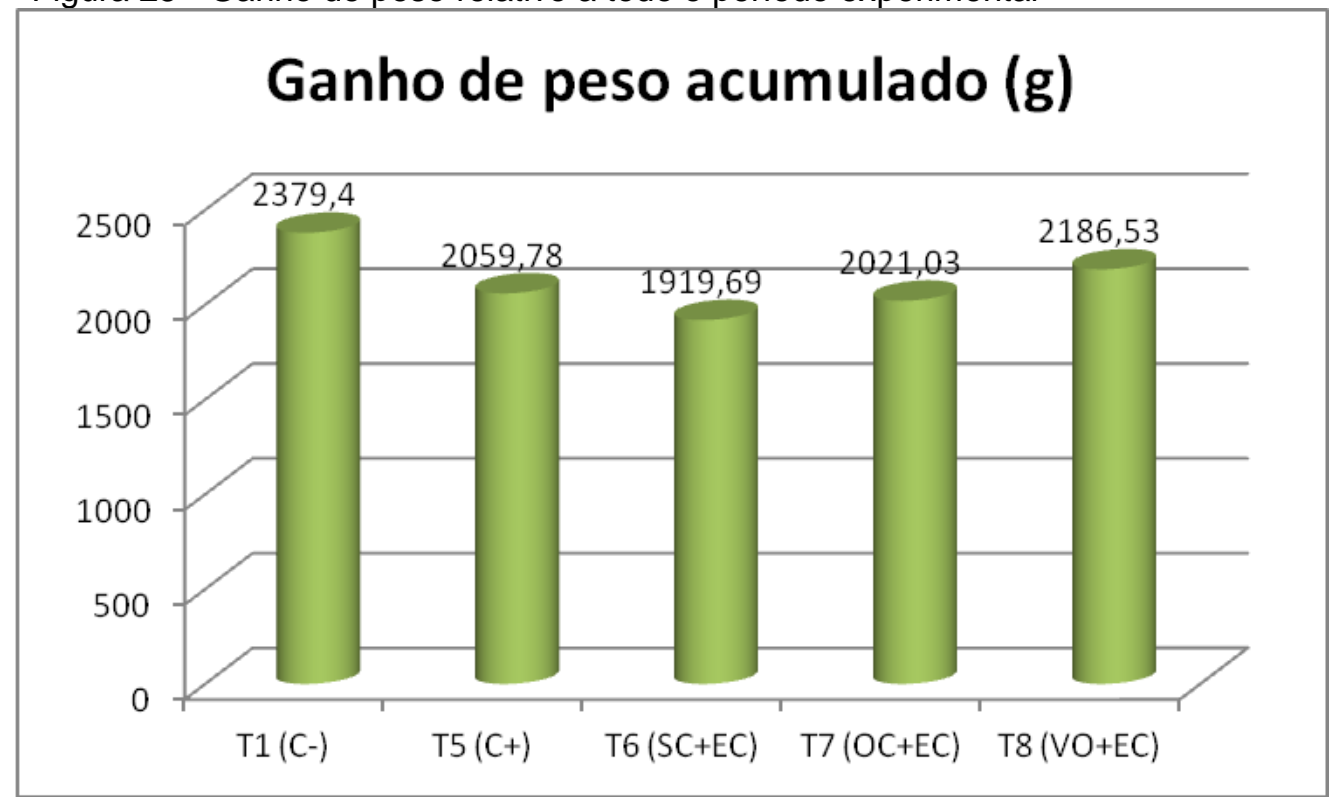

A conversão alimentar foi melhor nas aves do T8(VO+EC), com índice de 2,07. Os resultados das aves dos demais tratamentos foram: 2,16 no T1(C-), 2,19 no $\mathrm{T} 5(\mathrm{C}+), 2,31$ no $\mathrm{T} 6(\mathrm{SC}+\mathrm{EC})$ e 2,23 no $\mathrm{T} 7(\mathrm{OC}+\mathrm{EC})$. A figura 26 ilustra esses resultados.

Figura 26 - Conversão alimentar (CA) acumulada

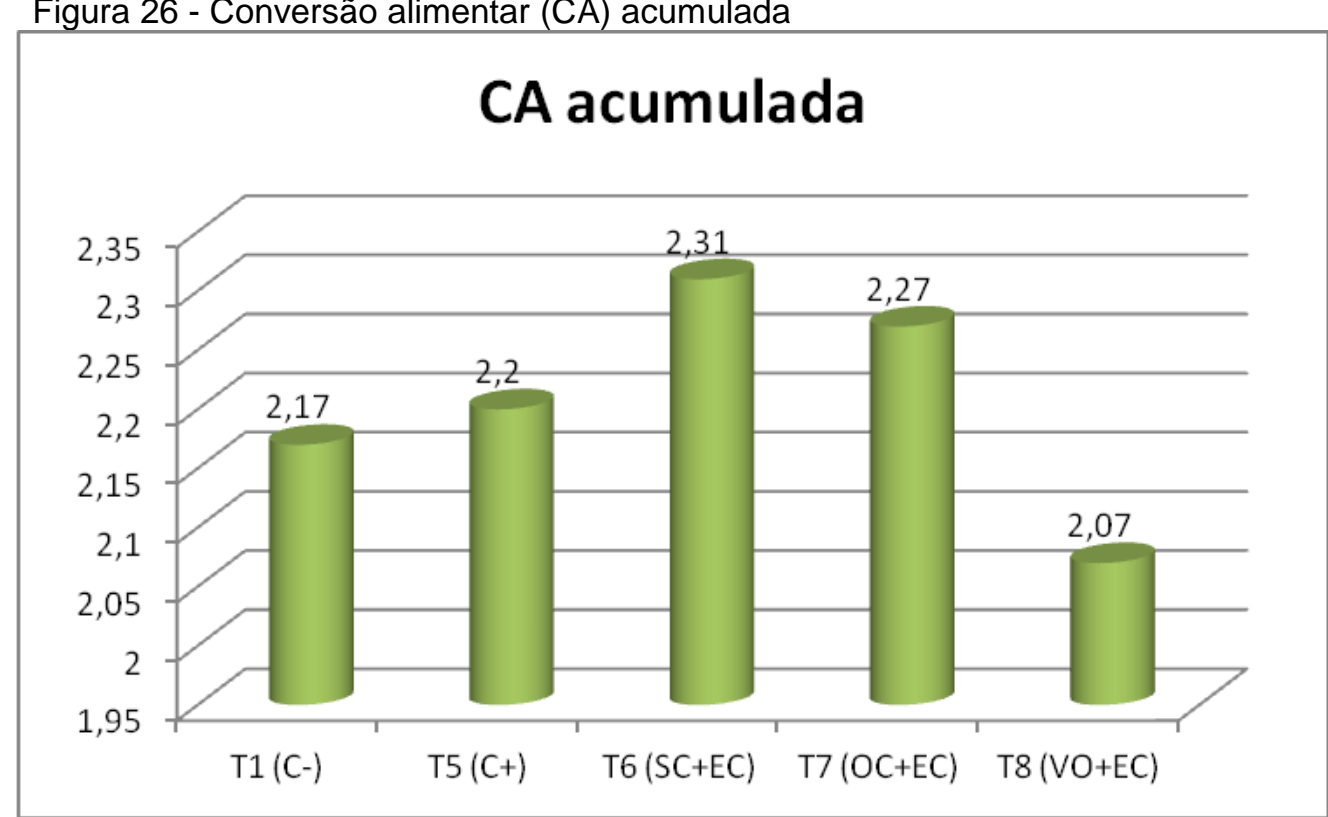


Dentre os grupos desafiados a maior viabilidade foi encontrada nas aves do $\mathrm{T7}(\mathrm{OC}+\mathrm{EC}), 90 \%$. As aves do $\mathrm{T} 5(\mathrm{C}+)$ tiveram $60 \%$ de viabilidade, enquanto nas aves do T6(SC+EC) esta foi de $65 \%$ e nas aves do T8(VO+EC) esta foi de $50 \%$. A figura 27 mostra este resultado. Nas aves do T1(C-) a viabilidade foi de $100 \%$. 0 índice de eficiência produtiva foi maior nas aves do T1(C-), 261,73, e dentre os grupos desafiados com E. coli foi maior nas aves do T7(OC+EC), 194,3. O menor IEP foi encontrado com as aves do T8(VO+EC), 125,7. Os valores encontrados com as aves dos tratamentos T5(C+) (132,2), T6(SC+EC) $(127,8)$ e T8(VO+EC) $(125,7)$ foram semelhantes. Os resultados são ilustrados na figura 28.

Figura 27 - Viabilidade relativa a todo o período experimental

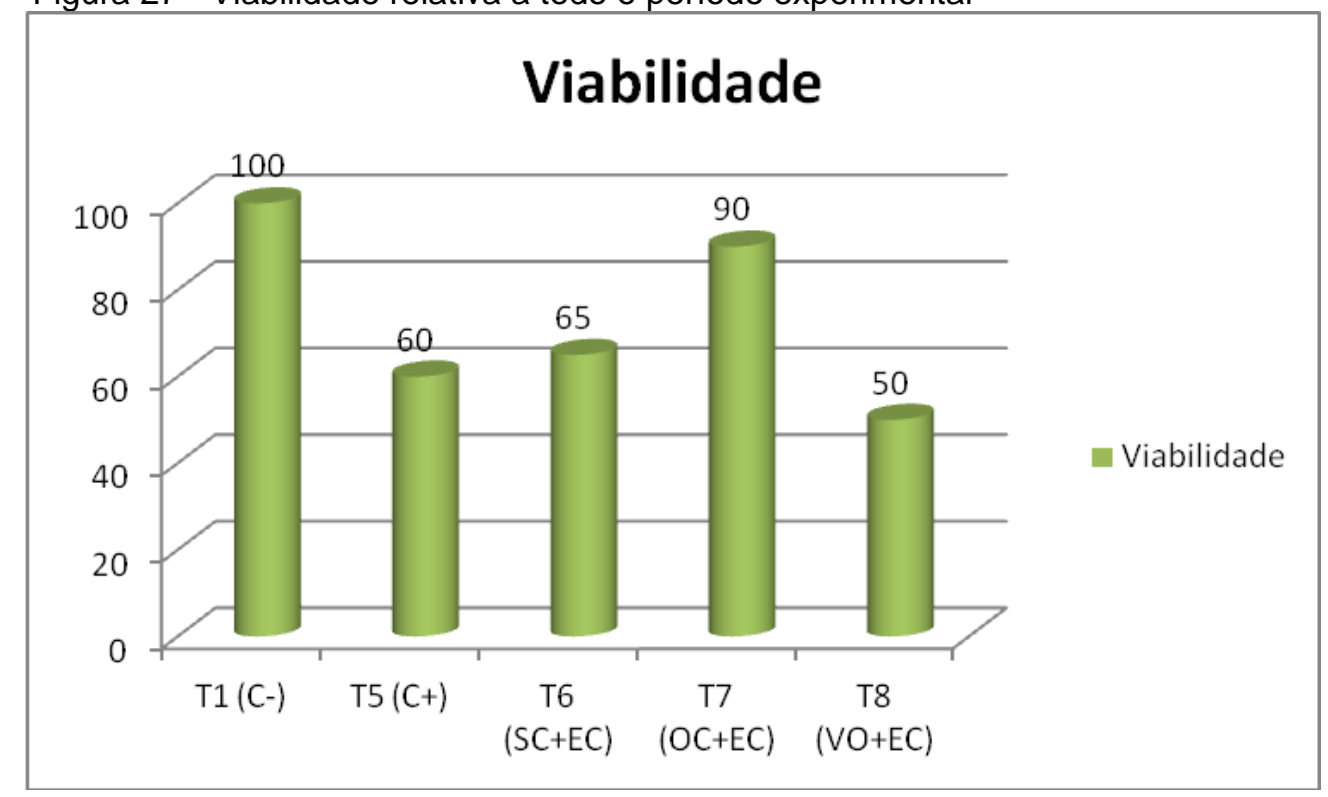

Figura 28 - Índice de Eficiência Produtiva (IEP)

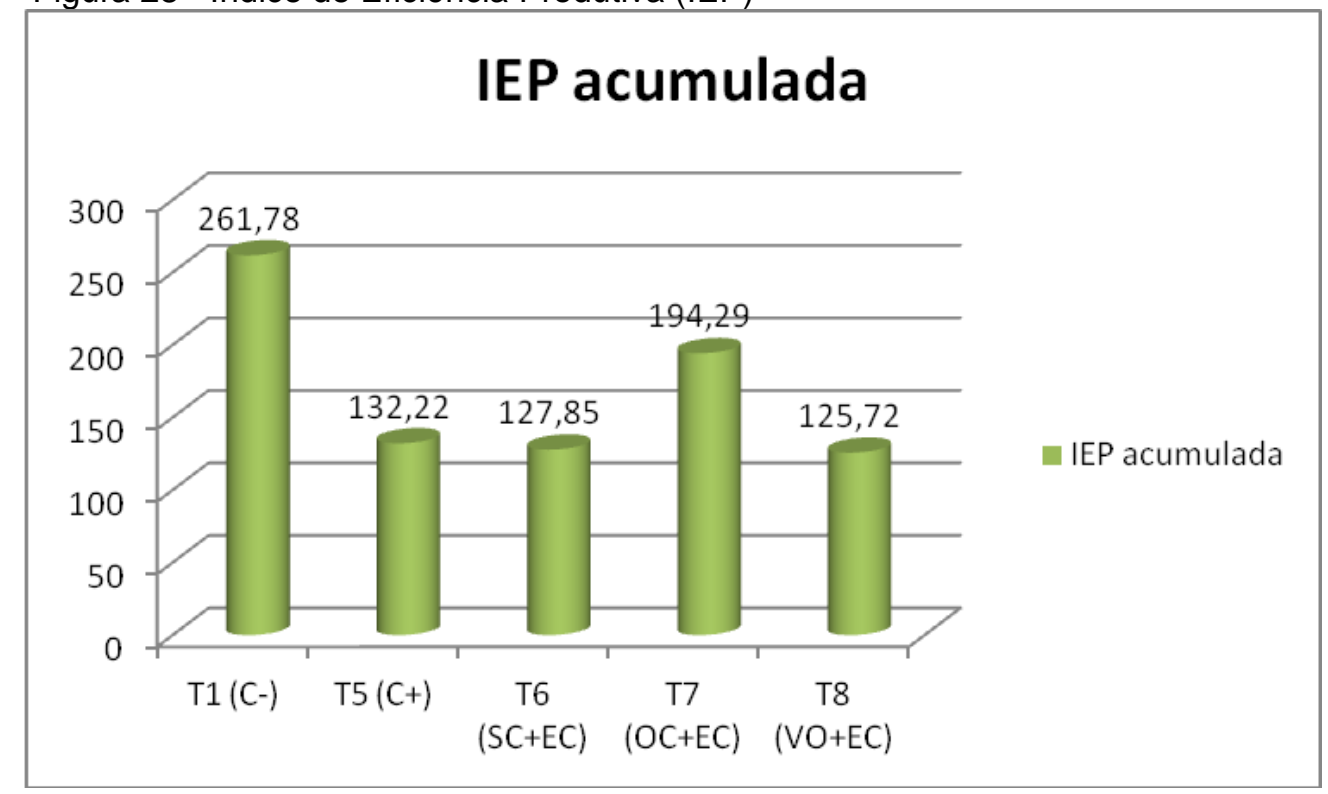




\subsubsection{Escore de Lesão}

O escore de lesões causadas pela E.coli foi avaliado tanto nas aves que morreram após a inoculação como naquelas que foram sacrificadas no último dia do experimento.

Quanto às aves que morreram após a inoculação todas apresentavam lesão em saco aéreo torácico direito, local da inoculação. No entanto, nos sacos aéreos torácico esquerdo e abdominal havia aves sem lesões. Em todas as aves dos tratamentos desafiados havia aves com pericardite. A perihepatite foi menos frequente, ou não havia lesões nas aves do T6(SC+EC) e do T7(OC+EC). Os dados estão expostos nas tabelas 31 e 32 .

As aves que foram sacrificadas aos 42 dias de idade apresentavam lesões, principalmente, em saco aéreo torácico direito e também em sacos aéreos torácicos esquerdos. Quanto ao saco aéreo abdominal a porcentagem de lesão foi baixa. Havia também presença reduzida de lesão no fígado. A presença de pericardite foi expressiva nas aves do T7(OC+EC) e naquelas do T8(VO+EC). As tabelas 33 e 34 mostram os dados.

Tabela 31 - Porcentagem de aves que morreram após o desafio com lesões em sacos aéreos classificadas em um escore de 0 a 4

\begin{tabular}{|c|c|c|c|c|c|c|c|c|c|c|c|c|c|c|c|c|}
\hline \multirow{2}{*}{ Tratamento } & \multirow{2}{*}{$\mathbf{n}$} & \multicolumn{5}{|c|}{ Saco aéreo toracico direito } & \multicolumn{5}{|c|}{ Saco aéreo torácico esquerdo } & \multicolumn{5}{|c|}{ Saco aéreo Abdominal } \\
\hline & & 0 & 1 & 2 & 3 & 4 & 0 & 1 & 2 & 3 & 4 & 0 & 1 & 2 & 3 & 4 \\
\hline T1(C-) & 0 & 0 & 0 & 0 & 0 & 0 & 0 & 0 & 0 & 0 & 0 & 0 & 0 & 0 & 0 & 0 \\
\hline T5(C+) & 7 & 0 & 0 & 0 & 100 & 0 & 14,29 & 28,57 & 42,86 & 14,29 & 0 & 28,57 & 14,29 & 28,57 & 28,57 & 0 \\
\hline T6(SC+EC) & 8 & 0 & 12,5 & 12,5 & 75 & 0 & 37,5 & 37,5 & 12,5 & 12,5 & 0 & 50 & 25 & 25 & 0 & 0 \\
\hline T7(OC+EC) & 2 & 0 & 0 & 50 & 50 & 0 & 50 & 0 & 50 & 0 & 0 & 100 & 0 & 0 & 0 & 0 \\
\hline T8(VO+EC) & 9 & 0 & 0 & 33,33 & 66,67 & 0 & 22,22 & 66,67 & 11,11 & 0 & 0 & 44,44 & 44,44 & 11,11 & 0 & \\
\hline
\end{tabular}

Tabela 32 - Porcentagem de aves que morreram após o desafio com lesões em coração e fígado classificadas em um escore de 0 a 4

\begin{tabular}{c|c|ccccc|cccccc}
\hline \multirow{2}{*}{ Tratamento } & $\mathbf{n}$ & $\mathbf{7}$ & \multicolumn{7}{c}{ Perichepatite } \\
\cline { 3 - 12 } & & $\mathbf{0}$ & $\mathbf{1}$ & $\mathbf{2}$ & $\mathbf{3}$ & $\mathbf{4}$ & $\mathbf{0}$ & $\mathbf{1}$ & $\mathbf{2}$ & $\mathbf{3}$ & $\mathbf{4}$ \\
\hline T1(C-) & 0 & 0 & 0 & 0 & 0 & 0 & 0 & 0 & 0 & 0 & 0 \\
T5(C+) & 7 & 14,29 & 14,29 & 14,29 & 57,14 & 0 & 57,14 & 0 & 14,29 & 14,29 & 14,29 \\
T6(SC+EC) & 8 & 12,5 & 0 & 50 & 37,5 & 0 & 100 & 0 & 0 & 0 & 0 \\
T7(OC+EC) & 2 & 0 & 50 & 50 & 0 & 0 & 100 & 0 & 0 & 0 & 0 \\
T8(VO+EC) & 9 & 22,22 & 44,44 & 22,22 & 11,11 & 0 & 66,67 & 11,11 & 22,22 & 0 & 0 \\
\hline
\end{tabular}


Tabela 33 - Porcentagem de aves sacrificadas aos 42 dias com lesões em sacos aéreos classificadas em escore de 0 a 4

\begin{tabular}{|c|c|c|c|c|c|c|c|c|c|c|c|c|c|c|c|c|}
\hline \multirow{2}{*}{ Tratamento } & \multirow{2}{*}{$n$} & \multicolumn{5}{|c|}{ Saco aéreo torácico direito } & \multicolumn{5}{|c|}{ Saco aéreo torácico esquerdo } & \multicolumn{5}{|c|}{ Saco aéreo Abdomina } \\
\hline & & 0 & 1 & 2 & 3 & 4 & 0 & 1 & 2 & 3 & 4 & 0 & 1 & 2 & 3 & 4 \\
\hline T1(C-) & 20 & 90 & 10 & v & 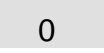 & 0 & 95 & 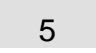 & 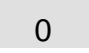 & $v$ & 0 & 100 & 0 & 0 & 0 & 0 \\
\hline T5(C+) & 12 & 8,33 & 41,67 & 25 & 25 & 0 & 16,67 & 33,33 & 50 & 0 & 0 & 91,67 & 8,33 & 0 & 0 & 0 \\
\hline $\mathrm{T} 6(\mathrm{SC}+\mathrm{EC})$ & 12 & 0 & 33,33 & 33,33 & 25,00 & 8,33 & 16,67 & 41,67 & 25,00 & 8,33 & 8,33 & 91,67 & 8,33 & 0 & 0 & 0 \\
\hline $\mathrm{T7}(\mathrm{OC}+\mathrm{EC})$ & 18 & 5,56 & 50,00 & 33,33 & 11,11 & 0 & 16,67 & 83,33 & 0 & 0 & 0 & 100 & 0 & 0 & 0 & 0 \\
\hline $\mathrm{T} 8(\mathrm{VO}+\mathrm{EC})$ & 10 & 0 & 40 & 50 & 10 & 0 & 20 & 60 & 20 & 0 & 0 & 90 & 10 & 0 & 0 & 0 \\
\hline
\end{tabular}

Tabela 34 - Porcentagem de aves sacrificadas aos 42 dias com lesões em coração e fígado classificadas em escore de 0 a 4

\begin{tabular}{c|c|ccccc|ccccc}
\hline \multirow{2}{*}{ Tratamento } & \multirow{4}{*}{$\mathbf{n}$} & $\mathbf{4}$ & Pericardite & \multicolumn{5}{c}{ Perihepatite } \\
\cline { 3 - 11 } & & $\mathbf{0}$ & $\mathbf{1}$ & $\mathbf{2}$ & $\mathbf{3}$ & $\mathbf{4}$ & $\mathbf{0}$ & $\mathbf{1}$ & $\mathbf{2}$ & $\mathbf{3}$ & $\mathbf{4}$ \\
\hline T1(C-) & 20 & 100 & 0 & 0 & 0 & 0 & 100 & 0 & 0 & 0 & 0 \\
T5(C+) & 12 & 41,67 & 16,67 & 33,33 & 8,33 & 0 & 66,67 & 33,33 & 0 & 0 & 0 \\
T6(SC+EC) & 12 & 50 & 16,67 & 25 & 8,33 & 0 & 75 & 25 & 0 & 0 & 0 \\
T7(OC+EC) & 18 & 11,11 & 44,44 & 33,33 & 11,11 & 0 & 94,44 & 5,56 & 0 & 0 & 0 \\
T8(VO+EC) & 10 & 20 & 20 & 50 & 10 & 0 & 100 & 0 & 0 & 0 & 0 \\
\hline
\end{tabular}

$\mathrm{Na}$ tabela 35 se apresenta o grau de escore de lesão tanto das aves que morreram como o das que foram sacrificadas. Esses resultados são ilustrados na figura 29.

Quanto ao saco aéreo torácico direito o maior grau de lesão foi encontrado nas aves do T6(SC+EC), 2,30. As aves do T5(C+) e as do T8(VO+EC) tiveram 2,16 e aquelas do $T 7(\mathrm{OC}+\mathrm{EC}) 1,6$.

Duas aves do $\mathrm{T} 1(\mathrm{C}-)$ apresentaram leve opacidade no saco aéreo torácico direito, por isso o grau de lesão foi de 0,10. O mesmo ocorreu no saco aéreo torácico esquerdo, onde houve lesão em uma ave do T1(C-), levando ao resultado de 0 ,05. Nos demais locais analisados não ocorreu lesão nas aves do T1(C-).

No saco aéreo abdominal as aves do $\mathrm{T} 5(\mathrm{C}+)$ tiveram o maior grau de lesão, 0,67 . As aves do $T 7(O C+E C)$ não apresentaram lesão, enquanto aquelas do $\mathrm{T} 6(\mathrm{SC}+\mathrm{EC})$ e do T8(VO+EC) tiveram respectivamente grau de lesão de 0,35 e 0,37.

Quanto à pericardite os resultados foram os seguintes: 1,47 nas aves do $\mathrm{T} 5(\mathrm{C}+), 1,40$; nas aves do T6(SC+EC), 1,45; nas aves do T7(OC+EC) e 1,37 nas aves do T8(VO+EC). Observou-se pequena variação entre os tratamentos. As aves do $\mathrm{T} 5(\mathrm{C}+)$ tiveram maior grau de perihepatite, 0,47. Enquanto as aves do $\mathrm{T7}(\mathrm{OC}+\mathrm{EC})$ apresentaram o menor grau, 0,05. As aves do T6(SC+EC) tiveram 0,15 e aquelas do T8(VO+EC) 0,26. 
Tabela 35 - Grau de Escore de lesão das aves que morreram após o desafio e que foram sacrificadas aos 42 dias

\begin{tabular}{cccccc}
\hline Tratamento & $\begin{array}{c}\text { Saco aéreo } \\
\text { torácio direito }\end{array}$ & $\begin{array}{c}\text { Saco aéreo } \\
\text { torácico esquerdo }\end{array}$ & $\begin{array}{c}\text { Saco aéreo } \\
\text { abdominal }\end{array}$ & Pericardite & Perihepatite \\
\hline T1(C-) & 0,10 & 0,05 & 0 & 0 & 0 \\
T5(C+) & 2,16 & 1,42 & 0,63 & 1,47 & 0,47 \\
T6(SC+EC) & 2,30 & 1,30 & 0,35 & 1,40 & 0,15 \\
T7(OC+EC) & 1,60 & 0,85 & 0 & 1,45 & 0,05 \\
T8(VO+EC) & 2,16 & 0.95 & 0,37 & 1,37 & 0,26 \\
\hline
\end{tabular}

Figura 29 - Escore de lesão em sacos aéreos, coração e fígado das aves que morreram após o desafio e das que foram sacrificadas aos 42 dias

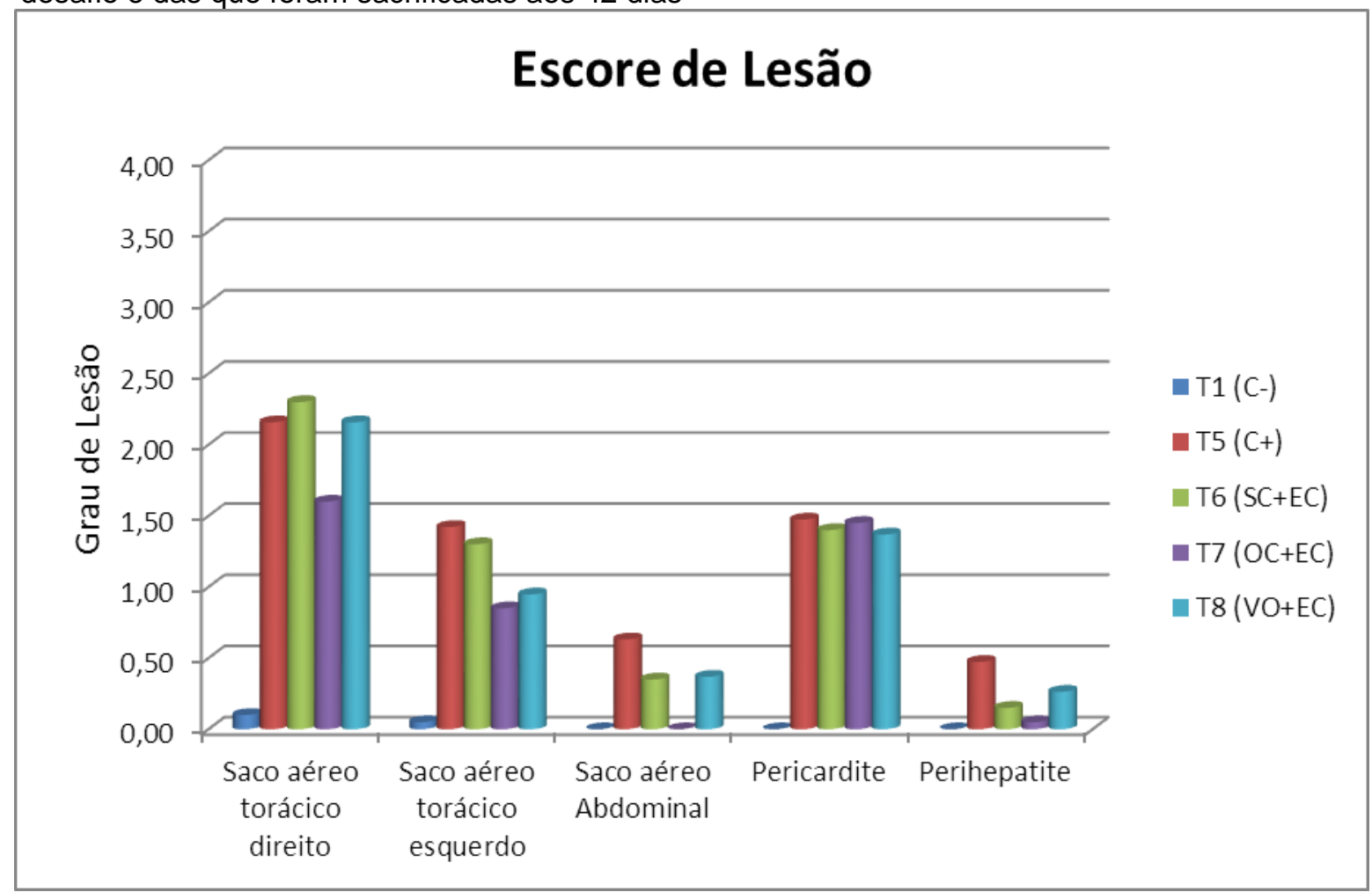




\section{DISCUSSÃO}

Os efeitos imunomoduladores do $\beta$-glucano tanto na resposta imunológica celular quanto na humoral são bem conhecidos nos mamíferos, mas nas aves as pesquisas são relativamente recentes. As diversas fontes do $\beta$-glucano, diferentes estruturas químicas e vias de administração, além da solubilidade são diferenças que dificultam a discussão dos dados da literatura.

A pesquisa de imunoestimulantes naturais é importante em avicultura, especialmente nas aves jovens que possuem um sistema imunológico ainda imaturo (ZHANG et al., 2012). Além disso, é preciso se encontrar alternativas para a substituição dos antibióticos como promotores de crescimento, de forma que não se tenha perdas econômicas. Outro aspecto importante dos imunoestimulantes é melhorar a resposta vacinal.

As concentrações séricas de $\lg A$ em todos os grupos aumentou do dia 28 para o dia 35 e diminuiu aos 42 dias. As concentrações séricas de $\lg G$ aumentaram de acordo com a idade das aves. Isso provavelmente ocorreu devido a meia-vida da IgG ser maior do que a da IgA (DAVISON; MAGOR; KASPERS, 2008).

As concentrações séricas de $\lg A$ foram menores do que as de $\lg G$. Estes resultados são compatíveis com a literatura, uma vez que os anticorpos da classe IgG são predominantes no soro (DAVISON; MAGOR; KASPERS, 2008).

Ao se avaliar as concentrações séricas de IgA no Experimento 1 (Vias de Administração), a maior concentração foi obtida aos 35 dias (322911 ng/mL), nas aves do grupo controle negativo (T1). A menor concentração foi detectada aos 28 dias $(189223 \mathrm{ng} / \mathrm{mL})$, nas aves do tratamento 3 que receberam $\beta$-glucano solúvel por via ocular (T3-OC). Dessa forma, entre os grupos de aves estudados isso correspondeu em $\mathrm{mg} / \mathrm{mL}$ a uma variação de 0,32 a 0,19 mg/mL.

Lebacq-Verheyden, Vaerman e Heremans (1974) determinaram as concentrações de anticorpos séricos em frangos (Leghorn) entre sete e nove semanas de idade, foram avaliados dois pools de soros ( $\mathrm{n}$ de 100 aves em cada pool). A concentração de $\mathrm{IgA}$ foi de $0,45 \mathrm{mg} / \mathrm{mL}$ e $0,22 \mathrm{mg} / \mathrm{mL}$ em cada pool gerando uma média de $0,33 \mathrm{mg} / \mathrm{mL}$. Esses autores também avaliaram individualmente o soro de 20 aves e obtiveram uma média de $0,377 \mathrm{mg} / \mathrm{mL}$ de $\operatorname{lgA}$. 
A idade das aves analisadas por Lebacq-Verheyden, Vaerman e Heremans (1974) foi diferente das analisadas no presente estudo, assim como a linhagem. No entanto, aos 42 dias (6 semanas) de idade, a mais próxima daquela analisada por estes autores, os títulos de $\lg A$ variaram entre $213612 \mathrm{ng} / \mathrm{mL}$ nas aves do T3(OC) e $295364 \mathrm{ng} / \mathrm{mL}$ nas aves do T4(VO), ou seja, 0,21 e 0,30 mg/mL, respectivamente. Resultados menores do que a média encontrada por estes autores. Contudo, levando-se em consideração que um dos pools analisados apresentou concentração de $\lg \mathrm{A}$ de $0,22 \mathrm{mg} / \mathrm{mL}$ é possível considerar que os resultados neste estudo estão dentro da variação encontrada por estes autores.

No Experimento 1 (Vias de Administração) aos 28 dias, as aves do T1(C-) apresentaram concentrações séricas de $\lg A(291374 \mathrm{ng} / \mathrm{mL})$ significativamente maiores que aquelas do tratamento que recebeu o $\beta$-glucano por via ocular (T3) $(189223 \mathrm{ng} / \mathrm{mL})$. Apesar da diferença não ser significativa os valores obtidos de $\lg A$ nas aves do $\mathrm{T} 3(\mathrm{OC})$ foram menores que nas aves dos demais tratamentos, em todas as idades.

Revolledo (2005) determinou a concentração sérica de $\lg A$ e $\lg G$ em frangos da linhagem Ross, que receberam $\beta$-glucano particulado pela dieta ( $1000 \mathrm{~g} / \mathrm{tonelada}$ de ração) e que foram desafiados com Salmonella Thyphimurium. Aos 28 dias, a concentração de $\operatorname{lgA}$ era de $258,97 \mathrm{ng} / \mathrm{mL}$ no grupo que recebeu o $\beta$-glucano e foi desafiado por Salmonella Thyphimurium. No grupo controle negativo a concentração era de $395,49 \mathrm{ng} / \mathrm{mL}$, ou seja, valores menores do que os encontrados no presente estudo. Porém, Revolledo (2005) encontrou valor de $\lg A$ sérico significativamente menor nas aves que receberam o $\beta$-glucano quando comparados aos das aves do grupo controle, resultados que concordam com os dados observados nesta pesquisa aos 28 dias.

As aves possuem o tecido linfoide associado à cabeça (HALT-Head associated lymphoid tissue) que incluem a glândula de Harder e o tecido linfoide associado à conjuntiva (CALT), como os principais sítios indutivos da resposta imunológica, assim como tecidos linfoides distribuídos nas superfícies de mucosa (MASLAK; REYNOLDS, 1995; OLÁH; VERVELDE, 2008).

Aos 28 dias a maior concentração sérica de $\lg A$ foi encontrada nas aves do $\mathrm{T} 1(\mathrm{C}-)$, porém no dia 35 foram as aves do T2(SC) que tiveram concentrações maiores de IgA, e aos 42 dias as aves do T4(VO). Quando se avaliou os efeitos principais em relação às vias de inoculação, desconsiderando a idade foi possível 
observar: menor produção sérica de IgA nas aves do T3(OC), e maiores títulos nas aves do $\mathrm{T} 1(\mathrm{C}-)$.

Assim, é possível que o $\beta$-glucano solúvel administrado por via ocular tenha estimulado as células do tecido linfoide associada à cabeça, principalmente o CALT e a glândula de Harder. Akaki et al. (1997) demostraram a migração de células IgA positivas da glândula de Harder para outros tecidos e órgãos linfoides, como as glândulas lacrimais e a lamina própria do intestino. Neste estudo, pode ser sugerido que o estimulo imunológico ocorrido pela administração do $\beta$-glucano por via ocular tenha levado ao aumento na produção de $\lg A$ em outros órgãos linfoides ou mucosa intestinal, mas não no soro. Também se verificou, neste estudo, que as aves infectadas com E. coli que receberam $\beta$-glucano solúvel por via ocular, apresentavam concentrações menores de $\lg A$ quando esta foi comparada com as concentrações de aves dos demais grupos estudados. Dessa forma, estes resultados sugerem que a ave que recebeu o $\beta$-glucano solúvel pela mucosa ocular, tem como característica apresentar concentrações de imunoglobulinas menores no soro. Além disso, é possível que existam concentrações maiores destas imunoglobulinas na mucosa intestinal, pois foi demonstrado por Akaki et al. (1997) que linfócitos $B \lg \mathrm{A}^{+}$migravam da glândula de Harder para a mucosa intestinal.

Burns (1976) utilizou diferentes vias de administração de soro albumina bovina (BSA), um antígeno solúvel. O autor observou que as aves que receberam o antígeno por via intravenosa produziram anticorpos específicos para BSA, séricos e também na lágrima. Enquanto, as aves que receberam o antígeno por via ocular produziram anticorpos na lágrima, mas não no soro. Survashe, Aitken e Powell (1979) demonstraram que a aplicação de hemácia de carneiro por via intravenosa não levava a ativação da glândula de Harder, isso ocorria apenas quando a administração do antígeno era por via ocular. Contudo, outros dados não corroboram com essa hipótese. A imunização ocular de Salmonella induziu a produção de $\lg A$ em baixos níveis e de $\lg G$ em altos níveis na mucosa intestinal. Ocorreu significativa produção sérica de IgA, IgG e IgM (FUKUTOME et al. 2001). Esses autores encontraram significativa produção sérica de anticorpos através da via ocular. Neste estudo a produção de $\lg A$ sérica, na via de administração ocular, foi menor do que nos demais tratamentos, portanto não concordando com estes autores. 
Em relação à concentração de IgG no Experimento 1 (Vias de Administração), a menor concentração foi detectada nas aves do T2(SC), aos 28 dias (1017004 $\mathrm{ng} / \mathrm{mL}$ ) e a maior (2379506 $\mathrm{ng} / \mathrm{mL}$ ) aos 42 dias nas aves do T4(VO), estes valores correspondem a $1,017 \mathrm{mg} / \mathrm{mL}$ e $2,38 \mathrm{mg} / \mathrm{mL}$, respectivamente. A concentração de IgG no trabalho de Lebacq-Verheyden, Vaerman e Heremans (1974) foi de $6,0 \mathrm{mg} / \mathrm{mL}$ e $5,0 \mathrm{mg} / \mathrm{mL}$ em cada $\mathrm{poo}$ e a média de $5,5 \mathrm{mg} / \mathrm{mL}$. Na avaliação individual do soro de 20 aves a média foi de $6,9 \mathrm{mg} / \mathrm{mL}$. Comparando esses resultados com os obtidos no presente estudo, o título de IgG obtido foi menor mesmo na idade mais próxima a analisada por estes autores.

Revolledo (2005) obteve valores menores de lgG que os observados nesta pesquisa, sendo $36,57 \mathrm{ng} / \mathrm{mL}$ no grupo que recebeu o $\beta$-glucano e foi desafiado por Salmonella Thyphimurium e $44,76 \mathrm{ng} / \mathrm{mL}$ nas aves do grupo controle.

Não ocorreu diferença significante, nas concentrações de lgG, entre as aves dos diferentes tratamentos em uma mesma idade. Apesar disso as concentrações de IgG nas aves que receberam $\beta$-glucano, por via oral (T4), foi maior em todas as idades avaliadas. Aos 28 dias, a menor concentração foi encontrada nas aves do T2(SC), aos 35 dias nas aves do controle negativo (T1) e aos 42 dias nas aves do $\mathrm{T} 3(\mathrm{OC})$.

Morales-López et al. (2009) verificaram que o uso do $\beta$-glucano na ração não influenciava a produção de anticorpos contra a doença de Newcastle. Chen et al. (2008) também não observaram interferência nas concentrações de $\operatorname{lgA}$, IgM e de proteínas séricas em frangos que receberam pela dieta $\beta$-glucano de Schizophyllum commune. Estes resultados encontrados neste estudo corroboram estes estudos, considerando que não ocorreu diferença significativa nas concentrações séricas de IgG dentre as aves de uma mesma idade.

Por outro lado, apesar de não ter ocorrido diferença significante entre as concentrações de IgG nas aves que receberam o $\beta$-glucano, houve uma diferença numérica entre as aves dos diferentes tratamentos, portanto é possível sugerir diferenças em efeitos biológicos.

Rajapakse et al. (2010) observaram que as concentrações de anticorpos em aves vacinadas contra bronquite infecciosa das galinhas foi maior em frangos que receberam o $\beta$-glucano solúvel (derivado da levedura Aureobasidium pollulans), por via água desde o primeiro dia de idade. An et al. (2008) determinaram concentrações sérica de anticorpos aumentada contra a doença de Newcastle e a 
bronquite infecciosa das galinhas em frangos que receberam o $\beta$-glucano na ração. Neste estudo ocorreu aumento de anticorpos lgG nas aves que receberam o $\beta$ glucano solúvel por via oral, dados que concordam com os obtidos por esses autores.

Gallego et al. (1992) ao imunizarem frangos com o antígeno O de Salmonella por via ocular, e observaram a produção de Imunoglobulinas da classe $\lg A$ e $\lg G$ tanto nos tecidos quanto no soro. No soro foi demonstrada um maior estimulo para a produção de $\lg$. Os resultados encontrados neste estudo corroboram estes estudos, uma vez que ocorreu uma menor produção de $\lg A$ sérico nas aves que receberam o $\beta$-glucano por via ocular, contudo quanto ao lgG isso não ocorreu.

Ao se avaliar os parâmetros zootécnicos foi observado que as aves do T3(OC) apresentaram maior peso médio e ganho de peso nas duas últimas semanas de criação, contudo as aves desse tratamento tiveram um maior consumo de ração levando ao pior índice de conversão alimentar.

A viabilidade observada nas aves do T3(OC) foi menor (80\%), mas isso foi influenciado pela mortalidade de duas aves deste grupo no segundo dia de experimento, sendo essas aves consideradas refugos. O Índice de Eficiência Produtiva (IEP) deste grupo foi menor, o que também foi influenciado pela menor viabilidade e pela pior conversão alimentar. Para se calcular o IEP é necessário se considerar a conversão alimentar, o ganho de peso e a viabilidade das aves.

As aves do T4(VO), apresentaram a maior produção de $\lg \mathrm{G}$ em todas as idades, foi o tratamento que teve o menor ganho de peso nas duas últimas semanas e também ao se considerar o período experimental. De acordo com Huff et al. (2006) o estimulo imunológico pode resultar em diminuição na produção em condições em que a ave não está sob desafio.

Não há consenso na literatura em relação aos efeitos do $\beta$-glucano nos parâmetros zootécnicos, havendo tanto relatos com resultados positivos como também casos em que não houve nenhuma interferência ou até mesmo se obteve resultados piores nos animais que receberam o $\beta$-glucano. Cox et al (2010a) não observaram efeitos no desempenho zootécnico de frangos que receberam o $\beta$ glucano na dieta. Morales-López et al., (2009) também não observaram influencia no desempenho zootécnico de frangos de corte que receberam $\beta$-glucano na ração.

Zhang, Guo e Wang (2008) encontraram aumento no peso médio das aves que receberam $\beta$-glucano na dieta. Frangos que receberam $\beta$-glucano solúvel 
(derivado da levedura Aureobasidium pollulans) por via água, desde o primeiro dia de idade apresentaram maior ganho de peso quando comparadas ao grupo controle (RAJAPAKSE et al., 2010).

O uso da parede celular de Saccharomyces cerevisiae na ração em frangos de corte aumentou o ganho de peso diário das aves, mas não influenciou na conversão alimentar (ZHANG et al., 2012). Frangos de corte que foram tratados por via ração com diferentes doses de $\beta$-glucano, derivado de Saccharomyces cerevisiae, apresentaram ganho de peso significativamente maior em frangos que receberam $0,025 \%$ e $0,1 \%$ de $\beta$-glucano. A conversão alimentar mostrou-se melhor nas aves tratadas (AN et al. 2008).

No Experimento 2 ( $\beta$-glucano e Escherichia coli) houve diferença significativa nas concentrações séricas de lgA, apenas aos 42 dias, nas aves do T7(OC+EC) que apresentaram concentrações menores do que as aves do T1(C-), que nesta idade tinha a maior concentração de lgA entre todos os tratamentos.

Apesar das diferenças não serem significativas a concentração de $\lg A$ aos 28 dias foi maior nas aves que receberam o $\beta$-glucano por via subcutânea, e aos 35 dias naquelas que receberam o $\beta$-glucano por via oral. Em todas as idades as concentrações de IgA foram menores nas aves do T7(OC+EC). Conforme sugerido acima, a via de administração ocular pode ter estimulado o sistema imunológico de mucosa, isso explicaria a maior viabilidade das aves neste tratamento.

Considerando a hipótese de que o uso de $\beta$-glucano, por via ocular ter levado a imunossupressão, uma vez que estas aves apresentaram concentrações de anticorpos menores do que as das aves do T1 (C-), é possível que e a sobrevida maior dos animais pode ser consequência de uma imunossupressão, sem uma inflamação exacerbada, que poderia levar a sepse. Há relatos na literatura que podem sustentar essa hipótese (BROWDER et al., 1983; BROWDER et al., 1983; BABINEAU et al. 1994; FALCO et al., 2012), porém não explicam o porquê da imunossupressão ocorrer, principalmente, nas aves que receberam o $\beta$-glucano, por via ocular. Em peixes o uso do $\beta$-glucano levou a imunossupressão dos animais. $O$ glucano foi administrado 14 dias antes do desafio com Aeromonas salmonicida, sendo que os animais tratados produziram menos anticorpos ( $\operatorname{lgM})$ contra a bactéria, além disso ocorreu a supressão na expressão de genes de citocinas inflamatórias comuns da carpa. A imunossupressão pode evitar que ocorra resposta inflamatória aguda de forma exagerada levando a danos e a morte (FALCO et al., 2012). 
Algumas pesquisas tem mostrado a eficácia do uso do $\beta$-glucano para se evitar a sepse e prevenir a ocorrência de infecções após cirurgias (BROWDER et al., 1983; BABINEAU et al. 1994).

O $\beta$-glucano PGG-glucan administrado em pacientes humanos antes de cirurgias torácicas e abdominais e também no inicio da recuperação, 48 horas e 96 horas depois da cirurgia mostrou reduzir o risco de infecções (BABINEAU et al. 1994). Ratos que receberam $\beta$-glucano no pós-operatório, por via venosa tiveram maior sobrevivência após esplenectomia e desafio intranasal com Streptococcus pneumoniae do que os animais controle (BROWDER et al., 1983).

É importante considerar também que a amostra de $E$. coli utilizada foi caracterizada por experimentos anteriores como patogênica (MORAES et al. 2011), dessa forma, a ausência de resposta imunológica aumentaria a mortalidade das aves e não diminuiria.

Aos 28 dias de idade as concentrações séricas de lgG foram significativamente menores nas aves do $\mathrm{T} 1(\mathrm{C}-)$ do que nas aves do $\mathrm{T} 5(\mathrm{C}+)$ e nas aves do T6(SC+EC), sendo determinado o maior título nas aves do T5(C+). Aos 35 e 42 dias de idade as maiores concentrações foram determinadas nas aves do tratamento $\mathrm{T} 6(\mathrm{SC}+\mathrm{EC})$, mas não foi significativamente diferente daquelas encontradas nas aves dos demais tratamentos nestas idades. Esses dois tratamentos (T5 e T6) foram os que tiveram maiores concentrações de lgG durante todo o experimento. Le et al. (2011) ao utilizarem $\beta$-glucano solúvel de Aureobasidium pollulans como adjuvante na vacina contra influenza aviária (SC), encontraram aumento nas concentrações séricas de anticorpos lgG indicando imunopotencialização pelo uso do $\beta$-glucano. Esses resultados concordam com os obtidos neste estudo, uma vez que o T6(SC+EC) apresentou maiores concentrações de $\lg G$ aos 35 e 42 dias.

Quando se comparou as concentrações de $\lg G$ detectadas nos dois experimentos realizados, se verificou que no Experimento 1 (Vias de Administração), as aves que receberam $\beta$-glucano por via oral apresentaram concentrações maiores de IgG. No entanto, no Experimento 2 ( $\beta$-glucano e Escherichia coli) a maior produção de IgG ocorreu nas aves que receberam o $\beta$-glucano por via subcutânea. Isso indica um comportamento diferente na imunomodulação pelo $\beta$-glucano quando se tem um desafio. 
No Experimento $1 \mathrm{em}$ que as aves foram desafiadas com Escherichia coli a variação dos parâmetros zootécnicos foi maior. As correções feitas devido à mortalidade podem ter prejudicado as analises.

Quanto ao peso médio, dentre os desafiados, observou-se o melhor resultado nas aves do T8(VO+EC), sendo que este foi também o melhor tratamento em relação à conversão alimentar.

O Índice de Eficiência Produtiva foi melhor, dentre os desafiados, nas aves do $\mathrm{T} 7(\mathrm{OC}+\mathrm{EC})$, uma vez que esse obteve uma viabilidade muito melhor que os demais grupos estudados.

Huff et al. (2006) relataram diminuição no desempenho de frangos que receberam o $\beta$-glucano, contudo quando tratou com o $\beta$-glucano e desafiou as aves com E. coli esta diminuição não ocorreu. $O \beta$-glucano auxiliou as aves a ter um desempenho zootécnico melhor frente a infecção. Neste estudo, o uso do $\beta$-glucano não foi capaz de evitar a perda de rendimento zootécnico, mas durante as duas semanas após o desafio todos os grupos tratados tiveram um peso médio maior do que o grupo $\mathrm{T} 5(\mathrm{C}+)$.

Em frangos desafiados com Eimeria não ocorreu melhora na performance pela administração de $\beta$-glucano na dieta (COX et al. 2010b). O uso de $\beta$-glucano derivado de Schizophyllum commune na dieta de frangos que foram desafiados com Salmonella Enteritidis não influenciou no ganho de peso dessas aves (CHEN et al., 2008).

A análise farmacocinética de três diferentes $\beta$-glucano solúveis (glucano fosfatado, laminaria e escleroglucano), administrados por via oral em ratos, mostrou que estes são internalizados pelas células epiteliais do intestino, células do tecido linfoide associado ao intestino e chegavam a corrente sanguínea. A concentração plasmática máxima do $\beta$-glucano fosfatado ocorreu quatro (04) horas após a administração, enquanto o laminaria e o escleroglucano tiveram dois momentos de concentração plasmática máxima 0,5 e 12 horas (RICE et al., 2005). Isso demonstrou que os diferentes $\beta$-glucanos tiveram ações diferentes e certamente além da fonte e da estrutura química a via de administração foi importante.

São necessários mais estudos analisando a farmacocinética do $\beta$-glucano em suas diferentes formas, e nas possíveis vias de administração. Esses dados poderiam facilitar a escolha de delineamentos experimentais de forma a se obter melhores resultados. 
O uso de $\beta$-glucano solúvel, por via intravenosa mostrou ter efeito protetor em ratos desafiados com Mycobacterium bovis. Isso ocorreu tanto em animais que receberam o $\beta$-glucano três dias antes quanto sete dias após a infecção (HETLAND; LOVIK; WIKER, 1998).

No entanto, em alguns estudos os efeitos benéficos só foram observados quando o $\beta$-glucano foi usado junto com outros componentes, mostrando que o $\beta$ glucano pode ter efeito sinérgico (BOWERS et al.,1989; KAISER; KERNODLE, 1998; TZIANABOS et al., 1998).

Em um modelo experimental utilizando ratos, a sepse foi induzida através da ligação e perfuração do ceco. Os animais foram tratados por via intravenosa com $\beta$ glucano solúvel ou particulado e ambos não aumentaram a sobrevida dos animais. Quando utilizados com ampicilina ocorreu sinergismo e a sobrevida dos animais foi significativamente maior do que quando se utilizou apenas o antibiótico (BOWERS et al.,1989). Kaiser e Kernodle (1998) demonstraram sinergismo entre o $\beta$-glucano (PGG-glucan) e cefazolin na prevenção de infecção por Staphylococcus em porcos da índia.

O $\beta$-glucano PGG-glucan administrado por via intramuscular reduziu a mortalidade e a formação de abcessos em modelo experimental de sepse em ratos. $O$ resultado foi melhor quando o $\beta$-glucano foi utilizado em associação ao polissacarídeo A de Bacteroides fragilis (PSA) (TZIANABOS et al., 1998).

$O$ tempo de sobrevivência de ratos que receberam $\beta$-glucano fosfatado, por via oral, um dia antes de serem desafiados com Staphylococcus aureus ou com Candida albicans foi maior quando comparado ao controle (RICE et al., 2005). No presente estudo, talvez os resultados tivessem sido melhores se a administração do $\beta$-glucano tivesse sido realizada mais próxima ao desafio, uma vez que o $\beta$-glucano foi administrado no primeiro dia e as aves foram desafiadas aos 14 dias de idade.

$O$ uso do $\beta$-glucano na dieta de frangos diminuiu as lesões no intestino em aves desafiadas com Eimeria, mas não reduziu a mortalidade das aves. O perfil de expressão de genes relacionados à resposta imunológica foi alterada, de forma que a resposta do tipo Th1 foi favorecida durante a coccidiose (COX et al. 2010b).

A administração de $\beta$-glucano derivado de Schizophyllum commune na dieta de frangos que foram desafiados com Salmonella Enteritidis reduziu a viabilidade da Salmonella no fígado e baço. Os macrófagos abdominais aumentaram a fagocitose e a sua capacidade bactericida (CHEN et al., 2008). 
Neste estudo foi observado que a maior presença e intensidade de lesões ocorreu no saco aéreo torácico direito, onde foi realizada a inoculação. Neste local as aves do T3 (SC) apresentaram um grau de lesão maior do que as aves do T2 $(\mathrm{C}+)$. Contudo, nos demais órgãos em todos os tratamentos que receberam o $\beta$ glucano, foi observada uma redução do escore de lesão.

As aves do grupo T4 (OC) apresentaram, dentre os grupos desafiados, menor grau de lesão nos sacos aéreos e no fígado. Com relação ao coração as aves do T5 (VO) apresentaram menor grau de lesão.

Muitas aves apresentaram pericardite, este resultado era esperado, pois em outro estudo no Laboratório de Ornitopatologia da FMVZ-USP, havia sido mostrado tropismo da bactéria EC 341 pelo coração (MORAES et al., 2011).

O uso do $\beta$-glucano reduziu a presença de lesões no fígado. No trabalho de Williams et al. (1991) o uso do $\beta$-glucano sulfatado solúvel levou a aumento da fagocitose especialmente de macrófagos do fígado. Talvez isso explique a redução de lesões hepáticas pelo uso do $\beta$-glucano.

Lowry et al. (2005) também demonstraram a redução na invasão de fígado e baço por Salmonella Enteritidis em frangos que receberam $\beta$-glucano purificado na alimentação desde o nascimento. Além disso, os heterófilos das aves que receberam o $\beta$-glucano fagocitaram significativamente mais Salmonella do que as aves do grupo controle e foram mais eficazes na destruição das bactérias fagocitadas. Demonstraram também aumento no burst oxidativo em aves que receberam o $\beta$-glucano.

A menor presença de lesões em fígado nas aves do T7(OC+EC) pode ser porque no último dia do experimento as lesões já haviam se solucionado, uma vez que ocorreu alta viabilidade neste grupo de aves. . Contudo nas aves dos tratamentos T6(SC+EC) e T8(VO+EC) também se verificou uma redução das lesões em comparação às aves do $T 5(C+)$, e nestes grupos de aves ocorreu mortalidade. 


\section{CONCLUSÃO}

Concluímos com esta pesquisa que:

- O $\beta$-glucano solúvel interferiu na produção de anticorpos séricos, sendo que a administração por via ocular diminui as concentrações séricas de $\lg \mathrm{A}$ nas aves desafiadas e não desafiadas por Escherichia coli;

- A via de administração do $\beta$-glucano interfere nos seus efeitos biológicos sobre o sistema imunológico das aves;

- Não foi possível se determinar a via de administração mais eficiente para a resposta imunológica e para o desempenho zootécnico das aves;

- O uso do $\beta$-glucano por via ocular aumentou a viabilidade das aves desafiadas com Escherichia coli;

- O $\beta$-glucano pode reduzir as lesões causadas pela Escherichia coli. 


\section{REFERÊNCIAS}

AN,B. K.; CHO, B. L.; YOU, S. J. PAIK, H. D. CHANG, H. I.; KIM S. W.; YUN, C. W.; KANG, C. W. Growth performance and antibody response of broiler chicks fed yeast derived $\beta$-glucan and single-strain probiotics.

Australasian Journal of Animal Sciences, v. 21, n. 7, p. 1027 - 1032, 2008.

ANTÃO, E. M.; GLODDE, S.; LI, G., SHARIFI, R.; HOMEIER, T., LATURNUS, C. DIEHL, I. BETHE, S., PHILIPP, H. C.; PREISINGER, R.; WIELER, L. H. EWERS, C. The chicken as a natural model for extraintestinal infections caused by avian pathogenic Escherichia coli (APEC). Microbial Pathogenesis, v. 45, p. 361-369, 2008.

AKAKI, C.; SIMAZU, M.; BABA, T.; TSUJI, S.; KODAMA, H.; MUKAMOTO, M.; KAJIKAWA, T. Possible migration of harderian gland immunoglobulin A bearing lymphocytes into the caecal tonsil in chickens. Zentralbl Veterinarmed B, v. 44, n. 4, p. 199-206, 1997.

AKRAMIENĖ, D.; KONDROTAS, A.; DIDŽIAPETRIENÉ J.; KE்VELAITIS, E. Effects of $\beta$-glucans on the immune system. Medicina (Kaunas), v. 43, n. 8, p.597-606, 2007.

ASK, B.; VAN DER WAAIJ, E. H.; VAN ECK, J. H. H.; VAN ARENDONK, J. A. M.; STEGEMAN, J. A. Defining susceptibility of broiler chicks to colibacillosis. Avian Pathology, v. 35 n. 2, p.147-153, 2006.

BARNES, H. J.; NOLAN, L. K.; VAILLANCOURT, J. P. COLIBACILLOSIS. In: SAIF, Y. M.; FADLY, A. M.; GLISSON, J. R.; MC DOUGALD, L. R.; NOLAN, L. K.; SWAYNE, D. E. Diseases of Poultry, 12. ed. Ames: Blackwell Publishing, 2008. p. 691-737.

BABINEAU, T. J.; HACKFORD, A.; KENLER, A.; BISTRIAN, B.; FORSE, R. A.; FAIRCHILD, P. G.; HEARD, S.; KEROACK, M.; CAUSHAJ, P.; BENOTTI, P. A phase II multicenter, double-blind, randomized, placebo-controlled study of three dosages of an immunomodulator (PGG-glucan) in high-risk surgical patients. Archives of Surgery, v. 129, p. 1204-1210, 1994

BARSANTI, L.; PASSARELLI, V.; EVANGELISTA, V.; FRASSANITO, A. N. E GUALTIERI, P. Chemistry, physico-chemistry and applications linked to biological activities of b-glucans. Natural Product Reports, v. 28, p. 457-466, 2011. 
BESCHIN, I.; BILEJ, M.; HANSSENS, F.; RAYMAKERSI, F.; DYCK, E. V.; REVETS, H.; BRYS, L.; GOMEZ, J.; BAETSELIER, P. E TIMMERMANS, M. Identification and cloning of a glucan- and lipopolysaccharide-binding protein from eisenia foetida earthworm involved in the activation of prophenoloxidase cascade. The Journal of Biological Chemistry, v. 273, n.38, p. 24948-24954, 1998.

BOWERS, G. J.; PATCHEN, M. L.; MACVITTIE, T. J.; HIRSCH, E. F.; FINK, M. P. Glucan enhances survival in an intraabdominal infection model. Journal of surgical research, v. 47,183-188, 1989.

BOHN, J. A.; BEMILLER, J. N. (1 $\rightarrow 3)-\beta-D-G l u c a n s$ as biological response modifiers: a review of structure-functional activity relationships. Carbohydrate Polyners, v. 28, p. 3-14, 1995.

BRITO, B. G. Fatores de virulência de Escherichia coli de origem aviária- APEC. II Simpósio de Sanidade Avícola, Santa Maria, 2000.

BROWN, D. G.; GORDON, D. S. Fungal $\beta$-glucans and mammalian immunity. Immunity, v. 19, p. 311-315, 2003.

BROWN, D.; TAYLOR, P. R.; REID, D. M.; WILLMENT, J. A.; WILLIAMS, D. L.; MARTINEZ-POMARES, L.; WONG, S. Y. C.; GORDON, S. Dectin-1 is a major $\beta$ glucan receptor on macrophages. The Journal of Experimental Medicine, v. 196, n. 3, p. 407-412, 2002.

BURNS, R. B. Specific antibody production against a soluble antigen in the Harderian gland of the domestic fowl. Clinical \& Experimental Immunology, v. 26, p. 371-374, 1976.

CASTANON, J. I. R. History of the use of antibiotic as growth promoters in european poultry feeds. Poultry Science, v. 86, p. 2466-2471, 2007.

CHAE, B. J. J. D.; LOHAKARE, W. K.; LEE, S. L.; PARK, Y. H.; HAHN, T. W. Effects of supplementation of $\beta$-glucan on the growth performance and immunity in broilers. Research in Veterinary Science, v. 80, p. 291-298, 2006.

CHAN, G. C-F.; CHAN, W. K.; SZE, D. M-Y. The effects of $\beta$-glucan on human immune and cancer cells. Journal of Hematology \& Oncology, v. 2, n.25, 2009. 
CHAN, W. K.; LAW, H. K.; LIN, Z. B.; LAU, Y. L.; CHAN, G. C. Response of human dendritic cells to different immunomodulatory polysaccharides derived from mushroom and barley. International Immunology, v. 19, n. 7, p. 891-899, 2007.

CHANG, J.; ZHANG, W.; MAI, K; MA, H; LIUFU, Z.; WANG, X.; AI, Q.; XU, W. Effects of dietary b-glucan and glycyrrhizin on nonspecific immunity and disease resistance of white shrimp, Litopenaeus vannamei (Boone) challenged with Vibrio alginolyticus. Aquaculture Research, v.42, p. 1101-1109, 2011.

CHEN, J.; SEVIOUR, R. Medicinal importance of fungal b- $(1 \rightarrow 3),(1 \rightarrow 6)$-glucans. Mycological Research, v. 3, p. 635-652, 2007.

CHEN, K. L.; WENG, B. C.; CHANG, M. T.; LIAO, Y. H.; CHEN, T. T.; CHU, C. Direct Enhancement of the Phagocytic and Bactericidal Capability of Abdominal Macrophage of Chicks by $\beta-1,3-1,6-G l u c a n$. Poultry Science, v. 87, p. 2242-2249, 2008.

CHIHARA, G.; MAEDA, Y.Y.; HAMURO, J.; SASAKI, T.; FUKUOKA, F. Inhibition of mouse sarcoma 180 by polysaccharides from Lentinus edodes (Berk.) sing. Nature, v. 222, p. 687-688, 1969.

COX, C. M.; DALLOUL, R. A. Beta-glucans as immunomodulators in poultry: use and potencial applications. Avian Biology Researsh, v. 3, n. 4, p. 171-178, 2010.

COX, C. M.; STUARD, L. H.; KIM, S.; MCELROY, A. P.; BEDFORD, M. R.; DALLOUL, R. A. Performance and immune responses to dietary $\beta$-glucan in broiler chicks. Poultry Science, v. 89, p. 1924-1933, 2010a.

COX, C. M.; SUMNERS, L. H.; KIM, S.; MCELROY, A. P.; BEDFORD, M. R.; DALLOUL, R. A. Immune responses to dietary $\beta$-glucan in broiler chicks during an Eimeria challenge. Poultry Science, v. 89, p. 2597-2607, 2010b.

CRISPIM, J. C. O.; MEDEIROS, A. C.; SALES, V. S. F. Proteção pela glucana em modelo experimental de sepse. Acta Cirúrgica Brasileira, v. 19, n. 13, p. 296-307, 2004.

CROSS, G. G.; JENNINGS, H. J.; WHITFIELD, D. M.; PENNEY, C. L.; ZACHARIE, B.; GAGNON, L. Immunostimulant oxidized $\beta$-glucan conjugates. International Immunopharmacology, v. 1, p. 539-550, 2011. 
DARPOSSOLO, F. P. B.; QUINTANA, L. R.; MAGNANI, M.; OBA, A.; VENÂNCIO, E. J.; CASTRO-GOMÉZ, R. J. H. Avaliação do potencial imunoestimulante da Carboximetil-glucana de Saccharomyces cerevisiae em frangos de corte (Gallus domesticus). Semina: Ciências Agrárias, v. 31, n. 1, p. 231-240, 2010.

DAVISON, F.; MAGOR, K. E.; KASPERS, B. Structure and evolution of avian Immunoglobulins. In: DAVISON, F.; KASPERS, B.; SCHAT, K. A. Avian Immunology. Elsevier, 2008. p. $109-110$.

DEL CACHO, E.; GALLEGO, M.; MARCOTEGUI, M. A.; BASCUAS, J. A. Folicular dendritic cell activation in the Harderian gland of the chicken. Veterinary Immunology e Immunopathology, v. 35, p.339-351, 1993.

DIBNER, J. J.; RICHARDS, J. D. Antibiotic growth promoters in agriculture: history and mode of action. Poultry Science, v. 84, p. 634-643, 2005.

DRITZ, S. S.; SHI, J.; KIELIAN, T. L.; GOODBAND, R. D.; NELSSEN, J. L.; TOKACH, M. D.; CHENGAPPA, M. M.; SMITH,J. D.; BLECHA, F. Influence of dietary $\beta$-glucan on growth performance, nonspecific immunity, and resistance to Streptococcus suis infection in weanling pigs. Journal of Animal Science, v. 73, p. 3341-3350, 1995.

FALCO, A.; FROST, P.; MIEST, J.; PIONNIER, N.; IRNAZAROW, I.; HOOLE, D. Reduced inflammatory response to Aeromonas salmonicida infection in common carp (Cyprinus carpio L.) fed with b-glucan supplements. Fish \& Shellfish Immunology, v. 32, p. 1051-1057, 2012.

FARIA, D. E.; HENRIQUE, A. P. F.; NETO, R. F.; MEDEIROS, A. A.; JUNQUEIRA, O. M.; FARIA FILHO, D. E. Alternativas ao uso de antibióticos como promotores de crescimento para frangos de corte: 2 ácidos orgânicos e probióticos. Ciência Animal Brasileira, v. 10, n. 1, p. 29-39, 2009.

FDA. FOOD AND DRUG ADMINISTRATION. Guidance for Industry: The Judicious Use of Medically Important Antimicrobial Drugs in Food-Producing Animals. Department of Health and Human Services, Food and Drug Administration, Center for Veterinary Medicine, 2012.

FERREIRA, A. J. P. Fatores de patogenicidade de Escherichia coli de origem aviária. Estudo comparativo entre amostras patogênicas e apatogênicas. 1989. 121 f. Dissertação (Mestrado) - Faculdade de Medicina Veterinária e Zootecnia, Universidade de São Paulo, São Paulo, 1989. 
FERREIRA, A. J. P.; KNÖBL, T. Colibacilose. In: BERCHIERI JÚNIOR, A.; SILVA, E. N.; DI FÁBIO, J.; SESTI, L.; ZUANAZE, M. A. F. Doenças das aves, 2. ed.

Campinas: FACTA, 2009. p. 457-471.

FERREIRA, A. J. P.; REVOLLEDO, L.; FERREIRA, C. S. A. Colibacilose. In: REVOLLEDO, L.; FERREIRA, A. J. P. Patologia aviária. Barueri: Manole, 2009. p. 67-74.

FUKUI, A.; INOUE, N.; MATSUMOTO, M.; NOMURA, M.; YAMADA, K.; MATSUDA,Y.; TOYOSHIMA, K.; SEYA, T. Molecular Cloning and Functional Characterization of Chicken Toll-like Receptors. The Journal of Biological Chemistry, v. 276, n. 50, p. 47143-47149, 2001.

FUKUTOME, K.; WATARAI, S.; MUKAMOTO, M.; KODAMA, H. Intestinal mucosal imune response in chickens following intraocular immunization with liposomeassociated Salmonella enterica serovar enteritidis antigen. Developmental and Comparative Immunology, v. 25, p. 475-484, 2001.

GOODRIDGE, H. S.; UNDERHILL, D. M.; TOURET, N. Mechanisms of Fc receptor and dectin-1 activation for phagocytosis. Traffic, v. 13, n. 8, p.1062-1071, 2012.

GOREN, E. Observations on experimental infection of chicks with Escherichia coli. Avian Pathology, v. 7, n. 2, p. 213-224, 1978.

GUO, Y.; ALI, R. A.; QURESHI, M. A. The influence of $\beta$-glucan on immune responses in broiler chicks. Immunopharmacology and Immunotoxicology, v. 25, n. 3, p. 461-472, 2003.

HE, H.; MACKINNON, K. M.; GENOVESE, K. J.; NERREN, J. R.; SWAGGERTY, C.L.; NISBET, D. J.; KOGUT, M. H. Chicken scavenger receptors and their ligandinduced cellular immune responses. Molecular Immunology, v. 46, p.2218-2225, 2009.

HETLAND, G.; LOVIK, M.; WIKER, H. G. Protective effect of $\beta$-glucan against Mycobacterium bovis, BCG Infection in BALB/c Mice. Scandinavian Journal of Immunology, v. 47, p. 548-556, 1998.

HUFF, G. R.; HUFF, W. E.; RATH, N. C.; TELLEZ, G. Limited treatment with $\beta$ $1,3 / 1,6$ glucan improves production values of broiler chickens challenged with 
escherichia coli. immunology, health and disease Poultry Science, v. 85, p. 613618, 2006.

ITOH, W.; SUGAWARA, I.; KIMURA, S.; TABATA, K.; HIRATA, A.; KOJIMA, T.; MORI, S.; SHIMADA, K. Immunopharmacological study of sulfated schizophyllan (SPG). I.--Its action as a mitogen and anti-HIV agent. International Journal of Immunopharmacology, v. 12, n. 2, p. 225-233, 1990.

KAISER, A. B.; KERNODLE, D. S. Synergism between poly-(1-6)-b-dglucopyranosyl-(1-3)-b-d-glucopyranose glucan and cefazolin in prophylaxis of staphylococcal wound infection in a guinea pig model. Antimicrobial Agents and Chemotherapy, v. 42, n. 9, p. 2449-2451, 1998.

KENNEDY, M. T.; BATES, P. J.; WHEATLEY, C. L.; ROHRBACH, M. S. Discrete pathways for arachidonic acid release from tannin versus $\beta$-glucan-stimulated rabbit alveolar macrophages. Journal of Leukocyte Biology, v. 58, p. 241-248, 1995.

KIM, H. S.; HONG, J. T.; KIM, Y; HAN, S.B. Stimulatory effect of $\beta$-glucans on immune cells. Immune Network, v. 11, n. 4, p. 191-195, 2011.

KOKOSHIS, P. L.; WILLIAMS, D. L.; COOK, J. A.; DI LUZIO, N. R. Increased resistance to staphylococcus aureus infection and enhancement in serum lysozyme activity by glucan. Science, v. 199, n. 24, p. 1340-1342, 1978.

KOUTSOS, E. A.; KLASING, K. C. Factores modulating the avian immune system. In: DAVISON, F.; KASPERS, B.; SCHAT, K. A. Avian Immunology. Great Britain: Elsevier, 2008. p. 323-338.

LA RAGIONE, R. M.; WOODWARD, M. J. Virulence factors of Escherichia coli serotypes associated with avian colisepticaemia. Research in Veterinary Science, v. 73, p. 27-35, 2002.

LEBACQ-VERHEYDEN, A- M.; VAERMAN, J. -P.; HEREMANS, J. F. Quantification and distribution of chicken immunoglobulins iga, igm and igg in serum and secretions. Immunology, v. 27, p. 683-692, 1974.

LE, T. H.; LE, T. B.; DOAN, T. H. T.; QUYEN, D. V.; LE, K. X. T.; PHAM, V. C.; NAGATAKI, M.; NOMURA, H.; IKEUE, Y.; WATANABE, Y.; AGATSUMA, T. The adjuvant effect of sophy $\beta$-glucan to the antibody response in poultry immunized by the avian influenza a H5N1 and H5N2 vaccines. Journal of Microbiology and Biotechnology, v. 21 n. 4, p. 405-411, 2011. 
LI, J.; LI, D. F.; XING, J. J.; CHENG, C. B.; LAI, C. H. Effects of $\beta$-glucan extracted from Saccharomyces cerevisiae on growth performance, and immunological and somatotropic responses of pigs challenged with Escherichia coli lipopolysaccharide. Journal of Animal Science, v. 84, p. 2374-2381, 2006.

LOWRY, V.K.; FARNELL, M. B; FERRO, P.J.; SWAGGERTYC, C.L.; BAHLD, A.; KOGUT. M.H. Purified h-glucan as an abiotic feed additive up-regulates the innate immune response in immature chickens against Salmonella enterica serovar

Enteritidis. International Journal of Food Microbiology, v. 98, p. 309-318, 2005.

MAGNANI, M.; CASTRO-GÓMEZ, R. J. H. $\beta$-glucana de Saccharomyces cerevisiae: constituição, bioatividade e obtenção. Ciências Agrárias, Londrina, v. 29, n. 3, p. 631-650, 2008.

MASLAK, D. M.; REYNOLDS, D. L. B cells and T-lymphocyte subsets of the headassociated lymphoid tissues of the chicken, v. 39, n. 4, p. 736-742, 1995.

MENÃO, M. C.; FERREIRA, C. S. A.; CASTRO, A. G. M.; KNÖBL, T.; FERREIRA, A. J. P. Sorogrupos de Escherichia coli isoladas de frangos com doença respiratória crônica. Arquivos do Instituto Biológico, v. 69, n. 4, p. 15-17, 2002.

MORAES, M. E.; PEREIRA, G. B. A.; ASTOLFI-FERREIRA, C. S.; FERREIRA, A. J. P. Infecção experimental por Mycoplasma gallisepticum e Escherichia coli em perus. In: 22ํㅡㄹ Congresso Brasileiro de Avicultura. São Paulo, 2011.

MORALES-LÓPEZ, R.; AUCLAIR, E.; GARCÍA, F.; ESTEVE-GARCIA, E.; BRUFAU, $J$. Use of yeast cell walls; $\beta$-1,3/6-glucans; and mannoproteins in broiler chicken diets. Poultry Science, v. 88, p. 601-607, 2009.

MORGULIS, M. S. Imunologia Aplicada. In: MACARI, M.; FURLAN, R. L.; GONZALES, E. Fisiologia aviária aplicada a frangos de corte, 2. ed. Jaboticabal: FUNEP/UNESP, 2002. p. 231-245.

MOYES, R. B.; KOGUT, M. H.; DROLESKEY, R. E.; DELOACH, J. R. Differential expression of adhesion molecules by chicken heterophils activated in vivo with Salmonella enteritidis-immune lymphokines. Veterinary Immunology and Immunopathology, v. 62, p. 83-95, 1998.

NERREN, J. R.; KOGUT, M. H. The selective Dectin-1 agonist, curdlan, induces an oxidative burst response in chicken heterophils and peripheral blood mononuclear cells. Veterinary Immunology and Immunopathology, v. 127, p. 162-166, 2009. 
NONO, I.; OHNO, N.; MASUDA, A.; OIKAWA, S.; YADOMAE, T. Oxidative Degradation of an Antitumor (1-3)- $\beta$-D-Glucan, Grifolan. Journal of pharmacobiodynamics, v. 14, p. 9-19, 1991.

NOVAK, M.; VETVICKA, V. $\beta$ - Glucans, History, and the Present: Immunomodulatory Aspects and Mechanisms of Action. Journal of Immunotoxicology, v. 5, p. 47-57, 2008.

NOVAK, M.; VETVICKA, V. Glucans as Biological Response Modifiers. Endocrine, Metabolic \& Immune Disorders, v. 9, p. 67-75, 2009.

OLÁH, I.; VERVELDE, L. Structure of the avian Lymphoid system. In: DAVISON, F.; KASPERS, B.; SCHAT, K. A. Avian Immunology, Great Britain: Elsevier, 2008. p. 38-39.

PATCHEN, M. L.; LIANG, J.; VAUDRAIN, T.; MARTIN, T.; MELICAN, D.; ZHONG, S.; STEWART, M.; QUESENBERRY, P. J. Mobilization of peripheral blood progenitor cells by betafectin $\AA$ pgg-glucan alone and in combination with granulocyte colonystimulating factor. Stem Cells, v. 16, p.208-217, 1998.

PEDROSO, A. C. Modulação da resposta imune em aves imunizadas com Vacinas Aviárias associadas ao $\beta$-glucano. 2009. 107f. Tese (Doutorado em Microbilologia), Instituto de Ciências Biomédicas, Universidade de São Paulo, São Paulo, 2009.

PETTERSON, J. P.; BURKHOLDER, K. M. Application of prebiotcs and probiotcs in poultry production. Poultry Science, v. 82, p. 627-631, 2003.

PILLEMER, L.; ECKER, E. E. Anticomplementary factor in fresh yeast. Journal of Biological Chemistry, v. 137, p. 139-142, 1941.

RAJAPAKSE, J. R. P. V.; BUDDHIKA, M. D. P.; NAGATAKI, M.; NOMURA, H.; WATANABE, Y.; IKEUE, Y.; AGATSUMA, T. Effect of sophy $\beta$-glucan on immunity and growth performance in broiler chicken. Journal of Veterinary Medical Science, v. 72, n. 12, p. 1629-1632, 2010.

LILIANA, R. Estudo da resposta imune, da colonização e invasão por Salmonella entérica subsp entérica sorotipo Typhimurium $\mathrm{Nal}$ em frangos de corte, tratados com glucano, probióticos e produtos de exclusão competitiva. 
2005. 121 f. Tese (Doutorado)- Faculdade de Medicina Veterinária e Zootecnia, Universidade de São Paulo, São Paulo, 2005.

REDMOND, S. B.; TELL, R. M.; COBLE, D.; MUELLER C.; PALIĆ, D.; ANDREASEN, C. B.; LAMONT, S. J. Differential splenic cytokine responses to dietary immune modulation by diverse chicken lines. Poultry Science, v. 89, p. 1635-1641, 2010.

RICE, P. J.; ADAMS, E. L.; OZMENT-SKELTON, T.; GONZALEZ, A. J.; GOLDMAN, M. P.; LOCKHART, B. E.; BARKER, L. A.; BREUEL, K. F.; DEPONTI, W. K.;

KALBFLEISCH, J. H.; ENSLEY, H. E.; BROWN, G. D.; GORDON, S.; WILLIAMS, D. $\mathrm{L}$. Oral delivery and gastrointestinal absorption of soluble glucans stimulate increased resistance to infectious challenge. The Journal of Pharmacology and Experimental Therapeutics, v. 314, n. 3, p. 1079-1086, 2005.

RIGGI, S. J.; DI LUZIO, N. R. Identification of a reticuloendothelial stimulating agent in zymosan. The American Journal of Physiology, v. 200, p. 297-300, 1961.

$\mathrm{RIZZO}, \mathrm{P}$. V. Misturas de extratos vegetais como alternativas ao uso de antibióticos melhoradores do desempenho nas dietas de frangos de corte. Dissertação Mestrado, Escola Superior de Agricultura Luiz de Queiroz (ESALQ), 2008.

ŞAHAN, A.; DUMAN, S. Influence of $\beta-1,3 / 1,6$ glucan applications on some nonspecific cellular immune response and haematologic parameters of healthy Nile tilapia (Oreochromis niloticus L., 1758) Turkish Journal of Veterinarian and Animal Sciences, v. 34, n. 1, p. 75-81, 2010.

SOLTANIAN, S.; STUYVEN, E.; COX, E.; SORGELOOS, P.; BOSSIER, P. Betaglucans as immunostimulant in vertebrates and invertebrates. Critical Reviews in Microbiology, v. 35, n. 2, p. 109-138.

SPRING, P.; WENK, C.; DAWSON, K. A.; NEWMAN, K. E. The effects of dietary mannanoligosaccharides on cecal parameters and the concentrations of enteric bacteria in the ceca of salmonella-challenged broiler chicks. Poultry Science, v. 79, p 205-211, 2000.

SURVASHE, B. D.; AITKEN, I. D.; POWELL, J. R. The response of the Harderian gland of the fowl to antigen given by the ocular route i. Histological changes. Avian Pathology, v. 8, p. 77-93, 1979. 
SUZUKI, I.; TANAKA, H.; KINOSHITA, A.; OIKAWA, S.; OSAWA, M.; YADOMAE, T. Effect of orally administered $\beta$-glucan on macrophage function in mice. International Journal of Immunopharmacology, v. 12, n. 6, p. 675-684, 1990.

TORRES, D. M.; COTTA, J. T. B.; TEIXEIRA, A. S.; MUNIZ, J. A.; FONSECA, R. A.; SANTOS, E. C.; ALVES, E. L. Dietas à base de milho e farelo de soja suplementadas com enzimas na alimentação de frangos de corte. Ciência agrotécnica, Lavras, v. 27, n. 1, p. 199-205, 2003.

TSONI, S. V.; BROWN, G. D. $\beta$-Glucans and dectin-1. Annals of the New York Academy of Sciences, v. 1143, p. 45-60, 2008.

TZIANABOS, A. O.; GIBSON III, F. C.; CISNEROS, R. L.; KASPER, D. L. Protection against experimental intraabdominal sepsis by two polysaccharide

immunomodulators The Journal of Infectious Diseases, v. 178, p. 200-206, 1998.

TZIANABOS, A. O. Polysaccharide immunomodulators as therapeutic agents:

structural aspects and biologic function. Clinical Microbiology Reviews, v. 13, n. 4, p. 523-533, 2000.

UBABEF acesso em 16/01/2012

http://www.abef.com.br/ubabef/exibenoticiaubabef.php?notcodigo=3113

USLU, K.; BAGRIACIK, E. U. Differential adjuvant effects of soluble beta glucans from barley and saccharomychescerevisia in primary and secondary humoral immune responses. International Journal of Hematology and Oncology, v. 21, n. 3, p.176-182, 2011.

VETVICKA, V. Glucan-immunostimulant, adjuvant, potential drug. Word Journal of Clinical Oncology, v. 2, n. 2, p. 115-119, 2011.

VETVICKAA, V.; VANCIKOVA, B, Z. Anti-stress action of several orally-given $\beta$ glucans. Biomedical papers of the Medical Faculty of the University Palacký, Olomouc, Czechoslovakia, v. 154, n. 3, p. 235-238, 2010.

WALLER, K. P.; COLDITZ, I. G. Effect of intramammary infusion of beta-1,3-glucan or interleukin-2 on leukocyte subpopulations in mammary glands of sheep. American Journal of Veterinary Research, v. 60, n. 6, p. 703-707, 1999. 
WASHBURN, W. K.; OTSU, I.; GOTTSCHALK, R.; MONACO, A. P. PGG-Glucan, a leukocyte-specific immunostimulant, does not potentiate GVHD or allograft rejection. Journal of Surgical Research, v. 62, p. 179-183, 1996.

WILLIAMS, D. L. Overview of (1 3)-D-glucan immunobiology. Mediators of Inflammation, v. 6, p. 247-250, 1997.

WILLIAMS, D. L.; DI LUZIO, N. R. Glucan induced modification of experimental Staphylococcus aureus infection in normal, leukemic and immunosuppressed mice. Advances in Experimental Medicine and Biology, v. 121, p. 291-306, 1979.

WILLIAMS, D. L.; YAEGER, R. G.; PRETUS, H. A.; BROWDER, I. W.; MCNAMEE, R. B.; JONES, E. L. Immunization against Trypanossoma cruzi: Adjuvant effect of glucan. International Journal of Immunopharmacollogy, v. 11, n. 4, p. 403-410, 1989.

WILLIAMS, D. L.; PRETUS, H. A.; MCNAMEE, R. B.; JONES, E. L.; ENSLEY, H. E.; BROWDER, I. W. E DI LUZIO, E. N. R. Development, phisicochemical characterization and preclinical efficacy evalution of water soluble glucan sulfate derives from Saccharomyces cerevisae. Immunopharmacology, v. 22, p. 139-156, 1991.

WILLIAMS, D. L. SHERWOOD, E. R. BROWDER, I. W.; MCNAMEE, R. B. Preclinical safety evaluation of soluble glucan. International Journal of Immunopharmacology, v.10, n.4, p.405-414, 1988a.

WILLIAMS, D.L.; SHERWOOD, E. R.; BROWDER, I. W.; MCNAMEE, R. B.; JONES, E. L.; RAIUNIC, J.; DI LUZIO, N. R. Effect of glucan on neutrophil dynamics and immune function in escherichia coii peritonitis. Journal of Surgical Research, v. 44, p. $54-61,1988 b$.

YUN, C. H.; Estrada, A. Kessel, A. V.; Park, B. C.; Laarveld, B. $\beta$-Glucan, extracted from oat, enhances disease resistance against bacterial and parasitic infections. Immunology and Medical Microbiology, v. 35, p. 67-75, 2003.

ZHANG, B.; GUO, Y.; WANG, Z. The modulating effect of $\beta-1,3 / 1,6$-glucan suplentation in the diet on performance and immunological responses of broiler chickens. Asian Australasian Journal Animal Sciences, v. 21, n. 2, p. 237-244, 2008. 
ZHANG, S.; LIAO, B.; LI, X.; LI, L.; MA, L.; YAN, X. Effects of yeast cell walls on performance and immune responses of cyclosporine A-treated, immunosuppressed broiler chickens. British Journal of Nutrition, v. 107, p. 858-866, 2012.

ZIMMERMAN, J. W.; LINDERMUTH, J.; FISH, P. A.; PALACE, G. P.; STEVENSON, T. T.; DEMONG, D. E. A Novel carbohydrate-glycosphingolipid interaction between a $\beta$-(1-3)-glucan immunomodulator, pgg-glucan, and lactosylceramide of human leukocytes. The Journal of Biological Chemistry, v. 273, n. 3, p. 22014-22020, 1998. 


\section{APÊNDICE A - Meios de cultura utilizados}

Modo de preparo do meio de cultura BHI caldo (Brain Heart Infusion):

- Ingredientes: $37 \mathrm{~g}$ de $\mathrm{BHI}, 1 \mathrm{~L}$ de água destilada.

- Misturar os ingredientes e autoclavar a $121^{\circ} \mathrm{C}$ por $15 \mathrm{~min}$.

Modo de preparo do meio de cultura BHI ágar (Brain Heart Infusion):

- Ingredientes: $37 \mathrm{~g}$ de $\mathrm{BHI}, 15 \mathrm{~g}$ de ágar $1 \mathrm{~L}$ de água destilada.

- Misturar os ingredientes e autoclavar a $121^{\circ} \mathrm{C}$ por $15 \mathrm{~min}$.

Modo de preparo da água peptonada 0,1\%:

- Ingredientes: $1 \mathrm{~g}$ Peptona, $1 \mathrm{~L}$ àgua destilada.

- Misturar os ingredientes e autoclavar a $121^{\circ} \mathrm{C}$ por $15 \mathrm{~min}$.

Modo de preparo do meio de cultura MacConkey (MC) ágar:

- Ingredientes: $50 \mathrm{~g}$ de MacConkey ágar, $1 \mathrm{~L}$ de água destilada.

- Misturar os ingredientes e autoclavar a $121^{\circ} \mathrm{C}$ por $15 \mathrm{~min}$. 
APÊNDICE B - Soluções utilizadas no ELISA

Modo de preparo da solução de Lavagem (1000 mL):

- $\quad 6,054 \mathrm{~g}$ de TRIS (50mM)

- 8,18 de $\mathrm{Na} \mathrm{Cl}(0,14 \mathrm{M})$

- $50 \mu \mathrm{L}$ de Tween $20(0,05 \%)$

- $800 \mathrm{~mL}$ de água destilada, ajustar o pH8 com HCl 1:2 e posteriormente acrescentar água destilada até completar o volume em 1000mL.

Modo de preparo da solução de Diluição (100 mL):

- Preparar a solução a partir da Solução de Lavagem acrescentando apenas $1 \mathrm{~g}$ de BSA (1\%).

Modo de Preparo da Solução de Bloqueio (100 mL):

- $\quad 0,6055 \mathrm{~g}$ de TRIS $(50 \mathrm{mM})$

- $\quad 0,818$ de $\mathrm{Na} \mathrm{Cl}(0,14 \mathrm{M})$

- $\quad 1 \mathrm{~g}$ de BSA (1\%)

- $80 \mathrm{~mL}$ de água destilada, ajustar o $\mathrm{pH} 8 \mathrm{com} \mathrm{HCl} \mathrm{1:2} \mathrm{e} \mathrm{posteriormente}$ acrescentar água destilada até completar o volume em $100 \mathrm{~mL}$. 
Modo de Preparo da Solução Stop:

- $\quad 959 \mu \mathrm{L} \mathrm{H} \mathrm{SO}_{4}(0,18 \mathrm{M})$

- $100 \mathrm{~mL}$ de água destilada 


\section{APÊNDICE C - Fórmulas dos Parâmetros Zootécnicos}

\section{Parâmetros zootécnicos analisados por semana}

- Peso Médio das Aves (PM):

$\mathrm{PM}=$ Peso semanal de todas as aves do grupo/ $\mathrm{n}$ de aves

- $\quad$ Ganho de Peso Médio (GP semanal):

GP semanal $=\mathrm{PM}-\mathrm{PM}$ da semana anterior

- Consumo Médio corrigido (CM corrigido):

№ de aves corrigido $=\left[\left(\mathrm{n}^{\circ}\right.\right.$ aves $\times \mathrm{n}^{\circ}$ de dias $)+\left(\mathrm{n}^{\circ}\right.$ aves $\mathrm{x} \mathrm{n}^{\circ}$ de dias $\left.)\right] / 7$

$\mathrm{CM}$ corrigido $=$ Consumo de ração total $/ \mathrm{n}^{\circ}$ de aves corrigido

- Conversão alimentar por fase (CA por fase):

Ganho de peso corrigido (GP corrigido $)=($ Peso das aves + Peso das aves mortas) - Peso das aves na semana anterior

$\mathrm{CA}$ por fase $=$ Ração consumida/ GP corrigido

\section{Parâmetros zootécnicos relativos a todo período experimental}

- Ganho de peso acumulado (GP):

$\mathrm{GP}=\mathrm{PM}$ no último dia $-\mathrm{PM}$ no dia zero (0)

- Ganho de peso diário (GPD):

GPD $=$ GP/ 42 
- Conversão alimentar acumulada (CA):

Ração consumida na semana ( $R C$ sem)

$C A=(R C$ sem $1+R C$ sem $2+R C$ sem $3+R C$ sem $4+R C$ sem $5+R C$ sem 6$) /$ (GP corrigido sem1+ GP corrigido sem 2+ GP corrigido sem 3+ GP corrigido sem 4+ GP corrigido sem 5+ GP corrigido sem 6)

- Viabilidade:

Viabilidade $=100-\{[(\mathrm{n}$ inicial de aves $-\mathrm{n}$ final de aves $) \times 100] / \mathrm{n}$ inicial de aves\}

- Índice de Eficiência Produtiva (IEP):

IEP $=($ GPD $\times$ Viabilidade $) /(C A \times 10)$ 